University of Texas at El Paso

\title{
DigitalCommons@UTEP
}

Open Access Theses \& Dissertations

2015-01-01

\section{GIS Approach in Vehicle Route Optimization for Residential Recyclables Collection}

Karel Kus

University of Texas at El Paso, karelkus.email@gmail.com

Follow this and additional works at: https://digitalcommons.utep.edu/open_etd

Part of the Transportation Commons

\section{Recommended Citation}

Kus, Karel, "GIS Approach in Vehicle Route Optimization for Residential Recyclables Collection" (2015). Open Access Theses \& Dissertations. 1082.

https://digitalcommons.utep.edu/open_etd/1082

This is brought to you for free and open access by DigitalCommons@UTEP. It has been accepted for inclusion in Open Access Theses \& Dissertations by an authorized administrator of DigitalCommons@UTEP. For more information, please contact lweber@utep.edu. 


\title{
GIS APPROACH IN VEHICLE ROUTE OPTIMIZATION FOR RESIDENTIAL RECYCLABLES COLLECTION
}

\author{
KAREL KƯS \\ Department of Civil Engineering
}

APPROVED:

Ruey Long Cheu, Ph. D., Chair

Ing. Tomáš Horák, Ph.D.

Raed E. Aldouri, Ph.D.

Carlos M. Ferregut, Ph.D.

prof. Dr. Ing. Miroslav Svítek

Charles Ambler, Ph.D.

Dean of the Graduate School 
Copyright (C)

by

Karel Kůs

2015 


\section{Declaration}

This thesis is an output of the Transatlantic Dual Masters Degree Program in Transportation Science and Logistic Systems, a joint project between Czech Technical University

in Prague, Czech Republic, The University of Texas at El Paso, USA and University of Zilina, Slovak Republic.

This thesis is jointly supervised by the following faculty members:

Ruey Long Cheu, Ph.D., The University of Texas at El Paso

Ing. Tomáš Horák Ph. D., Czech Technical University

The contents of this research were developed under an EU-U.S. Atlantis grant (P116J100057) from the International and Foreign Language Education Programs (IFLE), U.S. Department of Education. However, those contents do not necessarily represent the policy of the Department of Education, and you should not assume endorsement by the Federal Government.

This research is co-funded by the European Commission's Directorate General for Education and Culture (DG EAC) under Agreement 2010-2843/001-001-CPT EU-US TD. 


\section{Dedication}

I would like to dedicate this thesis to the memory of my supervisor Doc. Ing. Ladislav Bína, CSc.

I would also like to dedicate this thesis to my family and all my friend who gave me support and motivation. 


\title{
GIS APPROACH IN VEHICLE ROUTE OPTIMIZATION FOR RESIDENTIAL RECYCLABLES COLLECTION
}

\author{
by
}

KAREL KŮS, Bc.

\begin{abstract}
THESIS
Presented to the Faculty of the Graduate School of The University of Texas at El Paso

in Partial Fulfillment

of the Requirements

for the Degree of

MASTER OF SCIENCE

Department of Civil Engineering

THE UNIVERSITY OF TEXAS AT EL PASO
\end{abstract}

May 2015 


\section{Acknowledgements}

I would like to thank to my advisors Dr. Ruey Long Cheu and Dr. Tomáš Horák for their guidance, feedbacks, suggestions and patience. I thank to Dr. Read Aldouri for helping me understand the ArcGIS functionality. I would also like to thank the City of El Paso Environmental Service Department as an institution and by name to Richard Adams MSc., Jorge Avitia MSc. and Zacharias Hiram for data provided and for answering my questions. Special thanks goes to $\mathrm{Na}$ An and Jay Sandhu product engineers from ESRI for answering questions about ArcGIS Network Analyst extension. I would also like to thank to my father Ing. Jiří Kůs for SQL filter for a part of the data processing. My thanks goes also to Ken Nakamura for borrowing me his bike for site visit. Last but not least I would like to thank to my family and friends for their support. 


\begin{abstract}
This thesis focuses on evaluation of utilization of Geographic Information Systems (GIS) for solving the residential recyclables collection routing problems.

Recyclables collection is considered as a part of reverse logistics to which a specific routing problem is connected. Rise of recycling rate in recent years, and always high transportation costs are the main drivers for looking for the new methods how to optimize routing in residential recyclables collection. Geospatial relation of data by Geographic Information Systems (GIS) software can be used to design and analyze the routing strategy. In this thesis ArcGIS and its Network Analyst extension is used to analyze potential routing improvement in one selected recyclables collection shift in El Paso, Texas. Equation describing the time requirements for the process of recyclables collection with the consideration of effects of set-out rate and turns was established. Despite that the Network Analyst was not designed for solving high density routing tasks of this kind, an approach to obtain acceptable routing solution by this ArcGIS extension was developed. By applying this approach on the selected recyclables collection shift it was found that comparable, routing solution can be obtained. In the end, possible ways how to improve this approach to make the Network Analyst to perform even better in high density routing task is presented together with suggested changes in the investigated collection shift.
\end{abstract}

Key word: recycling, residential recyclables collection, GIS, ArcGIS Network Analyst, MSW, vehicle routing, arc routing problem 


\section{Table of Contents}

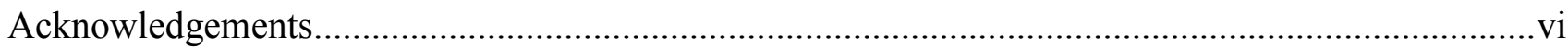

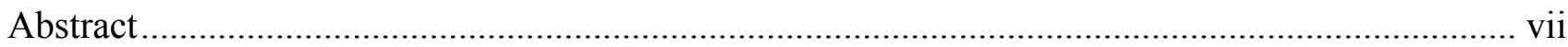

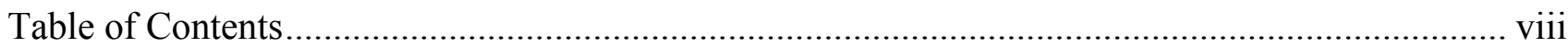

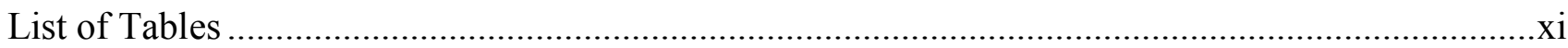

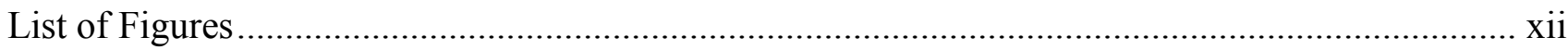

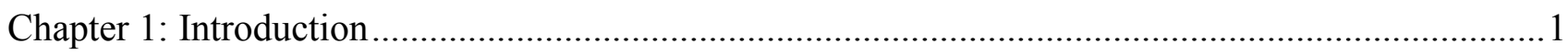

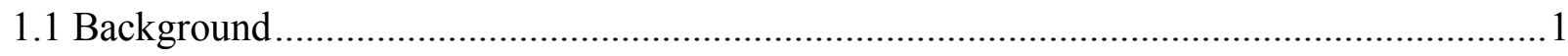

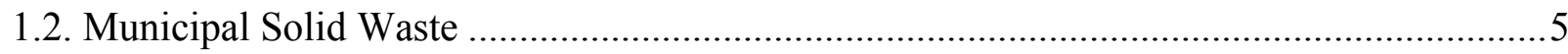

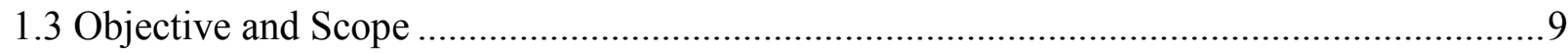

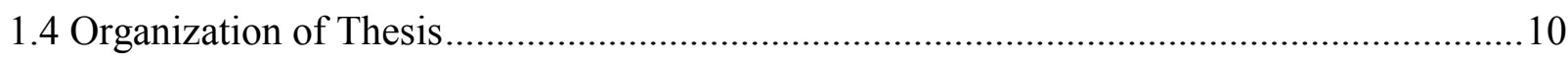

Chapter 2: Recyclables Collection Systems in EU and U.S..........................................................11

2.1 Bring and Curbside Collection Methods ........................................................................11

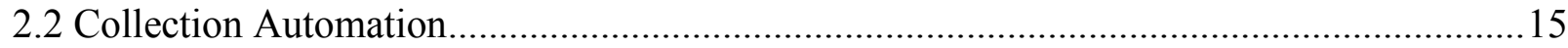

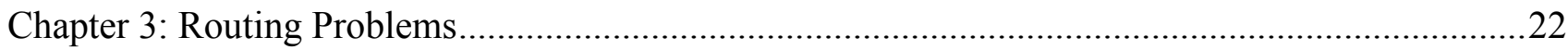

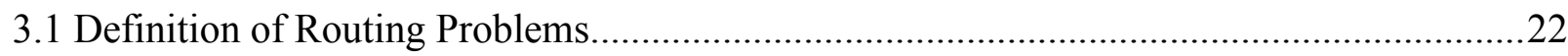

3.2 Vehicle Routing Problem and Arc Routing Problem .........................................................22

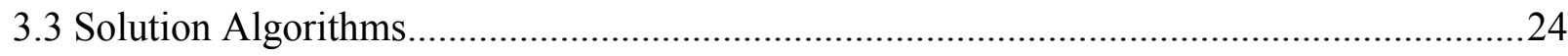

3.4 Residential Recyclables Collection Routing Problem ........................................................26

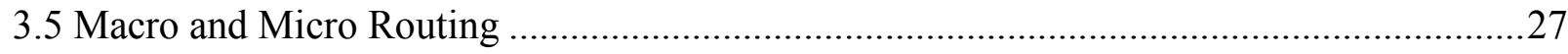


Chapter 4: Geographic Information Systems

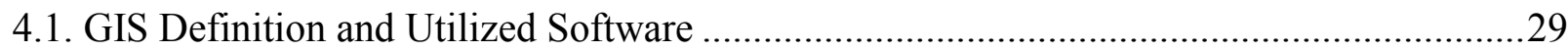

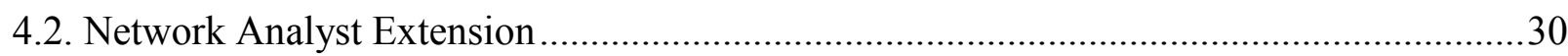

4.3 Using VRP solver for the Residential Recyclables Collection Routing................................31

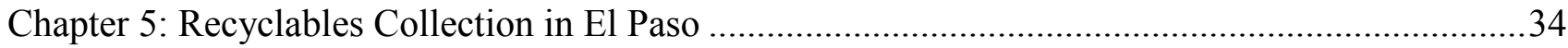

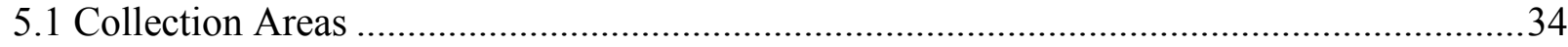

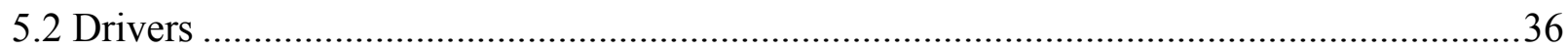

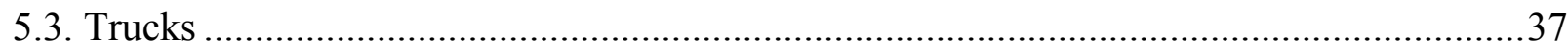

Chapter 6: Analysis of Recyclables Collection Routes ………............................................................39

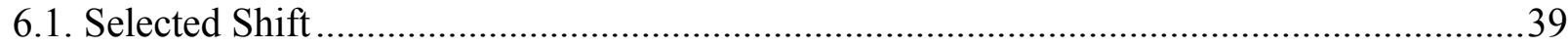

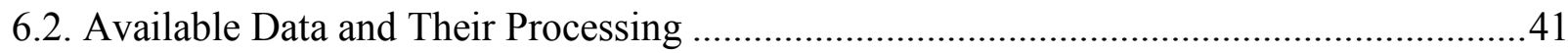

6.3 Adjusting Service Time and Bin Weight with Set-out Rate................................................49

6.4 Model Description and Validation..................................................................................5

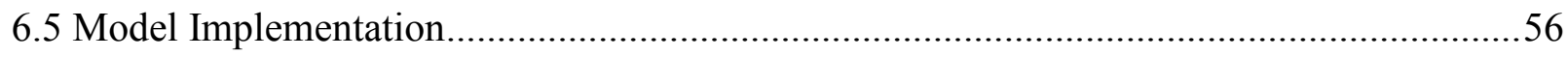

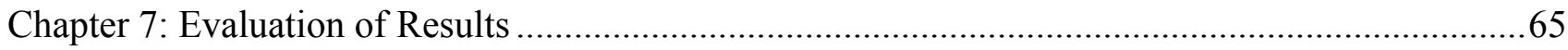

7.1 CARP Solved by NA for the Residential Recyclables Collection. ......................................65

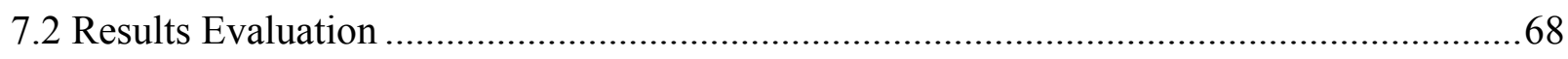

7.3 Recommendations to the City of El Paso Environmental Services Department (ESD) .......70

7.4 Recommendations for future use of Arc GIS ……………...............................................

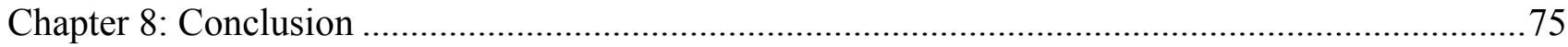

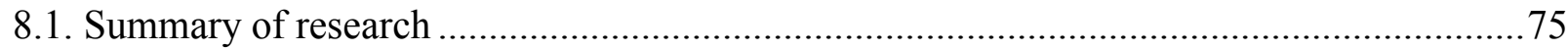




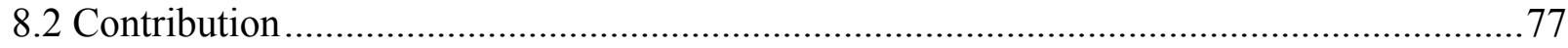

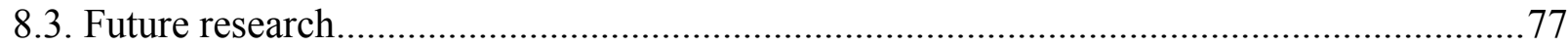

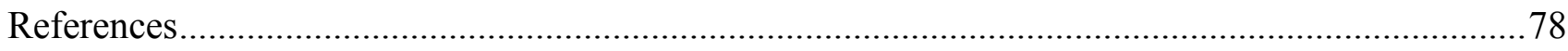

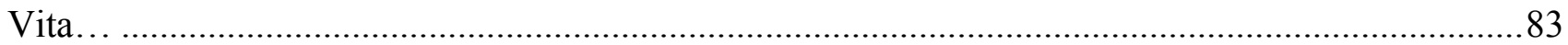




\section{List of Tables}

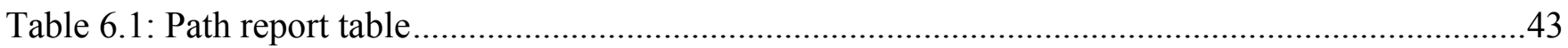

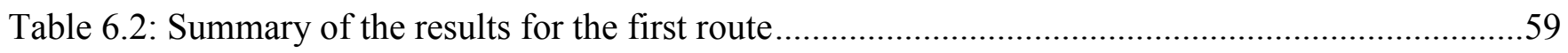

Table 6.3: Summary of the results for the second route ..............................................................64

Table 7.1: Summary of the results for the east and west route.......................................................68

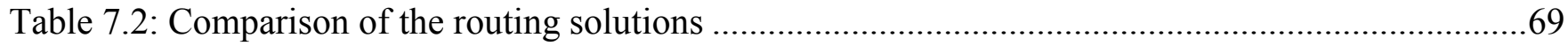




\section{List of Figures}

Figure 1.1: Typical closed-loop supply chain flows.............................................................2

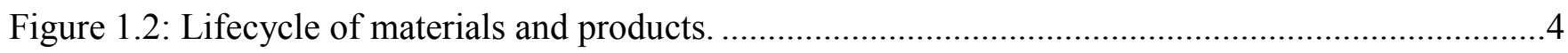

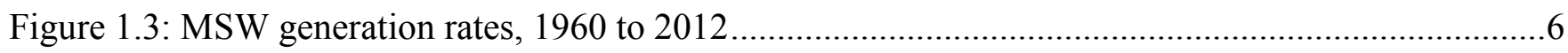

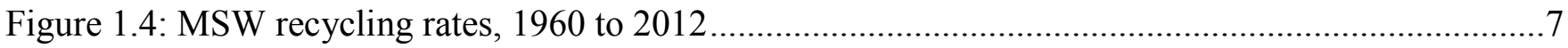

Figure 2.1: The spectrum of collection methods from 'bring' to 'kerbside' systems. ...........................12

Figure 2.2: Close-to-home drop off containers in high-rise housing area of Prague, Czech Republic.....13

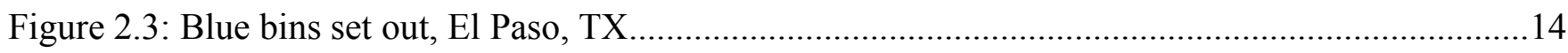

Figure 2.4: Manual recyclables collection, Philadelphia, PA ........................................................15

Figure 2.5: Recyclables set out at the curb, Philadelphia, PA ........................................................... 16

Figure 2.6: Collection truck, MSW and recyclables set out at the curb, Boston, MA ..........................17

Figure 2.7: Semi-automated collection, Prague, Czech Republic .................................................... 18

Figure 2.8: Semi-automated collection, Cartersville, GA. ............................................................19

Figure 2.9: Fully automated curbside recyclables collection, El Paso, TX .......................................20

Figure 2.10: Fully automated collection, Prague, Czech Republic ................................................21

Figure 3.1: Complete graph of one depot and three customers .....................................................24

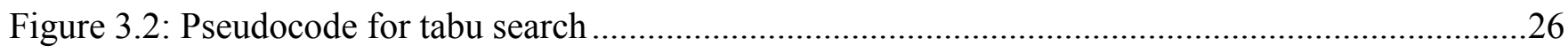

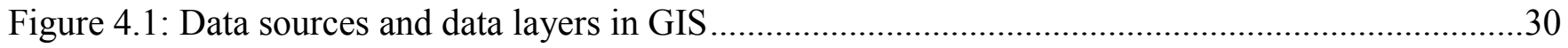

Figure 4.2: Diagram for anomalous sequencing correction algorithm .........................................33

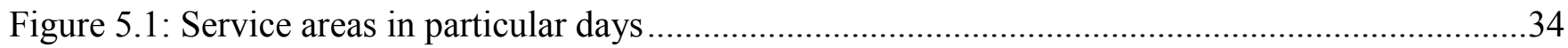

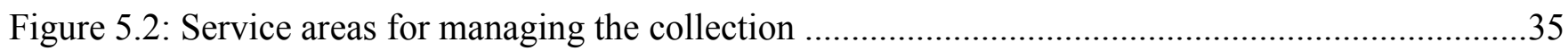

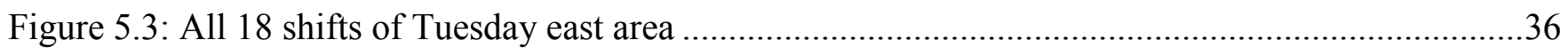

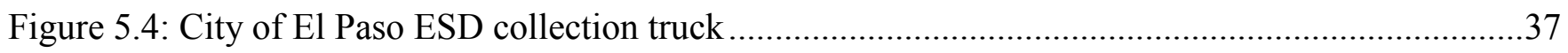

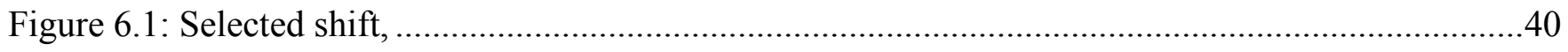

Figure 6.2: Containers located on the other side of street segment, ..............................................42

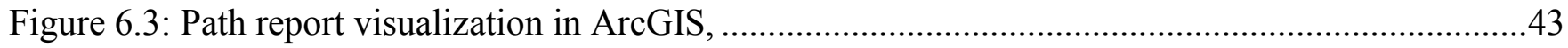

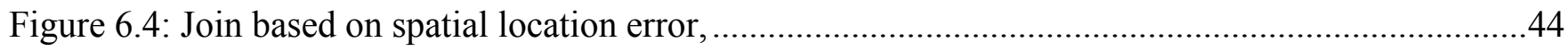


Figure 6.5: Area of constant speed of the truck speed with service

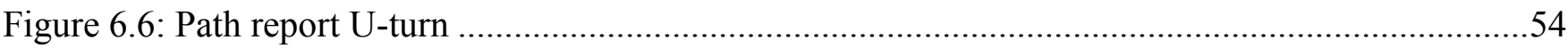

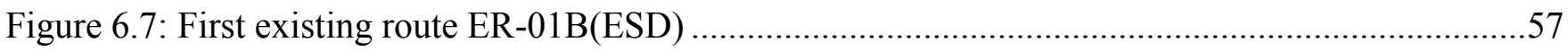

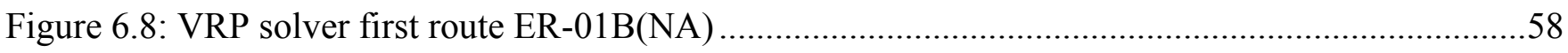

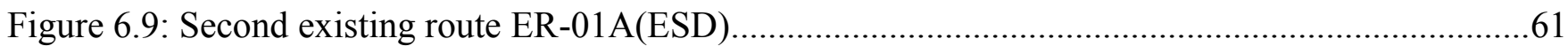

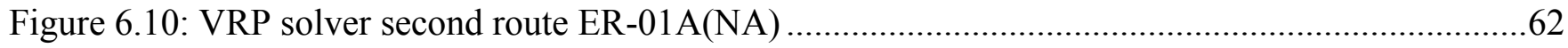

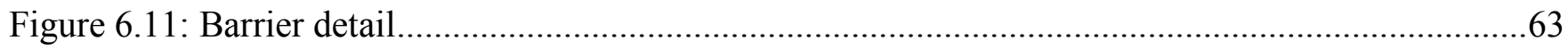

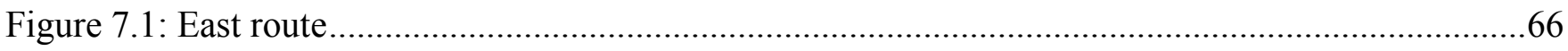

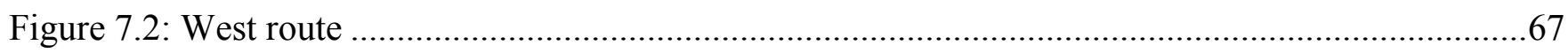

Figure 7.3: Selected shift with marked borders of routes and picture details............................................ 71

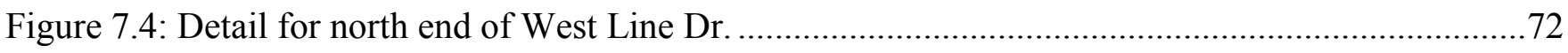

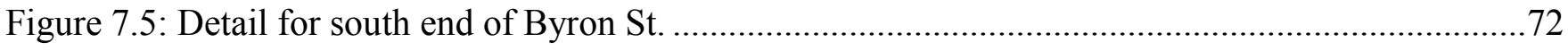




\section{Chapter 1: Introduction}

\subsection{BACKGROUND}

The Reverse Logistic Magazine states that logistics is "The process of planning, implementing, and controlling the efficient, cost effective flow of raw materials, in-process inventory, finished goods and related information from the point of origin to the point of consumption for the purpose of conforming to customer requirements" (Hawks 2006).

It is possible to say that reverse logistics includes all of the activities mentioned above, but they are operated in reverse. Therefore, reverse logistics may be defined as the process of planning, implementing, and controlling the efficient, cost effective flow of used materials, unconsumed inventory, finished goods and related information from the point of consumption to the point of origin for the purpose of recapturing value or proper disposal.

The regular supply chains ends in the point of the final customer. The reverse logistics is going further and its goal is to create a cycle in the supply chain. That is the reason why the term closed-loop supply chains is used together with reverse logistics. The company that perform the reverse logistics or closing the supply chain may be the Original Equipment Manufacturer (OEM), distribution partner or a third party not involved in the forward distribution.

Figure 1.1 shows a scheme of a closed-loop supply chain containing four entities: the material mining company, the company producing components, the end product producer and the customer. 


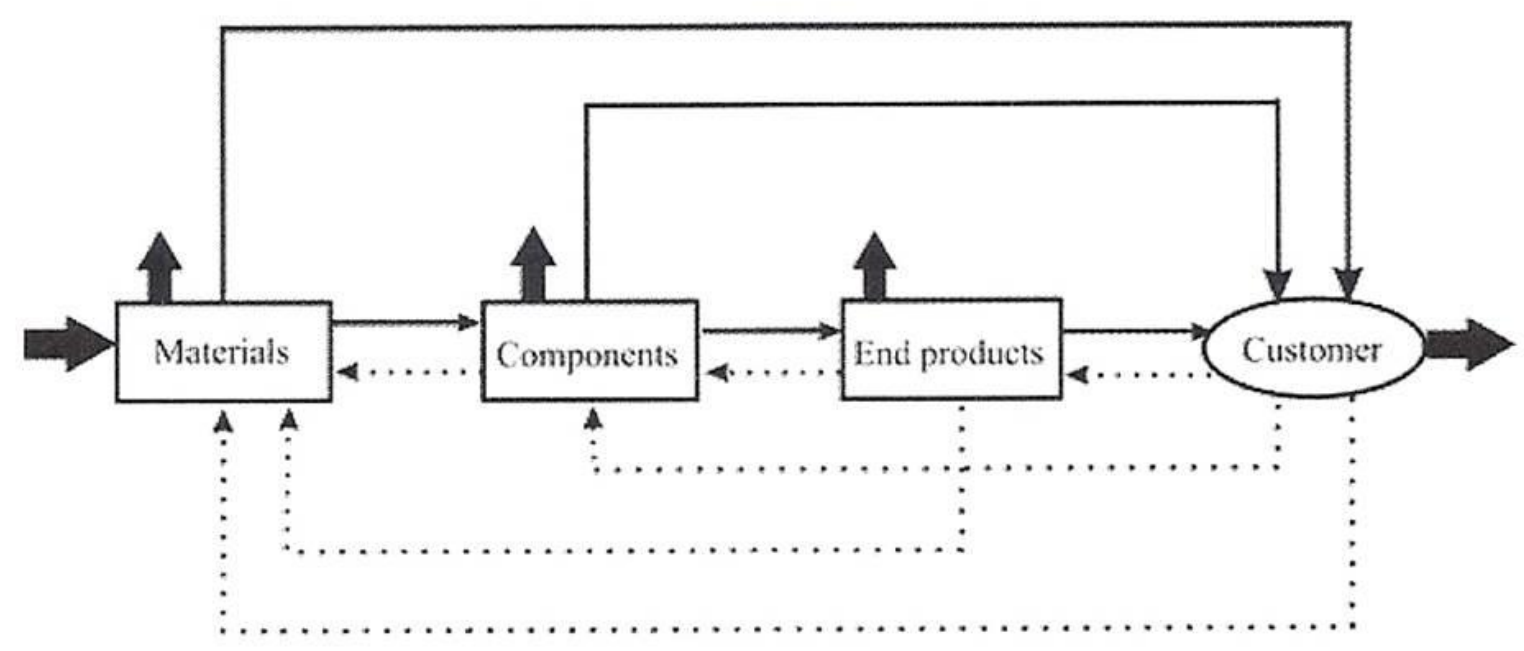

Legend:

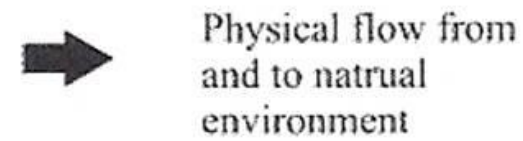

environment

$\Longrightarrow \begin{aligned} & \text { Physical flow to } \\ & \text { customer }\end{aligned}$

Figure 1.1: Typical closed-loop supply chain flows

Source: (Flapper et al. 2005)

Companies and corporations have to deal with large stream of returns in different forms over the life-cycle of their products. There are commercial returns, repair and replacement returns, end-of-life returns, production return flows and distribution returns. To all of these returns there are closed-loop supply chains. Flapper et al. (2005) tried to create a classification of closed-loop supply chains, according to the phases of a product lifecycle, where production phase, the distribution phase, the use phase and the end-of-life phase are considered.

An example of production phase related closed-loop chains can be the utilization of trimming waste from metal stamping in the car industry. Distribution phase related closed-loop chains consist of returns. Number of product that is sold with a return option is increasing due to the internet shopping. In 
addition, recall of products, for example recalls of dangerous food, toys, and etc., is connected with this phase. Warranties repairs and refurbishment are the services connected with the use phase, since they occur while the customers are using the product.

In the last mentioned phase (end-of-life phase) the product loses its identity, but some of the functional components or materials may find further use. Examples are the nationwide networks for car wrecks, white and brown goods, systems for the collection and processing of glass via containers, and systems for waste paper collection.

In the waste management literature, a similar scheme to the one presented by Flapper et al. (2005) (Figure 1.1) can be found. In Rogoff, (2014) it is presented as the "materials management" paradigm (Figure 1.2). Its aim is comprehensive evaluation of how materials are managed upstream of traditional waste management techniques so they can be sustainably managed at all stages of their life cycle throughout the economy. The goal is to address all the stages of materials and products from raw material extraction to product design, manufacture, and transport, consumption by the consumer, use, reuse, recycling, and then final disposal. Highest value is put on the source reduction and extended producer responsibility and then efforts for waste conversion such as energy, biofuels, and compost. Landfilling and waste incineration are considered as an option of "last resort" for those materials that cannot be recovered for beneficial reuse. This paradigm is broadly based on visions of future solid waste management expressed by both the United States Environmental Protection Agency (U.S. EPA) (U.S. EPA 2002) and the European Environment Agency (EEA) (EEA 2010). 


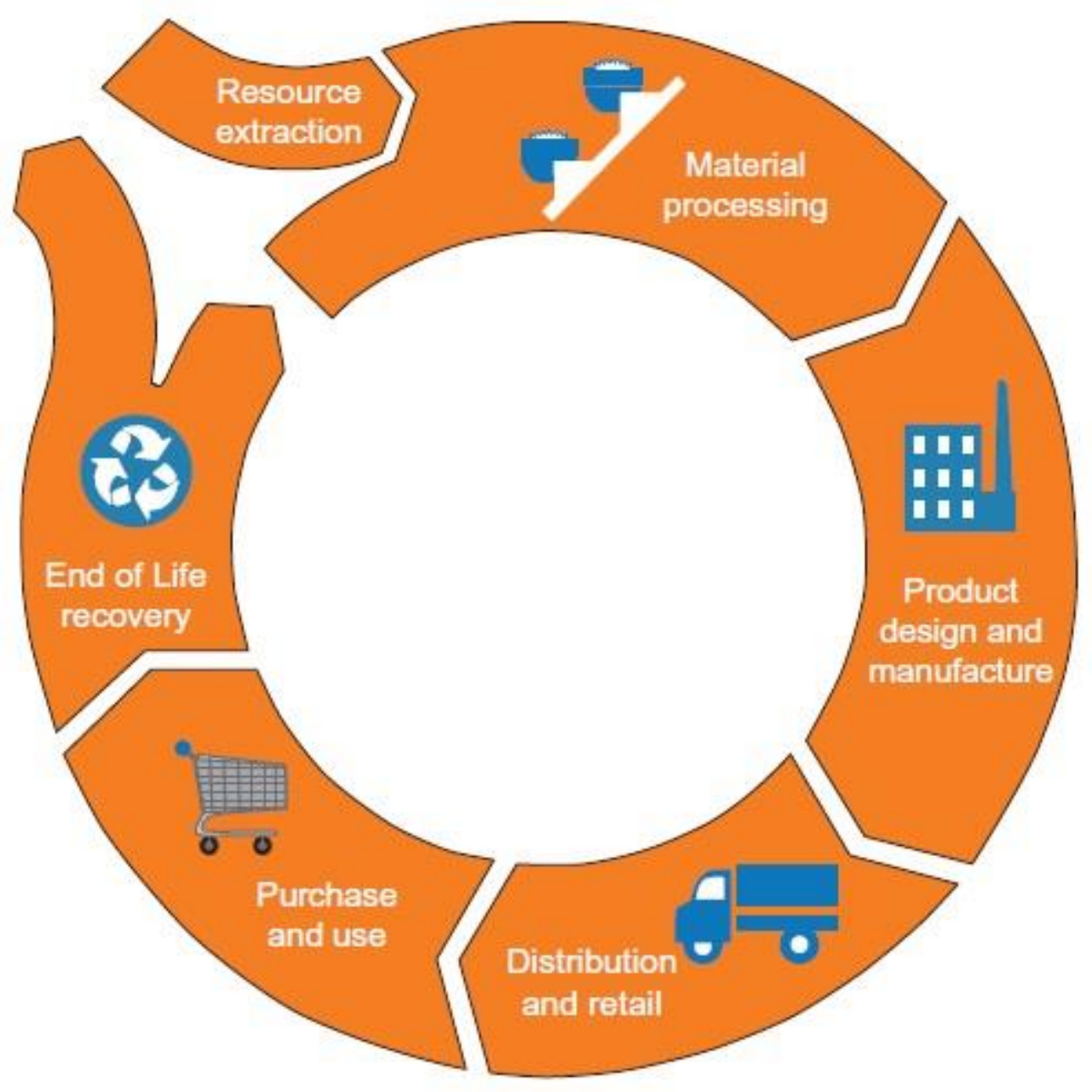

Figure 1.2: Lifecycle of materials and products.

Source: (Rogoff, M. 2014)

End-of life phase return material flows or in another words, the recovery of materials from final customers, involves processes that very often generate high transportation costs. To reduce these costs an optimal routing of material collection vehicles is needed. This thesis focuses on collection of recyclables in residential areas and how the routing of collection vehicles can be improved with the assistance of Geographic Information Systems (GIS). 


\subsection{Municipal Solid Waste}

\subsubsection{Municipal Solid Waste Statistics}

The United States (U.S.) generates more waste per person than any nation in the world (Rogoff, M. 2014). According to U.S. EPA, there were almost 251 million tons (U.S. short ton ${ }^{1}$ ) of Municipal Solid Waste (MSW) generated in the country in 2012, of this amount 87 million tons were recycled or composted, which means that the highest reported recycling rate was 34.5 percent. Out of the solid waste of $4.38 \mathrm{lb} /$ person/day (approximately $2 \mathrm{~kg} /$ person/day), $1.51 \mathrm{lb} /$ person/day were recycled and composted (U.S. EPA 2012). More detailed view on the long term trends of MSW generation can be seen in Figure 1.3.

1 One U.S. short ton is $2,000 \mathrm{lbs}$ or $907.184 \mathrm{~kg}$. 


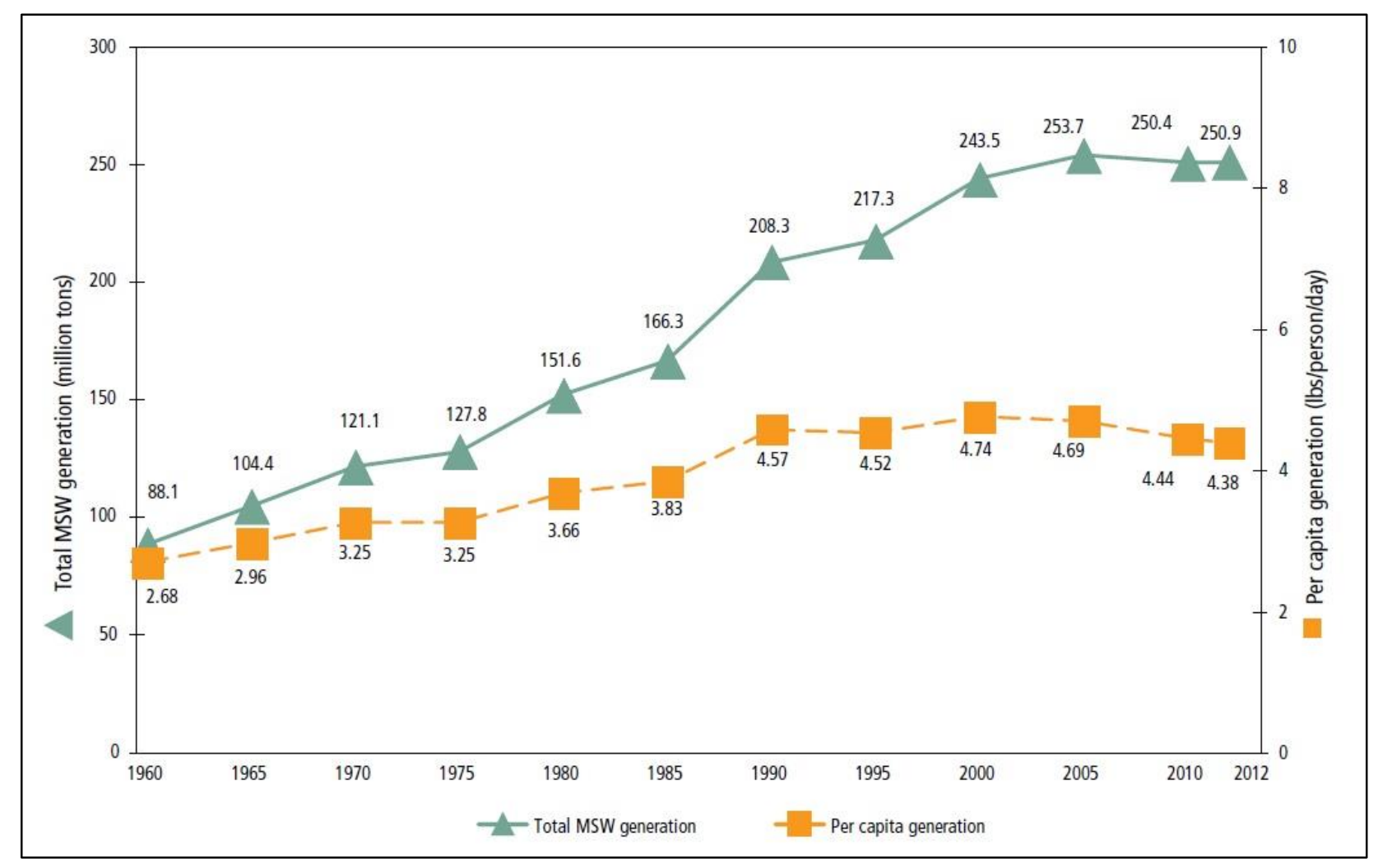

Figure 1.3: MSW generation rates, 1960 to 2012

Source: (U.S. EPA 2012)

There has been a decline in the total MSW per capital generation starting in year 2000. However, the population of U.S. is growing and so the effect of per capita reduction on total MSW generation is not that significant. Another EPA graph (Figure 1.4) shows the significantly increasing recycling rates in last two decades. 


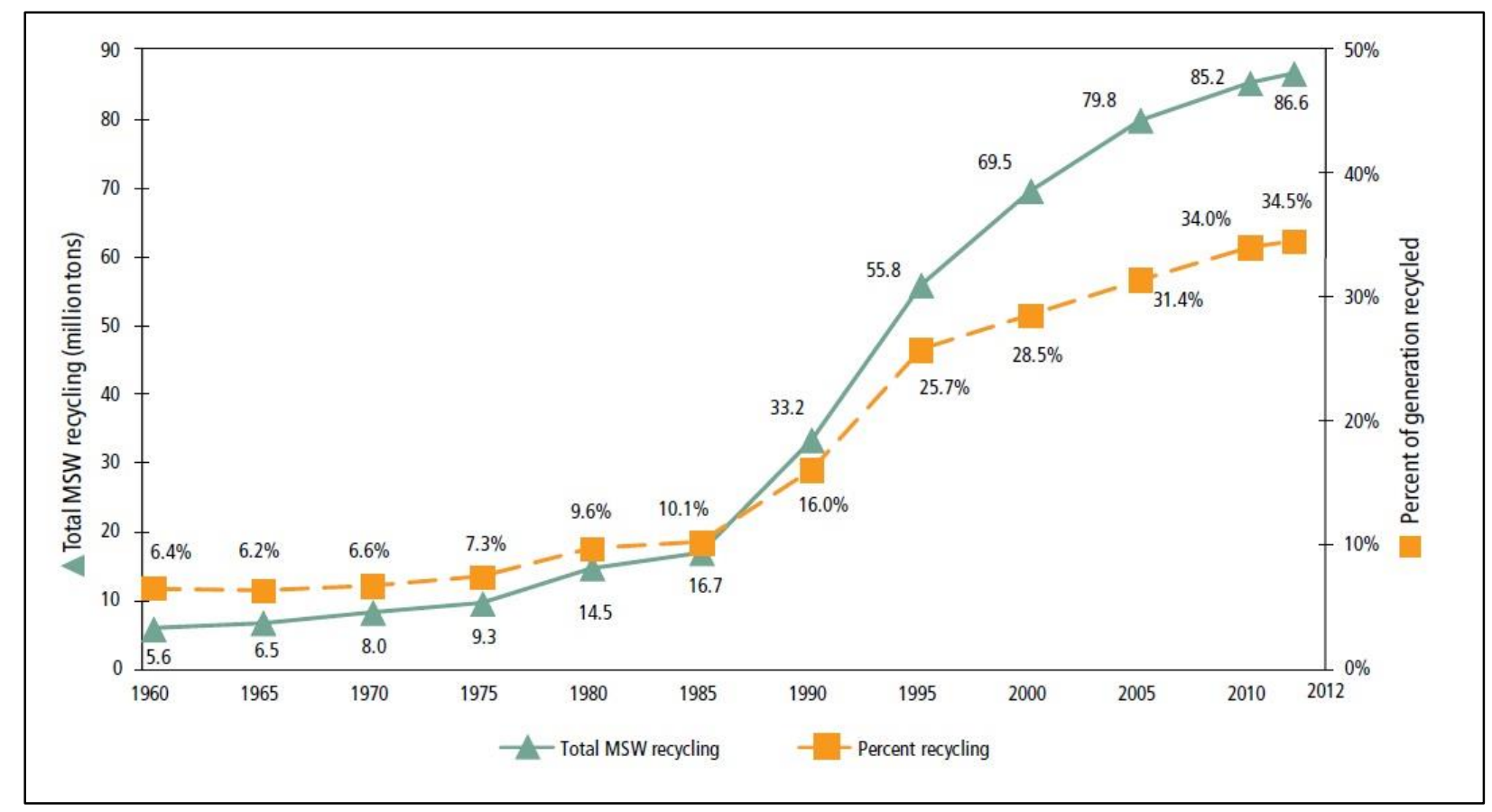

Figure 1.4: MSW recycling rates, 1960 to 2012

Source: (U.S. EPA 2012)

From Figures 1.3 and 1.4, we can conclude that the per capita MSW generation is not increasing and the percent of recycled waste is growing.

This trend of growing percent of recycled waste might cause a pressure on some collection systems in some areas in the future. At this point in time there is no evidence to show if the increase in recycling rate is driven by the growth of number of people actively recycling or by the improvements of recycling systems, infrastructure and etc.

It is also interesting to compare the EPA's statistics with the data from other countries. According the Eurostat (2014 (1)), in 2012 EU27 (the 27 countries in EU) generated $492 \mathrm{~kg} /$ person/year (about $1,085 \mathrm{lb} /$ person/year). It is roughly $2.97 \mathrm{lb} /$ person/day $(1.35 \mathrm{~kg} /$ person/day) which is $1.41 \mathrm{lb} /$ person/day $\left(0.64 \mathrm{~kg} /\right.$ person/day) less than in the U.S. EU27 recycled 102 million tons (metric tonnes $\left.{ }^{2}\right)$ in 2012

2 One metric tonne is $1,000 \mathrm{~kg}$ or $2,204 \mathrm{lbs}$. 
(Eurostat 2014 (2)) which corresponded to approximately 41 percent of waste generation. It is almost 6.8 percent more than the present U.S. recycling amount.

There is a variety of factors that affects the total performance of waste generation and recycling. Some of them, which are related to cultural and social differences, are hard to quantify. However, one can still analyze the different recyclables collection systems used in EU and U.S. The recycling collection system may also play a role in the recycling behavior (González-Torre et al. 2003).

The behavior and citizen participation in recycling programs also depends on the quality of collection service that is provided. However the providers of the collection service have limited resources in finance, human resources, equipment etc. Thus, to keep the level of service as high as possible, the collection system must work efficiently. Part of this efficiency may be contributed by the use of optimized collection routes. 


\subsection{OBJECTIVE AND SCOPE}

The main objectives of this thesis are:

1. To evaluate a suitability of GIS software for solving a Routing Problem connected to the recyclables collection.

2. To describe and evaluate the present recyclables collection in a selected shift.

3. To propose a new routing of a recyclables collection vehicle(s) in a selected shift by using a solving capabilities of GIS software. 


\subsection{ORganization OF THESIS}

Chapter 1 introduces the principles of reverse logistics and materials management, and importance of improving recycling.

Chapter 2 describes recyclables collection systems and collection automation.

Chapter 3 introduces routing problems and specifics for applied case of recyclables collection.

Chapter 4 describes the GIS software.

Chapter 5 describes the present recyclables collection in the city of El Paso.

Chapter 6 describes the selected area for the route optimization, data that were gathered and present established model, and examines present routing solution.

Chapter 7 suggest alternative solution and present evaluation and recommendations.

Chapter 8 summarizes the findings in the thesis and gives possible directions for future work. 


\section{Chapter 2: Recyclables Collection Systems in EU and U.S.}

Various recyclables collection systems are used in different places in the EU and U.S. These systems vary according to the materials that are collected and the specific methods of collection. Two collection methods are bring and curbside. In addition, some materials can be stored for collection in the same bin, mixed, using the so called single stream collection in some systems, while on the other hand, separate bins are used for different materials. Different levels of automation of the process of moving the recyclables from the point of the collection to the collection vehicle are used in the different collection systems.

\subsection{BRING AND CURbSIDE COLleCtion MethodS}

McDougall et al. (2007) defines bring collection method as those where "householders are required to take recyclable materials to one of a number of (communal) collection points" and curbside collection method as "householder places recoverables in a container/bag which they position, on a specific day, outside their property for collection". In bring systems, the householders transport the materials from their homes, whereas in curbside collection they are collected from their homes.

Bring and curbside are just the two ends of a spectrum of collection methods as emphasized by McDougall et al. (2007). The spectrum is graphically described in Figure 2.1. The extreme form of bring method is the central collection site, called citizen collection stations (U.S.), civic amenity site (United Kingdom), déchétterie (France), Recyclinghof (Germany), or sběrný dvůr (Czech Republic) to which householders drop off materials such as bulky items, old electric powered devices or garden waste. Such sites often also have collection containers for recyclable materials such as glass bottles and cans. 


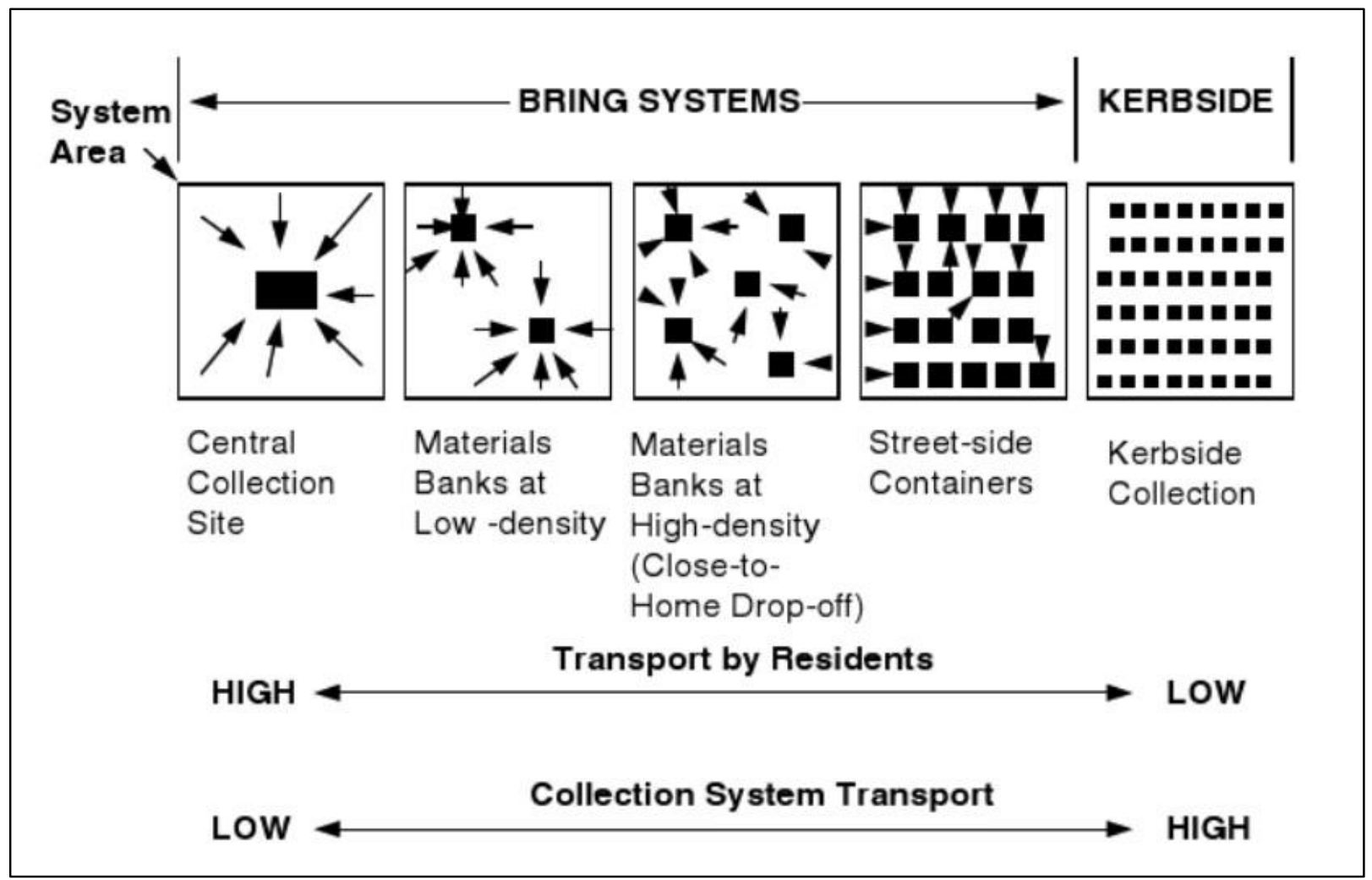

Figure 2.1: The spectrum of collection methods from 'bring' to 'kerbside' systems.

(Arrow lengths indicate distances travelled by residents to collection points.)

Source: (McDougall et al. 2007)

Materials banks at low density are next in the spectrum of the bring methods, in which each container serves a high number of inhabitants. They are often situated locally at supermarkets and large stores. In some countries (such as Czech Republic), old batteries are recycled this way. As the density of bring material containers increases, they become close-to-home drop off containers, to which householders can walk to rather than drive to. Such a system is often used in the areas of high population density with high-rise housing, where residents of apartment blocks usually take their waste and recyclables to large communal containers positioned outside the apartment blocks at the side of the street. An example of such an arrangement is in Figure 2.2. 


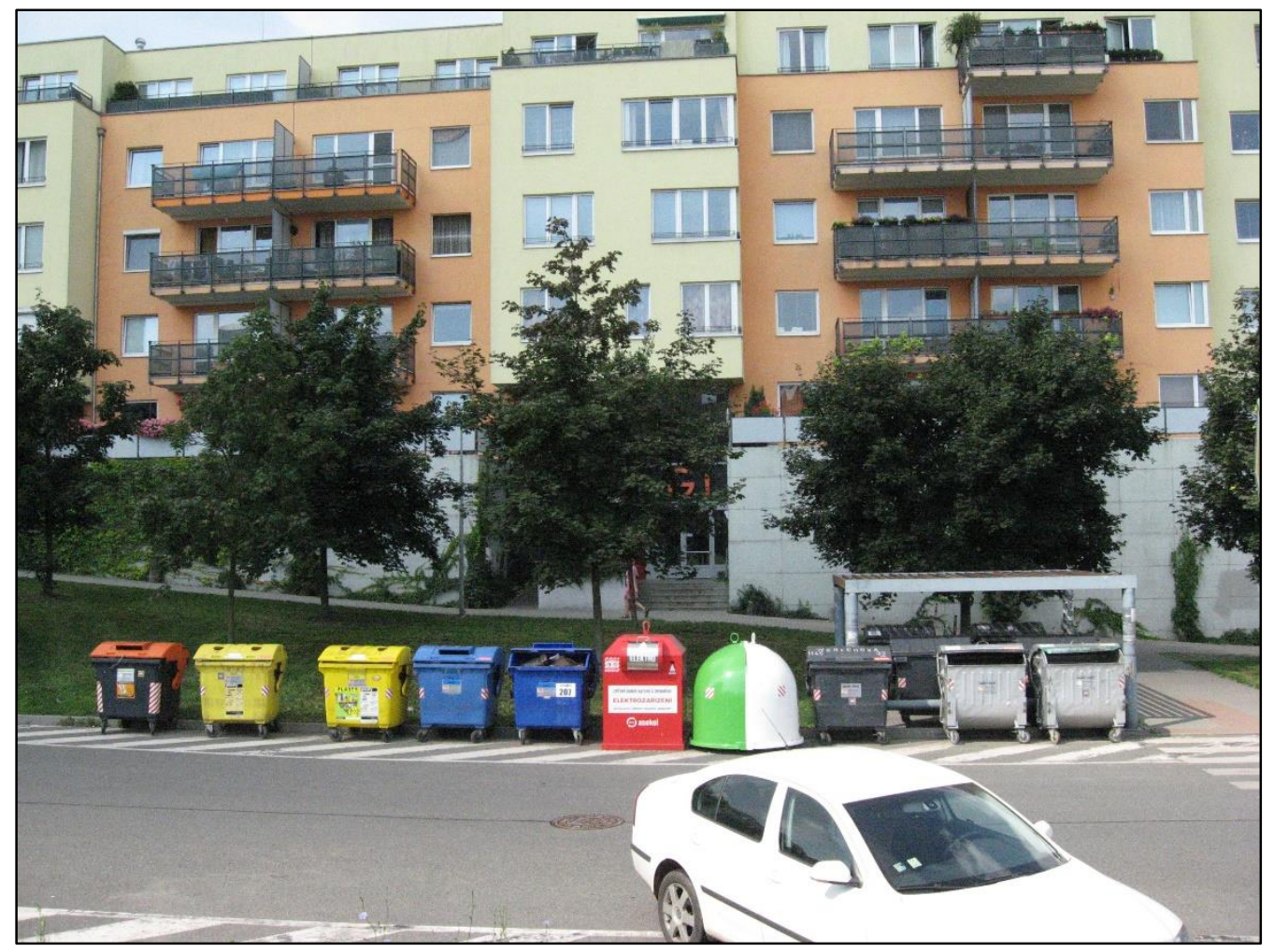

Figure 2.2: Close-to-home drop off containers in high-rise housing area of Prague, Czech Republic.

Starting at the right side of Figure 2.2, there are the black or grey containers for MSW, followed by one green/white container for pure or colored glass, one red container for electronic waste, two blue containers for paper, two yellow containers for plastics and one orange/black container for beverage cartons on the far left. This is the case where separate bins for different materials are used. This scheme allows the collection system to have a different number of containers for different recyclables (e.g. glass or electrical waste with lower density than paper and plastic), and different level of automation. On the other hand, special trucks for each type of recyclables (or trucks with more than one compartment) are needed.

In the residential areas with lower population density, the collection is mostly realized by the curbside collection method. In this method residents set out recyclable materials at the curb for collection in special bins (Figure 2.3). 


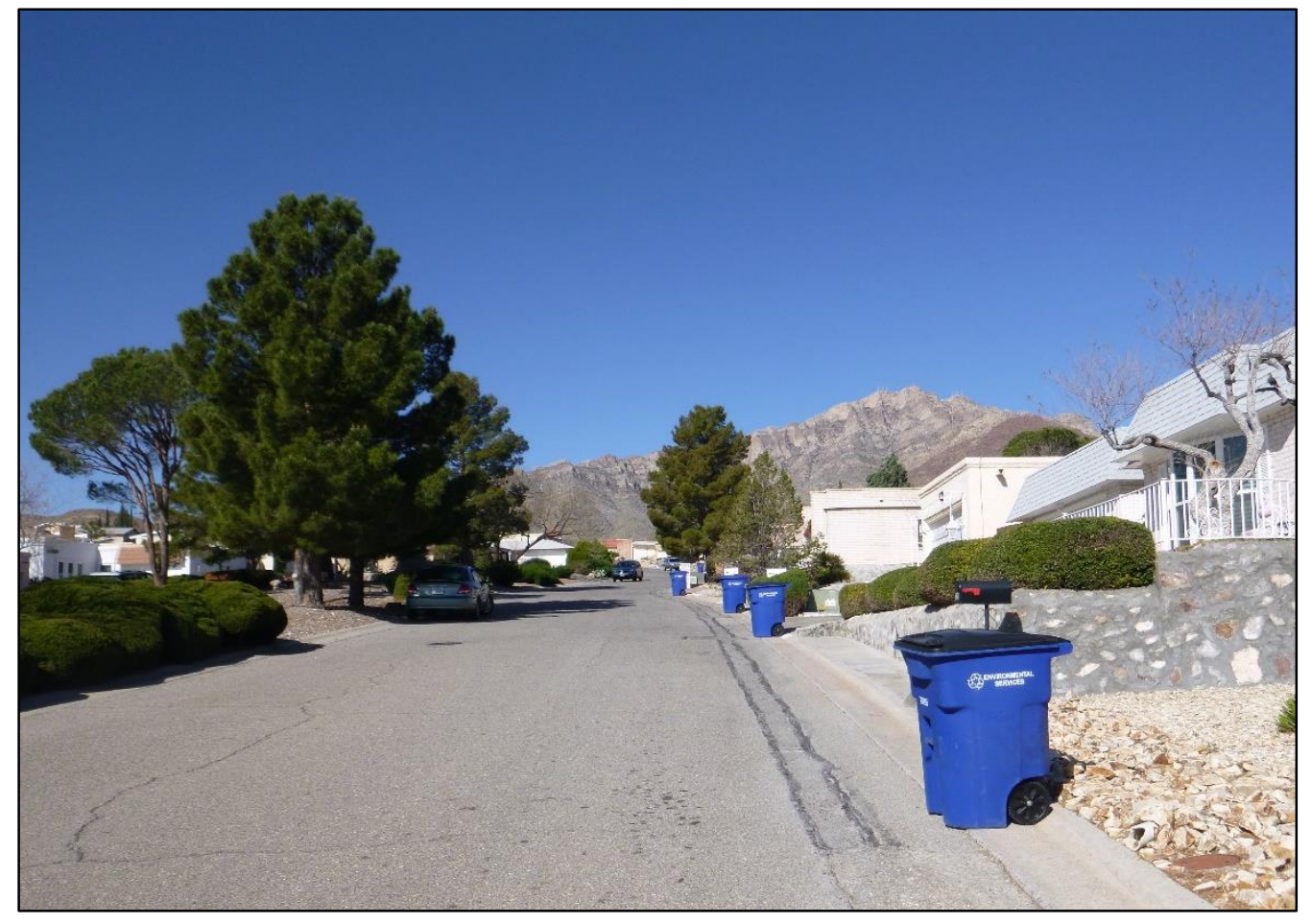

Figure 2.3: Blue bins set out, El Paso, TX

The curbside collection method is widely implemented in many urban areas in U.S. The most common is the single stream concept, where participants are allowed to mix all the acceptable materials together in one bin. Blue color bins is the most widely used. Therefore the term "blue bin" is sometimes used to describe the recyclable bin. Systems with separate bins for curbside collection, where households are provided with different types of recycling bins are also possible. However they are rare or of limited number of containers. Such a system is expensive, because it combines the highest density of collection points with the need of more vehicles (or vehicles with separate compartments).

In general, in the curbside method the bins are very near to the source of waste generation. The advantage is that the system is easy to use and also guarantee a high level of citizen participation. On the other hand it is an expensive system, because the need for a greater number of collection points brings higher investments in both collection time and cost (González-Torre et al. 2003). 


\subsection{Collection Automation}

Collection automation refers to the transfer of recyclables from the collection bins or containers to the collection vehicles. In collection automation, three stages or levels can be identified: manual, semiautomated and fully automated.

Manual collection is the level of no automation. In this system all the recyclables are moved from the point of collection to the proximity of the truck and lifted into the truck by human force. The crew assigned to a truck often consist of one or two workers and one driver (Figure 2.4).

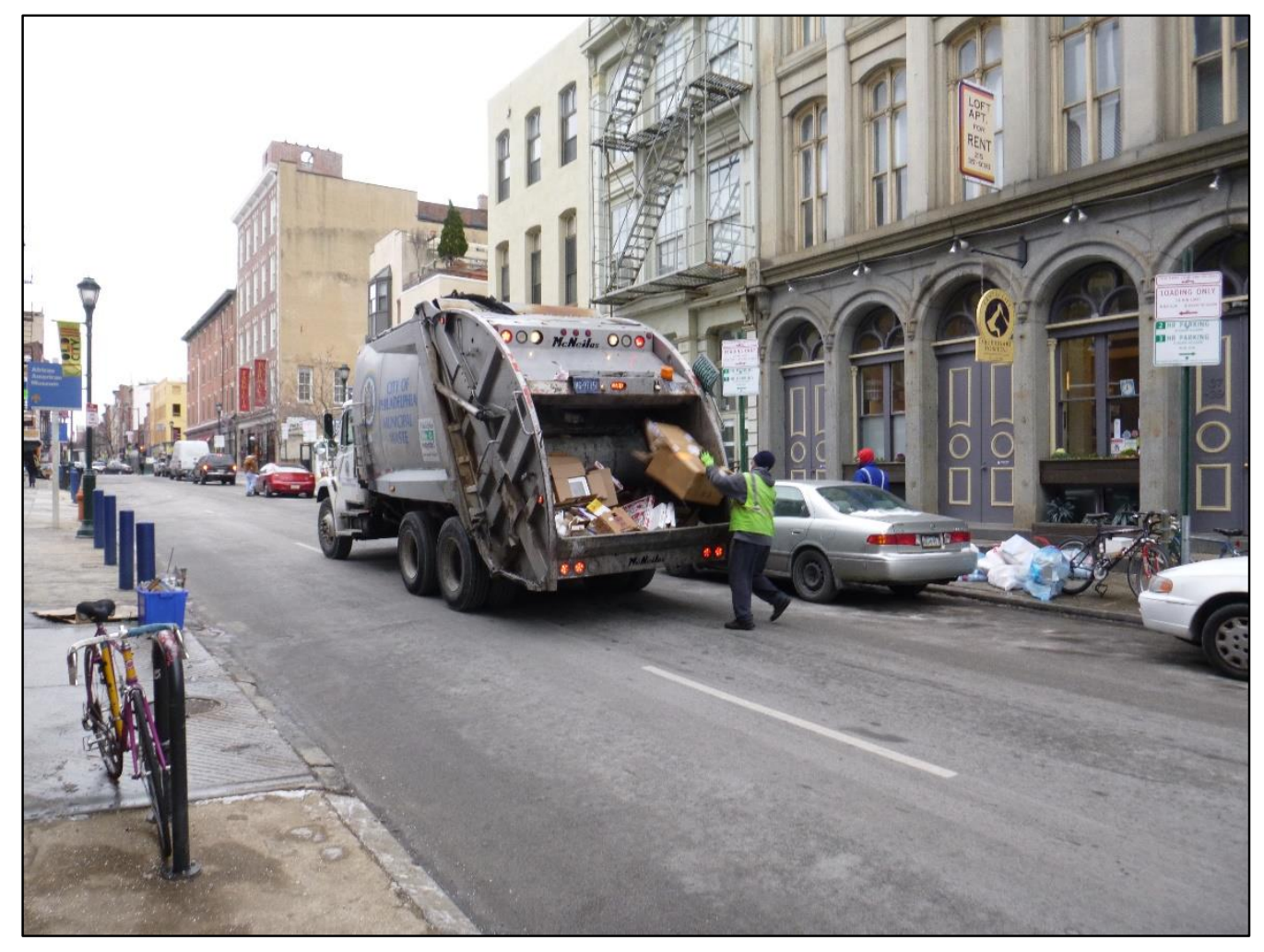

Figure 2.4: Manual recyclables collection, Philadelphia, PA

Bags or in some cases boxes are also used for recyclables curbside collection (Figure 2.5). Bags and boxes are associated with manual collection, which has high labor requirements and high risk of injury associated with lifting. 


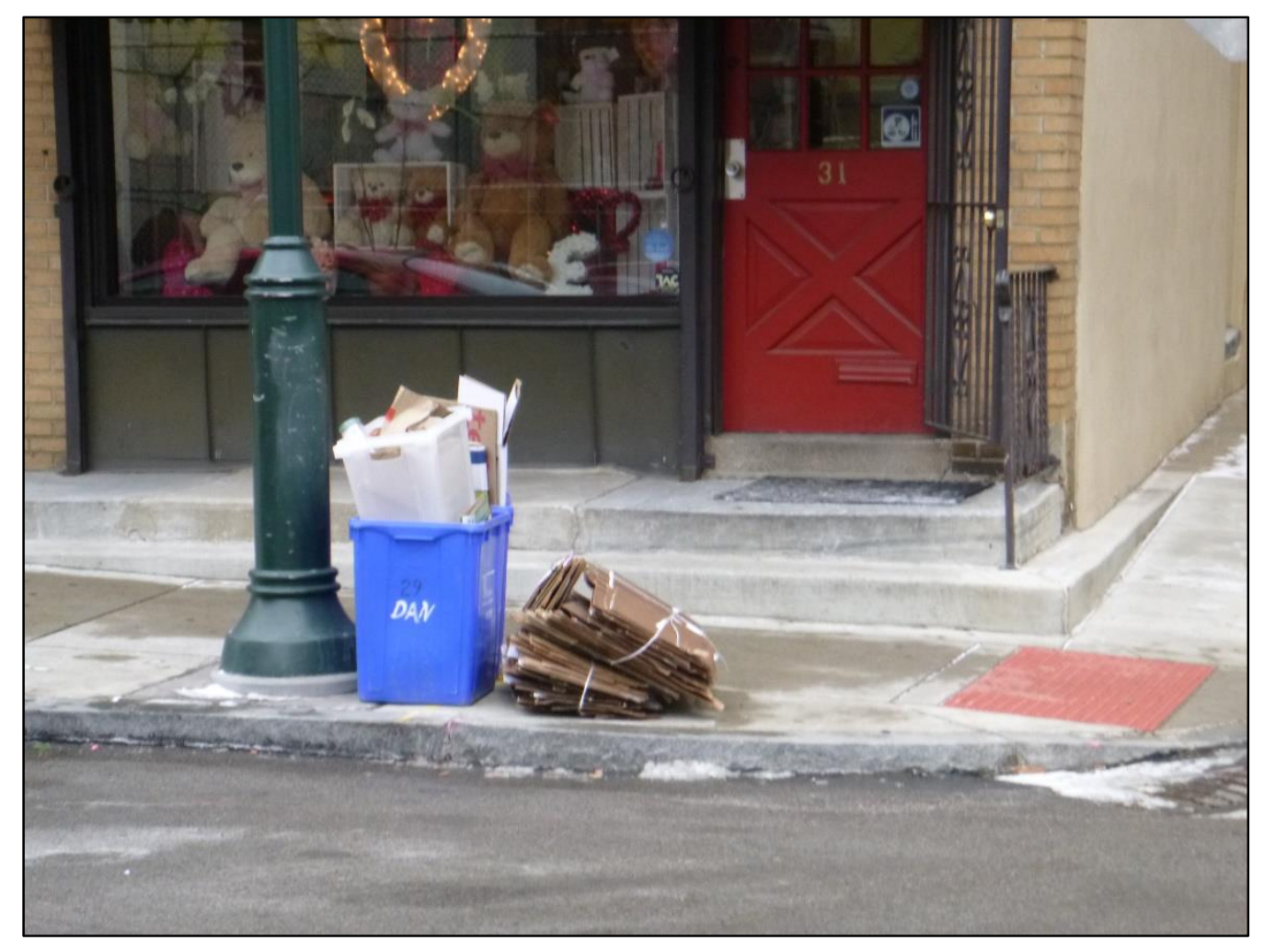

Figure 2.5: Recyclables set out at the curb, Philadelphia, PA

Automation in waste and recyclables collection is a way to decrease labor requirements, labor costs, reduce the number of vehicles required to serve a collection territory. Automation also helps to reduce injury associated with fatigue and lifting, reduce litter and unsightly set-outs (U.S. EPA 1999). However, in some places, automation might be hard to achieve, because of the local conditions like parking on the street (Figure 2.6). 


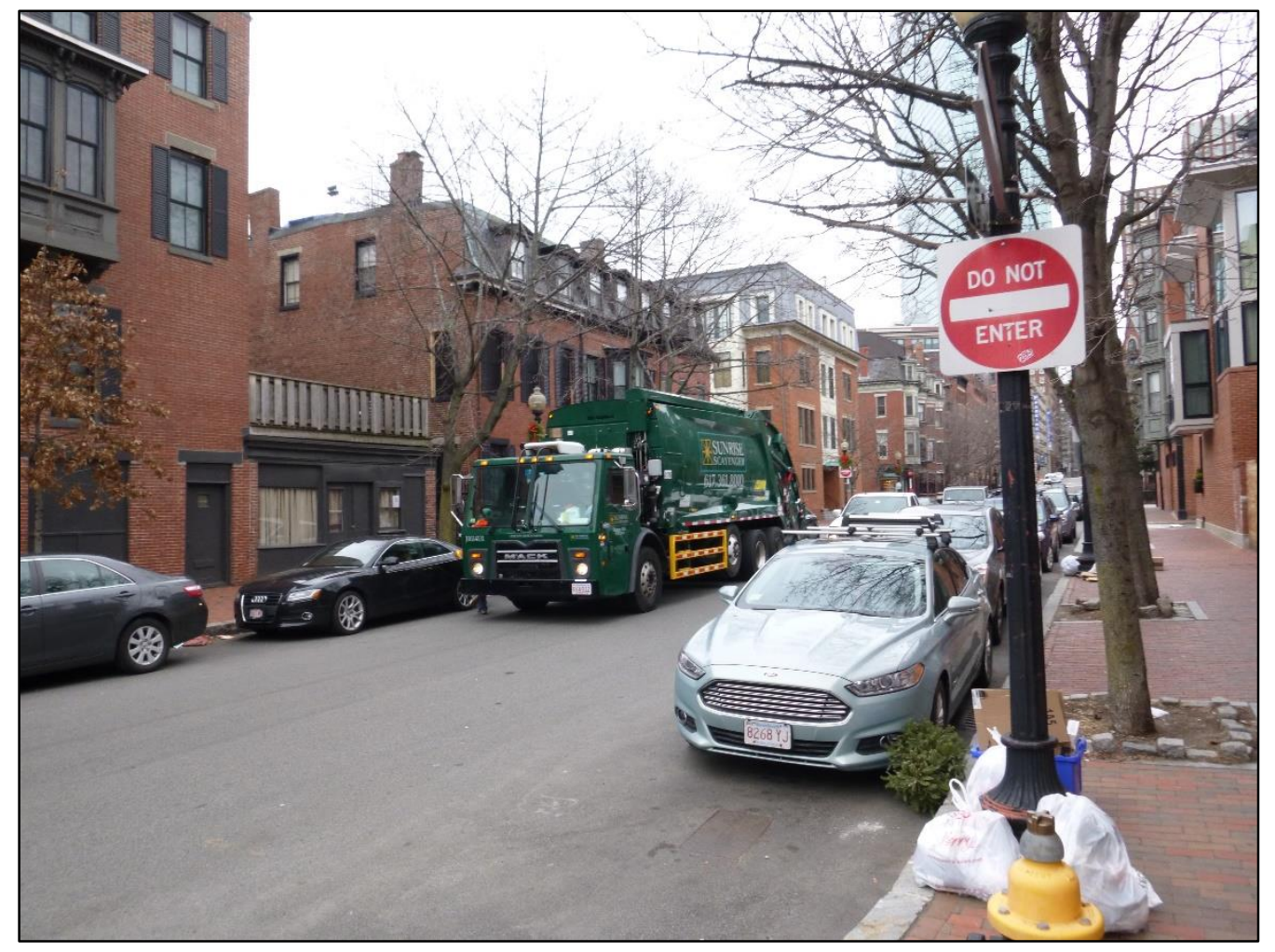

Figure 2.6: Collection truck, MSW and recyclables set out at the curb, Boston, MA

Semi-automation is often considered to be a bridge between manual collection and fully automated collection. Examples of this collection are in Figure 2.7 and 2.8. Customers are required to use special containers compatible with mechanical lifting equipment. The containers are designed with wheels and lids to make storing waste and moving containers easier for customers and collectors. Semi-automated collection vehicles are mostly designed for rear- or side-loading. This level of automation can be found for close to home drop-off (in bring method) as well as for the curbside collection method. In the curbside case customers wheel carts to the curb, typically facing them outward to facilitate handling by the crew. The collection crew wheel carts to the collection vehicle, line carts up with the lifting device, activate the lifting device, and the lifting device mechanically tip contents of the carts into the hopper of the collection vehicle.

The main benefits of semi-automated collection is its flexibility and ability to adapt to areas with constrains such as narrow streets, presence of on-street parking and one-way streets compared to fully 
automated collection. In addition, efficient manual collection can still be performed for out-of-cart setouts (i.e., materials left outside the containers) or bin overflow. However, the semi-automated collection also has drawbacks. In some cases it was found that semi-automated collection takes longer than manual collection, because the carts has to be returned to the curb and the mechanical lift might be slower than manual lifting. The labor needs may not decrease because workers are still needed to move the cart.

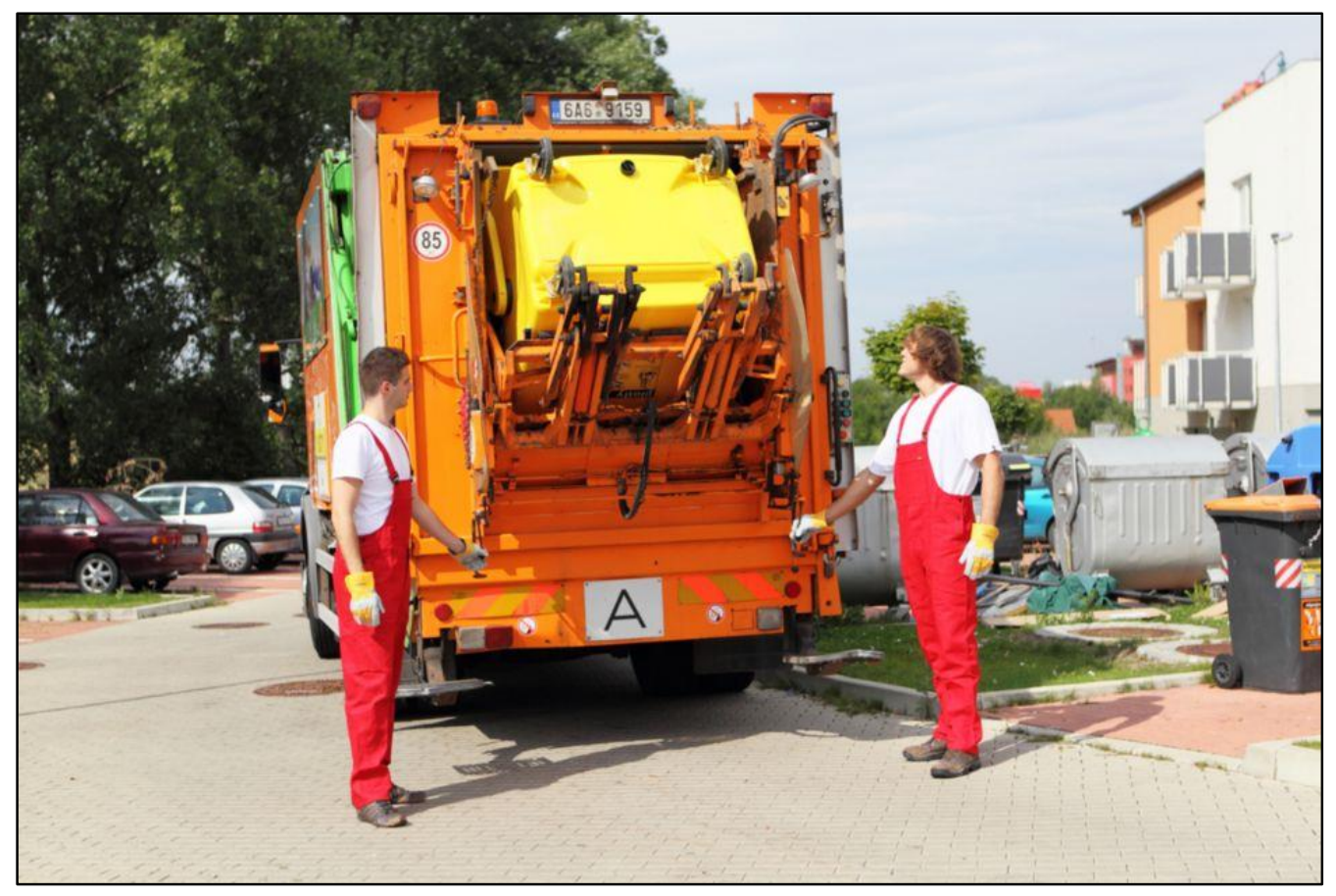

Figure 2.7: Semi-automated collection, Prague, Czech Republic Source: (Jaktridit n.d.) 


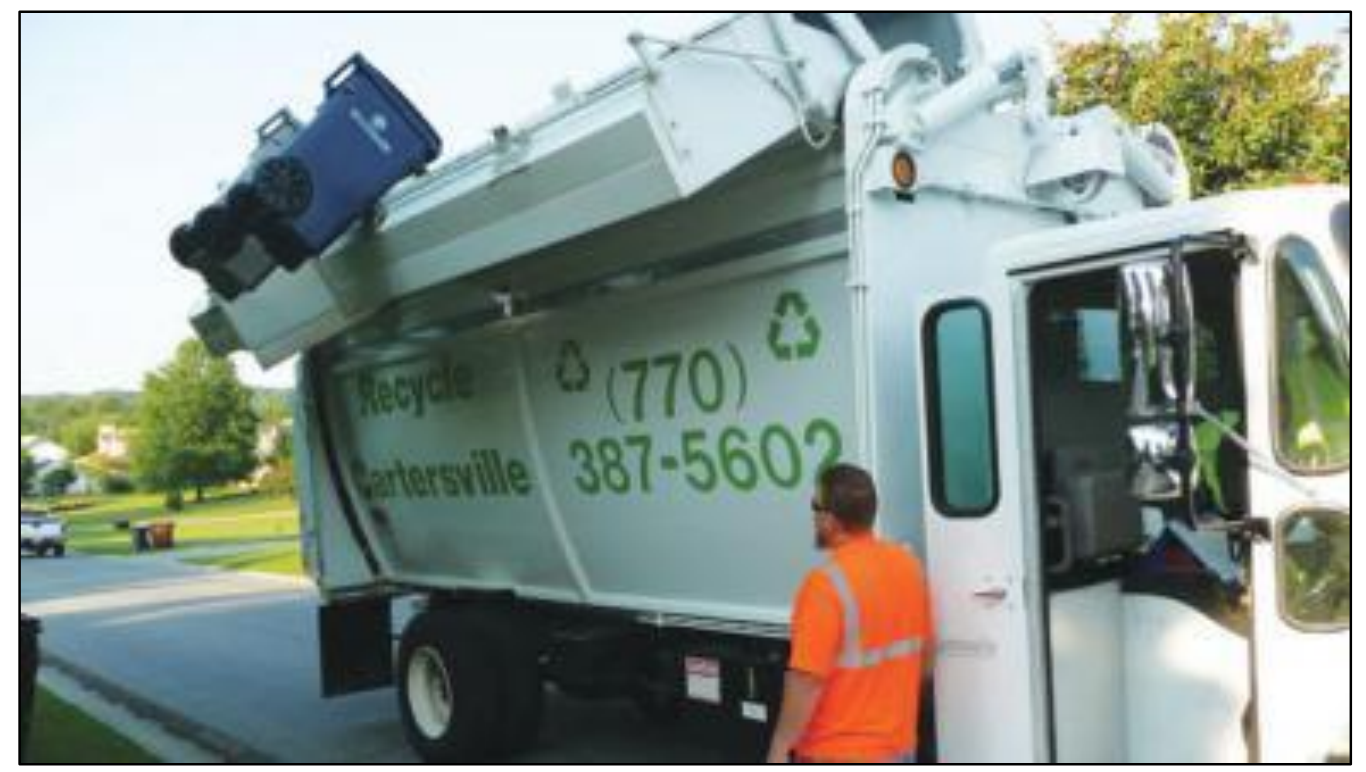

Figure 2.8: Semi-automated collection, Cartersville, GA.

Source: (American City and County, 2012)

In the fully automated collection level, containers are lifted, emptied, and returned to the collection point mechanically. Examples of fully automated collection in U.S. and EU are shown in Figure 2.9 and 2.10. The force of human hands in emptying the container in to the collection truck is needed only in the case when some problems occur (overflow materials, improperly prepared materials, improper container set-outs, and etc.). Crane-like arms or claw-like grippers are hydraulically controlled from the driver's seat.

Of the advantages of the fully automated collection systems, the most significant one is the reduction in labor. Fully automated vehicles are mostly operated by one-person crews. Automation should also reduce collection time. Productivity is increased and thus the fleet size reduction is possible. Also, the ability of physical lifting is not required, which leads to a higher level of worker safety compared to the previous two levels. On the other hand, fully automated collection vehicles are relatively more expensive. There is a reliance on customers placing containers in accessible location. Any out-of-cart setout can ruin the efficiency of automation, because of the operator needs to exit the vehicle and manually intervene the mechanical process (U.S. EPA 1999). On street parking, narrow streets or one-way streets 
(especially, when there are containers to be collected on the left side of the street and the vehicle's mechanical arm can operate on the right side only) can be a problem for fully automated collection and this negatively affect the productivity.

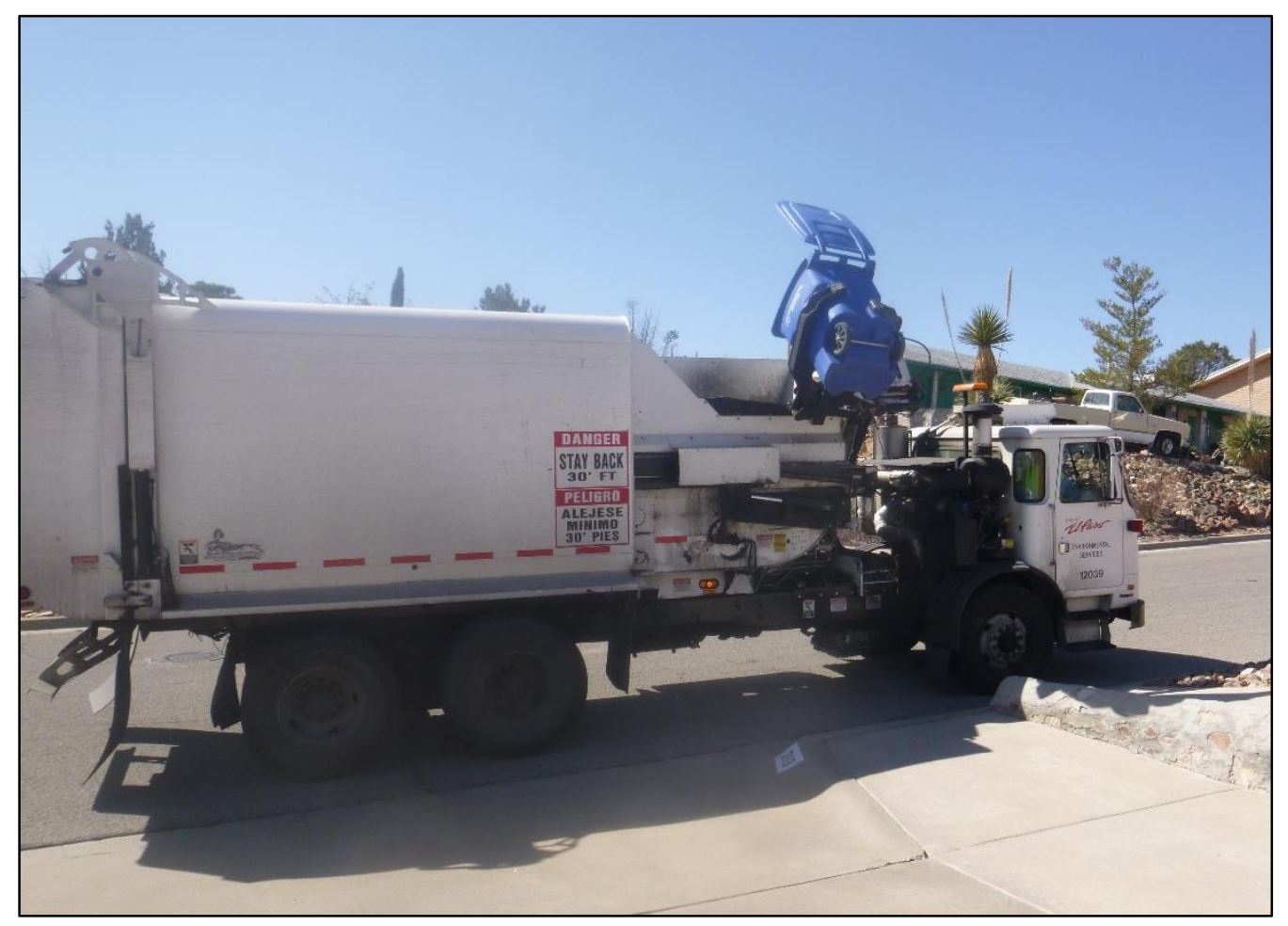

Figure 2.9: Fully automated curbside recyclables collection, El Paso, TX 


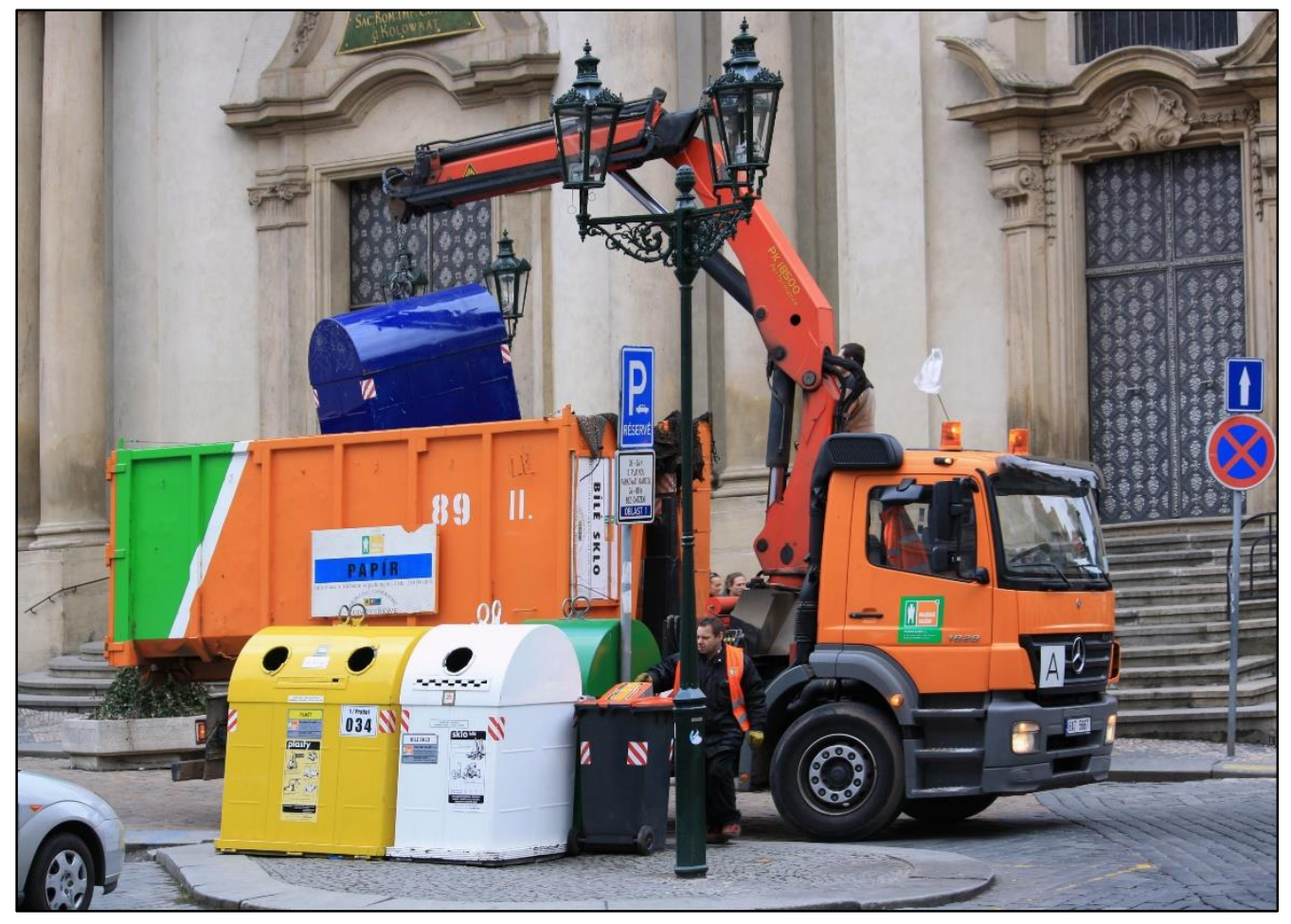

Figure 2.10: Fully automated collection, Prague, Czech Republic Source: (Bat'ha 2010) 


\section{Chapter 3: Routing Problems}

\subsection{Definition of Routing Problems}

Routing problems are problems concerning the distribution of goods, between the depots and the users (customers) (Toth and Vigo 2002). The flow of goods can be in both directions from depots to users or from users to depots.

The distribution of goods concerns the service in a given time period, to a set of customers by a set of vehicles. The vehicles are initially located in one or more depots, operated by a set of crews (drivers), and travel in an appropriate road network.

The solution of a routing problem calls for determination of a set of routes, each performed by a single vehicle that starts and ends at its own depot, such that all the requirements of the customers are fulfilled, all operational constrains are satisfied, and the global transportation cost is minimalized.

In the routing problem theory, by the position of the demand, two different kinds of routing problems are distinguished. If the demand (customers) is located at the nodes of the road network the problem is called Vehicle Routing Problem (VRP), if the customers are located along the arcs of the road network the problem is called Arc Routing Problem (ARP).

\subsection{Vehicle Routing Problem and Arc Routing Problem}

Operational constrains that need to be satisfied are different for every routing problem. The constraints depend on the requirements of the problem in practice. The following basic versions of VRP and ARP are generally mentioned in the literature. However, for each of these problems, several minor variants have been proposed and examined and often it results in different problems that are still given the same name (Toth and Vigo 2002).

\section{Traveling Salesman Problem (TSP)}


Traveling salesman problem (TSP) is a special case of VRP, for which only one vehicle is available at the single depot to which it must return to at the end of the route. In graph theory, TSP consists of determining the shortest Hamiltonian circuit in the given graph, where the graph can be directed or undirected (Laporte and Osman, 1995). Usually, no other constrain is taken into account in a TSP.

\section{Capacitated VRP (CVRP)}

In general, capacitated vehicle routing problems (CVRPs) are all VRPs where a capacity restriction for vehicles is a constraint. It means the sum of demands of all vertices visited does not exceed the vehicle capacity.

\section{VRP with Time Windows (VRPTW)}

In VRP with Time Windows, each customer must be served within a certain time interval called Time Window. Toth and Vigo (2002) mark this VRP as an extension of CVRP meaning that all the VRP with time windows are also capacitated.

\section{VRP with Pickup and Delivery (VRPPD)}

In case where goods need to be moved from certain pickup locations to other delivery locations, the problem is called vehicle routing problem with pickup and delivery (VRPPD). The goal is to find optimal routes for a fleet of vehicles to visit the pickup and drop-off locations.

\section{VRP with Backhauls (VRPB)}

In this variant of VRP, there are two subsets of customers, line-haul customers and backhaul customers. The goods are delivered for the line-haul customers while for the backhaul customers the inbound goods must be picked up. Also, for this VRP, vehicle capacity must be observed. Thus, VRPB is another extension of CVRP. If some customer is a line-haul customer and also a backhaul customer, the vehicle load is determined according to the rule that first the line-haul goods are delivered and then the backhaul goods are picked up.

\section{Capacitated ARP (CARP) and ARP with Time Windows (CVRP-TW)}

ARPs can be capacitated or have time windows. Their difference from CVRP is the location of the demand. The graph representation of the road network can be directed, undirected or mixed.

\section{Chinese Postman Problem (CPP)}


Chinese postman problem is a version of ARP, where all arcs in the network must be served. It is the unconstrained case of ARP.

\section{Rural Postman Problem (RPP)}

Rural postman problem is more general then CPP. In the rural postman problem only a part of the total road network is served. The rest of the network can be used for moving in-between arcs that are served.

\subsection{SOLUTION ALgORITHMS}

To describe a complexity of routing problems, consider a TSP in a complete graph (where every node is connected to each other) of three customers and one depot (Figure 3.1). There are six possible routes. We can evaluate all the routes and choose the one with the lowest cost.

But by adding customers the problem grows by relation: $r=n$ !, where $\mathrm{r}$ is the number of possible routes and $\mathrm{n}$ is number of customers. That makes exhaustive search for larger number of customers requiring too long computation time.

In fact, TSP, similar to most of the other routing problems, is a Non-Polynomial (NP) hard problem. NP problems are problems which should be solved in nondeterministic polynomial time. Golden and Wong (1981) proved that CARP belongs to the class of NP-hard problems.

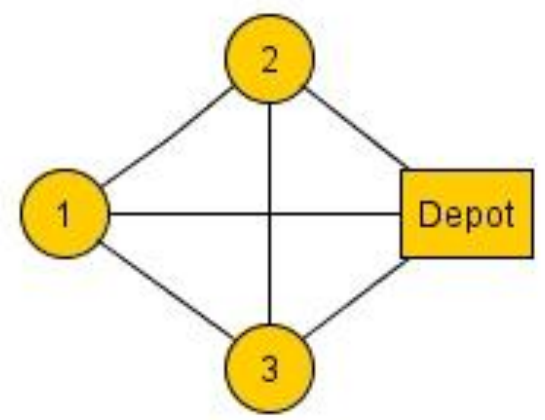

Figure 3.1: Complete graph of one depot and three customers 
Algorithms that give us solutions in reasonable time are needed to solve routing problems. There are exact algorithms, such as the branch-and-bound algorithm. Heuristic algorithms are not able to provide the optimal solution for every case, but the solution is always close to optimal and can be found in reasonable time. Heuristics algorithms may be distinguished as classical heuristics and metaheuristics. Example of a classical heuristics is the Clarck and Wright Algorithm. In this algorithm, a set of elementary routes is created. Two routes are then merged together to form a single route if there is a distance saving while the capacity and other constrains are kept.

Metaheuristics are methods that perform a relatively limited exploration of the search space, with a resulting good quality solution in modest computing time. These methods are performing a deep exploration of the most promising regions of the solution space. The neighborhood search rules, memory structures and recombination of solutions are involved in these methods (Toth and Vigo 2002). Examples of metaheuristics are: simulated annealing, genetic algorithms, ant colony or tabu search.

As described by Brownlee (2014), tabu search is a global optimization algorithm which has an embedded heuristic technique. The purpose of tabu search is to prevent it from returning to recently visited areas of the search space and being stuck in local extremes. To avoid this so called cycling, solutions that were recently examined are forbidden, or tabu, for a number of iterations. The algorithm creates a list of forbidden solutions so called tabu list. The strategy of the approach is to maintain this short term memory structure of the recent moves within the search space and prevent future moves from undoing those changes. Figure 3.2 is a pseudocode of the tabu search. 


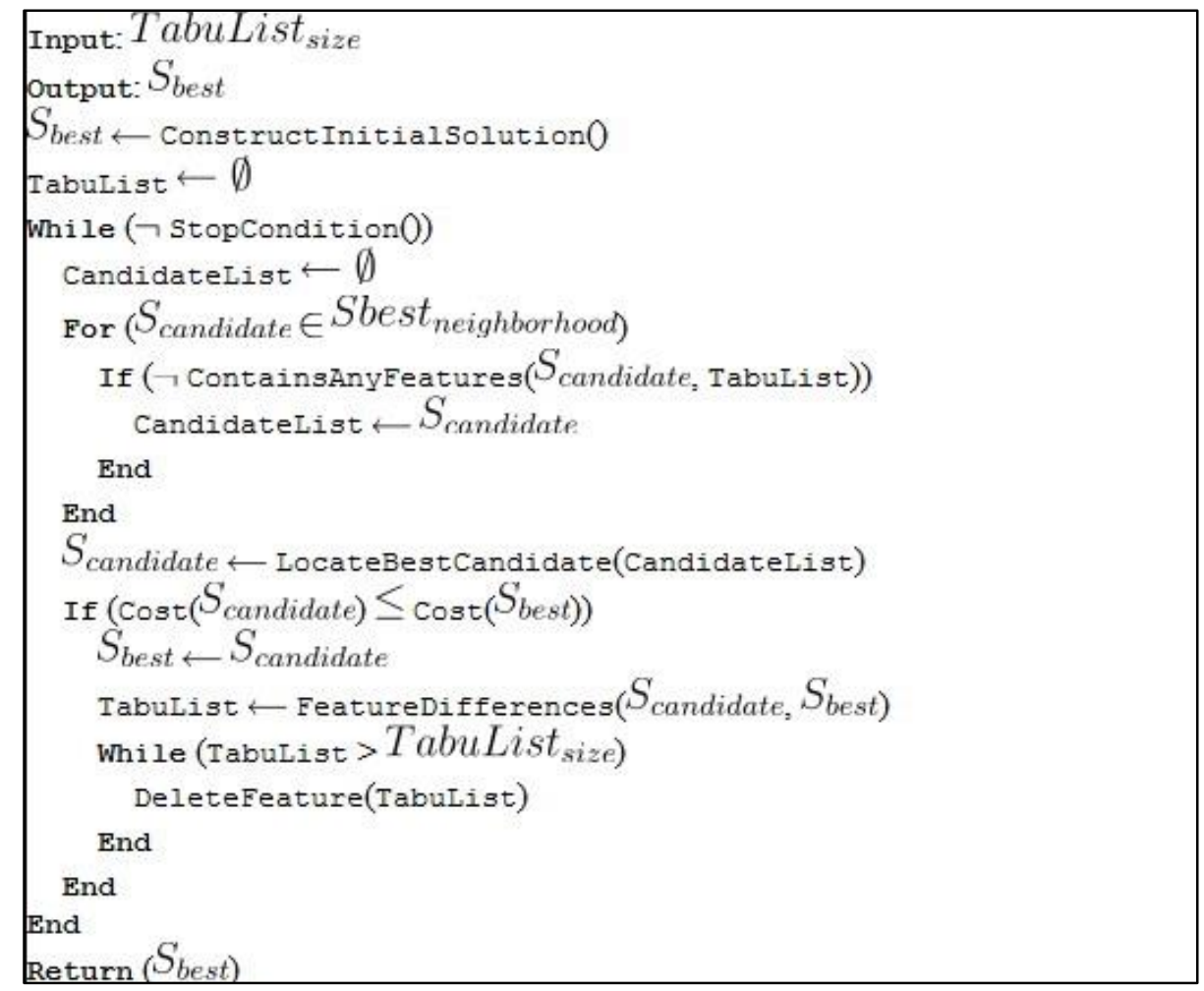

Figure 3.2: Pseudocode for tabu search

Source: (Brownlee 2014)

\subsection{Residential Recyclables Collection Routing Problem}

Routing of vehicles for residential collection involves visiting almost each of the streets in residential network. In Toth and Vigo (2002), the residential collection in vehicle routing in solid waste industry is referred to be a case of arc routing problems. There are many different categories of service e.g. garbage, recyclable and yard waste collection. The collection service is required at almost all arcs, however in real life application there are mostly always some arcs that, because there is no demand, do not require service. The problem is capacitated since there is a limited capacity of the collection truck. However, it is not accurate to mark the residential collection as a pure CARP. Santos et al. (2011) refer to such a routing problem as constrained CARP or C-CARP and mention the following specific operational conditions/constraints that differentiate C-CARP from CARP: 
1. One-way streets (i.e., the network includes directed arcs);

2. Prohibited turns (e.g., U-turns and left turns) at some intersections;

3. The route "drop-off point" (i.e., the landfill or processing plant) is not at the same location as the depot where the vehicles start and end their shifts;

4. Vehicles that can serve more than one route in a day. Every route must include a "drop-off point". Only after the last route, the vehicle must return to the depot immediately after visiting the "drop-off point."

5. There is a constraint of the maximum hours that the vehicle's crew can work on a given day.

In addition to these constraints in case of the automated side loaders there is another constraint of that the curb approach is needed from the side of the vehicle where the side-loader is located (mostly the right side of the vehicle). This may affect the collection in one-way street where there are residential houses on both sides of the street. In manual collection at some streets workers can collect from both sides

of the street and so only one pass through these streets is needed. Also, not all the residents will set out the bins to be collected at the collection day. In this case, the demand point is stochastic. In some ways, the quantity of recyclables collected is also stochastic. The uncertainties in demand points and in each point quantity have made the problem very challenging.

\subsection{MACro ANd Micro Routing}

In the waste management practice, the design of recyclables or MSW collection routes typically consists of two phases.

The first phase is known as macro routing. In this phase the total geographic area to be served is divided into few smaller subset and each of these subsets is assigned to one collection day. This means that on a given collection day all available crews and vehicles are collecting in that same area and nowhere else. In this macro routing phase, it is also decided that in one collection day how the area will be further spitted to individual crews and vehicles. 
The second phase is the micro routing phase in which the specific directions that each individual vehicle will follow to service each route is specified (U. S. EPA 1999). This can be done by solving the C-CARP. 


\section{Chapter 4: Geographic Information Systems}

In this Chapter the principle of geographic information systems is described. The Network analyst extension of ArcGIS is introduced and it is presented in general how this extension is used to solve routing problems in residential recyclables collection.

\subsection{GIS DEFINITION AND UTILIZED SOFTWARE}

Geographic Information System (GIS) is an integrated collection of computer software and data used to view and manage information about geographic places, analyze spatial relationships, and model spatial processes. A GIS provides a framework for gathering and organizing spatial data and related information so that it can be displayed and analyzed (Support ESRI n.d.).

GIS organizes data into layers, where each layer is a collection of geographic objects that have something in common. These geographic objects are called features and they can represent houses, roads, lakes, rivers or whole cities or countries depending on that how detailed representation of the real world is needed on the map to utilize the GIS for the analysis. The biggest advantage of GIS is its ability to integrate data from different data sources, and display them in their spatial relationship. Figure 4.1 shows the visual representation of how GIS works with different data sources. 


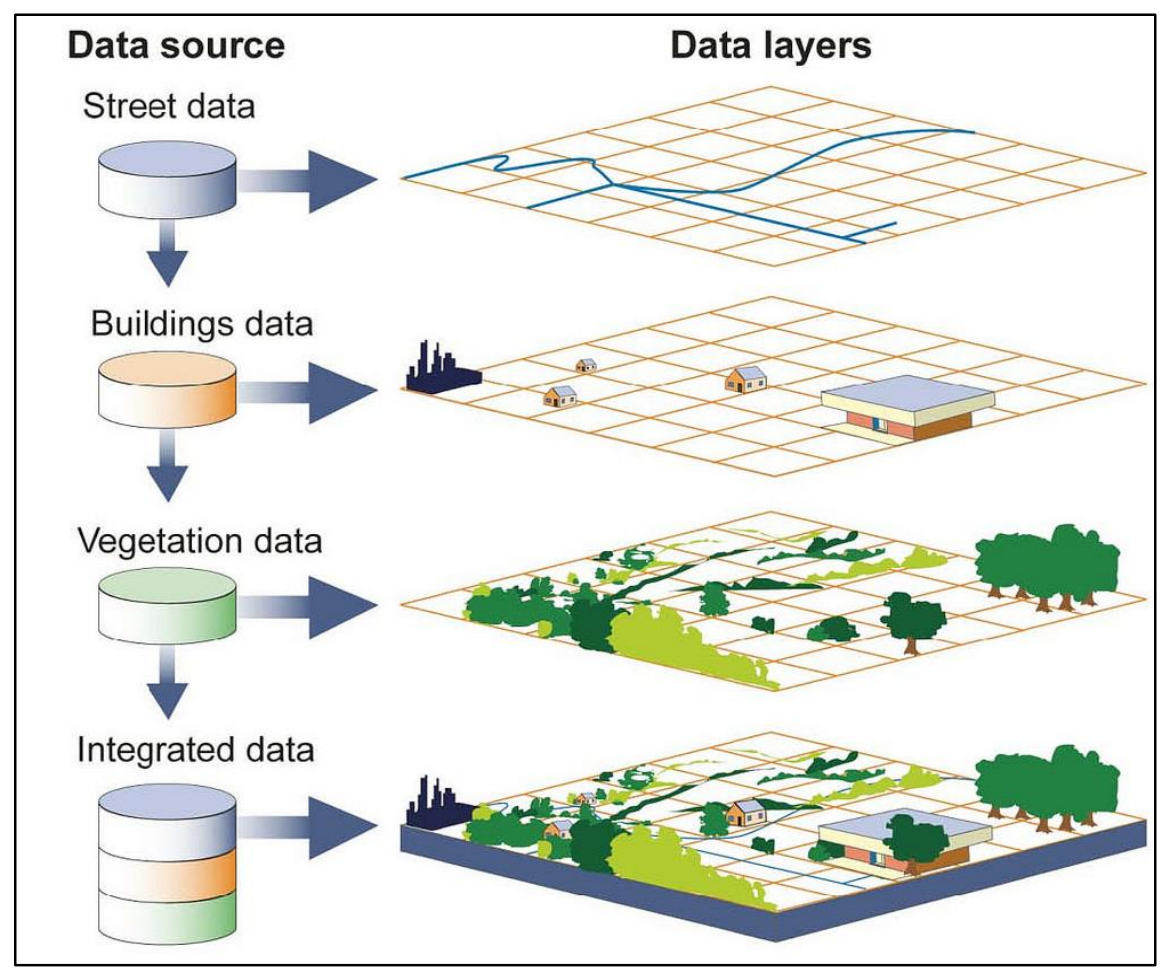

Figure 4.1: Data sources and data layers in GIS

Source: (U. S. GAO 2012)

For the analysis of the recyclables collection routing problem, the GIS software developed by ESRI, named ArcGIS (Version 10.1) was utilized (ESRI 2012). A range of optional extensions can be purchased separately from ESRI to expand the capabilities of ArcGIS. One of these extensions necessary for solving the routing problem is the ArcGIS Network Analyst (ESRI 2015).

\subsection{NETWORK ANALYST EXTENSION}

Spatial analysis in a transportation network is provided by the ArcGIS Network Analyst (NA) extension. This extension can solve problems like routing, fleet routing, travel directions, closest facility, service area, and location-allocation. For each of these problems there is a separate component of ArcGIS NA called solver. ArcGIS groups networks into two categories: geometric networks and network datasets. Geometric networks are designed for modeling river networks and utility networks such as electrical, gas, 
sewer, and water lines. The path is determined by external forces like gravity or electromagnetism and so the travel in these networks is allowed only in one direction at a time. Network datasets were designed for modeling transportation networks. In contrast to the geometric networks, travel is allowed in both directions in the network datasets. To run any solver in Network Analyst the network dataset has to be assigned first. Every network dataset contains two kind of elements: edges (lines) and connecting junctions (points). Using these elements, the actual network is defined and they represent possible routes from one location to another (Resources ArcGIS 2014).

Network Analyst comes with several solvers. The vehicle routing problem solver finds the best routes for the fleet of vehicles. The solver is capable to constrain the capacity of the truck in the fleet and also handles time windows or backhauls. It also allows users to set the desired curb approach of the vehicle, which is very useful for MSW or recyclables collection tasks. The geographical positions, where the demand for the VRP is located are in the NA denoted as the orders and these orders are stored in so called orders feature layer.

The algorithm in the VRP solver starts by generating an origin-destination matrix of shortest-path costs between all orders (recycling bins in this case) and depot locations along the network. Using this cost matrix, it constructs an initial solution by inserting the orders one at a time onto the most appropriate route. The initial solution is then improved by re-sequencing the orders (bins) on each route, as well as moving orders from one route to another, and exchanging orders between routes. The heuristics used in this process are based on the tabu search metaheuristic and are proprietary by ESRI (2010).

\subsection{USING VRP SOLVER FOR THE RESIDENTIAL RECYCLABLES COLLECTION ROUTING.}

Because there is no ARP solver in ArcGIS NA, it was decided to use the VRP solver for finding the solution of the residential recyclables collection routing problem.

The VRP solver is not designed for high density of orders (customers) such as the MSW or recyclables collection (Geonet 2010). It was found that there is a limit of one thousand orders in a one route (Geonet 2012). However, there has been an attempt to utilize VRP solver for MSW collection. O'Connor (2013) described the anomalous sequencing that occurred in the output of the VRP solver. In 
O'Connor's work, the VRP solver did not return reasonable results when solving for large groups of points, typically over 150 orders. The solver returned illogical sequence for points being serviced, which contributed to longer than expected travel times.

A preliminary experiment was conducted to investigate the cause of the sequencing errors, using El Paso's network dataset. It was found that the occurrence of this error does not depend only on the number of orders but also on the layout of the road network. In non-grid networks, the problem occur when number of orders is less than 150. Some of the orders are skipped on the first time the collection vehicle visit the street and the skipped bins are collected later while the truck is passing through the street the second time. It was also found that this error occurs not only in Version 10.1 of ArcGIS, but also in the most recent Version 10.3. This was discovered by an experiment with a smaller set of 229 orders.

To force the NA's VRP solver to produce a reasonable solution without anomalous sequence, the following steps were utilized. In the first step the VRP solver was run with the selected orders to obtain an initial solution with anomalous sequence. If there are prohibited turns at some intersections, a setting of allow U-turns only at dead ends should be made to obtain a feasible solution. In the second step, the sequence of orders from the VRP solver's initial solution was exported and joined to the layer that is representing the orders input. Then, in the third step the sequence was modified by using the field calculator in ArcGIS to correct the errors in sequencing. The algorithm used to modify the sequence is described in diagram in the figure 4.2. When the new correct sequence was established the VRP solver was run again with the setting to preserve this sequence and policy for U-turns set to the option "Allow U-turns at intersections and dead ends", which represents the fifth step. With this approach, the problem of unreasonable long travel time caused by anomalous sequencing described by O'Connor (2013) was eliminated. 


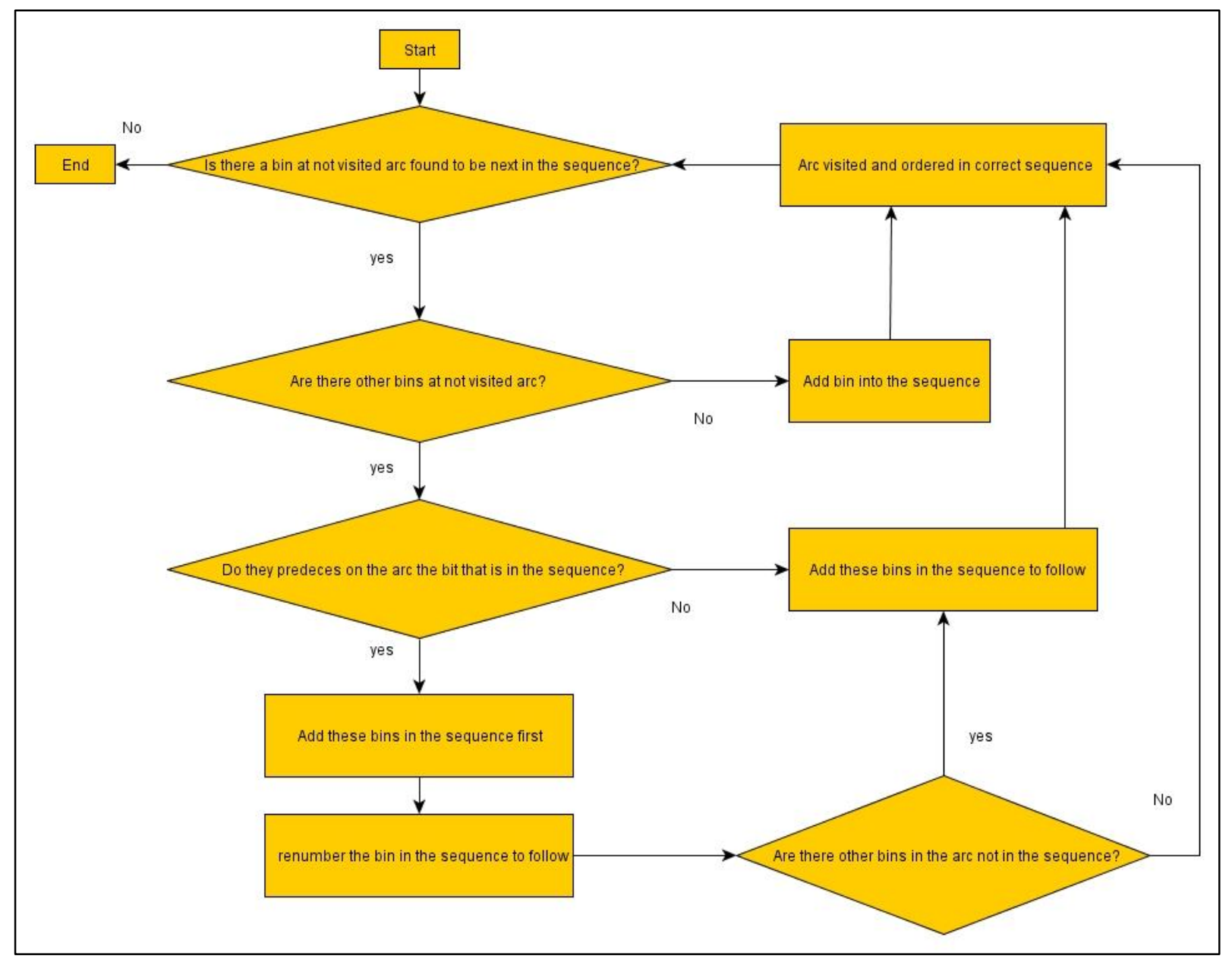

Figure 4.2: Diagram for anomalous sequencing correction algorithm

Network analyst extension allows users to evaluate the delay in routing caused by the turns at junctions (turn time impedances) by a tool called Global Turn Delay Evaluator (GTDE). This turn evaluator automatically adds penalties to specified turns in the whole network. Specific penalties for left turns, right turns and U-turns can be set. However, it was found that for some of the NA solvers this tool was not working (Geonet 2014) since its settings has no effect on the output solution. To overcome this problem the turn evaluation was added as one term in the model (to be described in Section 6.4) and the delay caused by the left turns and U-turns is evaluated after the processing in ArcGIS. 


\section{Chapter 5: Recyclables Collection in EI Paso}

\subsection{COLlection Areas}

In El Paso, the service provider of recyclable waste collection from residential areas in El Paso is the City of El Paso Environmental Services Department (ESD). Recyclables are collected once a week between Tuesday and Friday from more than 163,000 households. In the city, there are 28 recyclables collection shifts per day. Figure 5.1 shows how the city is divided according to the working (collection) days.

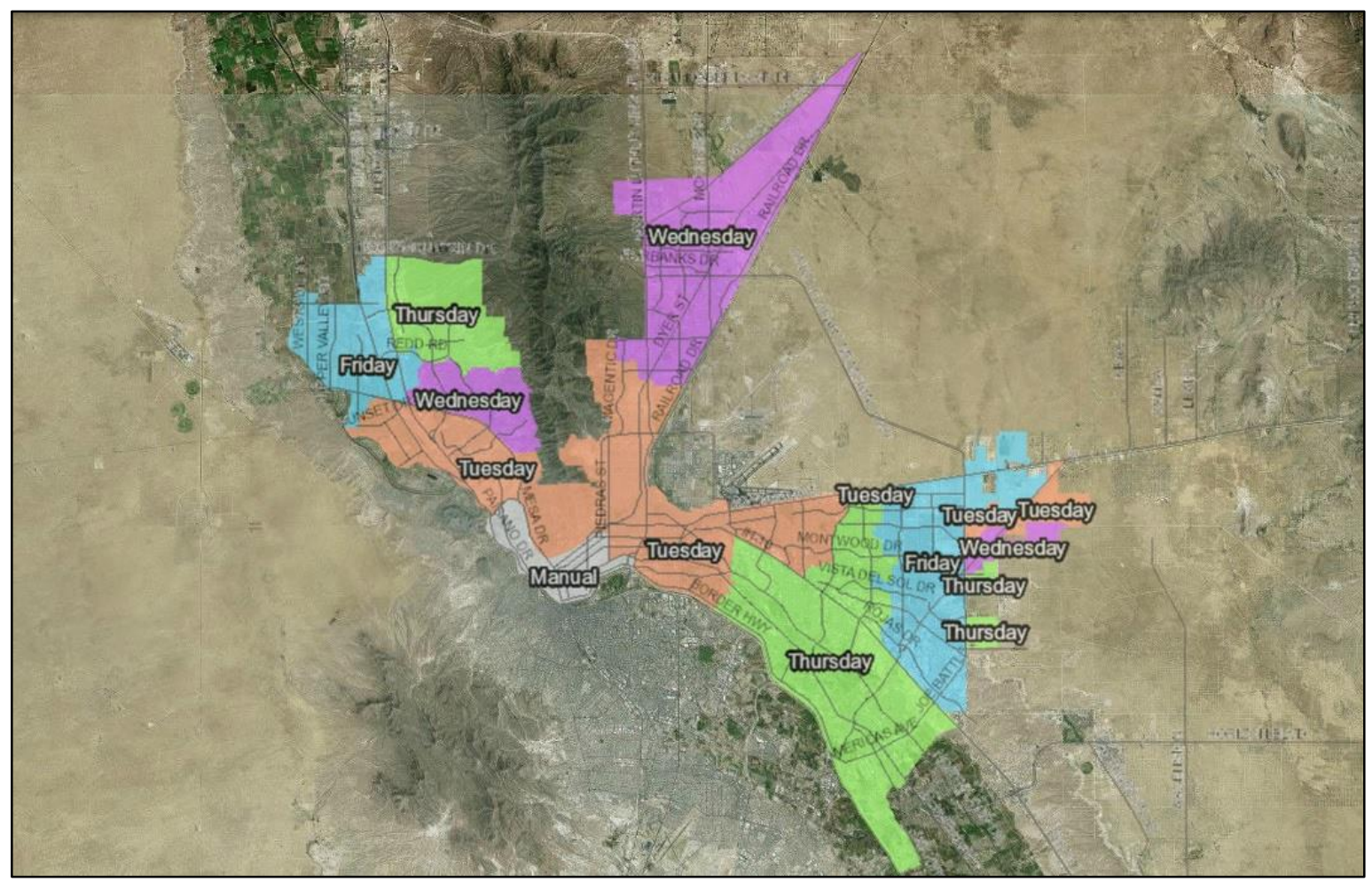

Figure 5.1: Service areas in particular days

Source: (DoITS, (2014)) 
For the collection of recyclables, the city is divided into the three areas: west, east and far east (Figure 5.2). The east area has two supervisors. Each supervisor has a region for which he or she is responsible. These regions also depend on the collection day. On Tuesday collection there are two regions in the east side area. In Figure 5.3, the polygon enclosed by bold yellow lines shows the borders of the east area. The thin yellow line is the border between the two regions in the east area. Work load of one driver-truck in one day is called a shift. Dots of different colors show the positions of bins to collect, where each color represents a shift covered by one driver-truck. In a collection day, there are nine driver-trucks working in each of the regions. There can be more than one route per shift. A route begins when an empty driver-truck picks up the first bin and ends when the driver-truck proceed to the processing plan to unload all the collected recyclables.

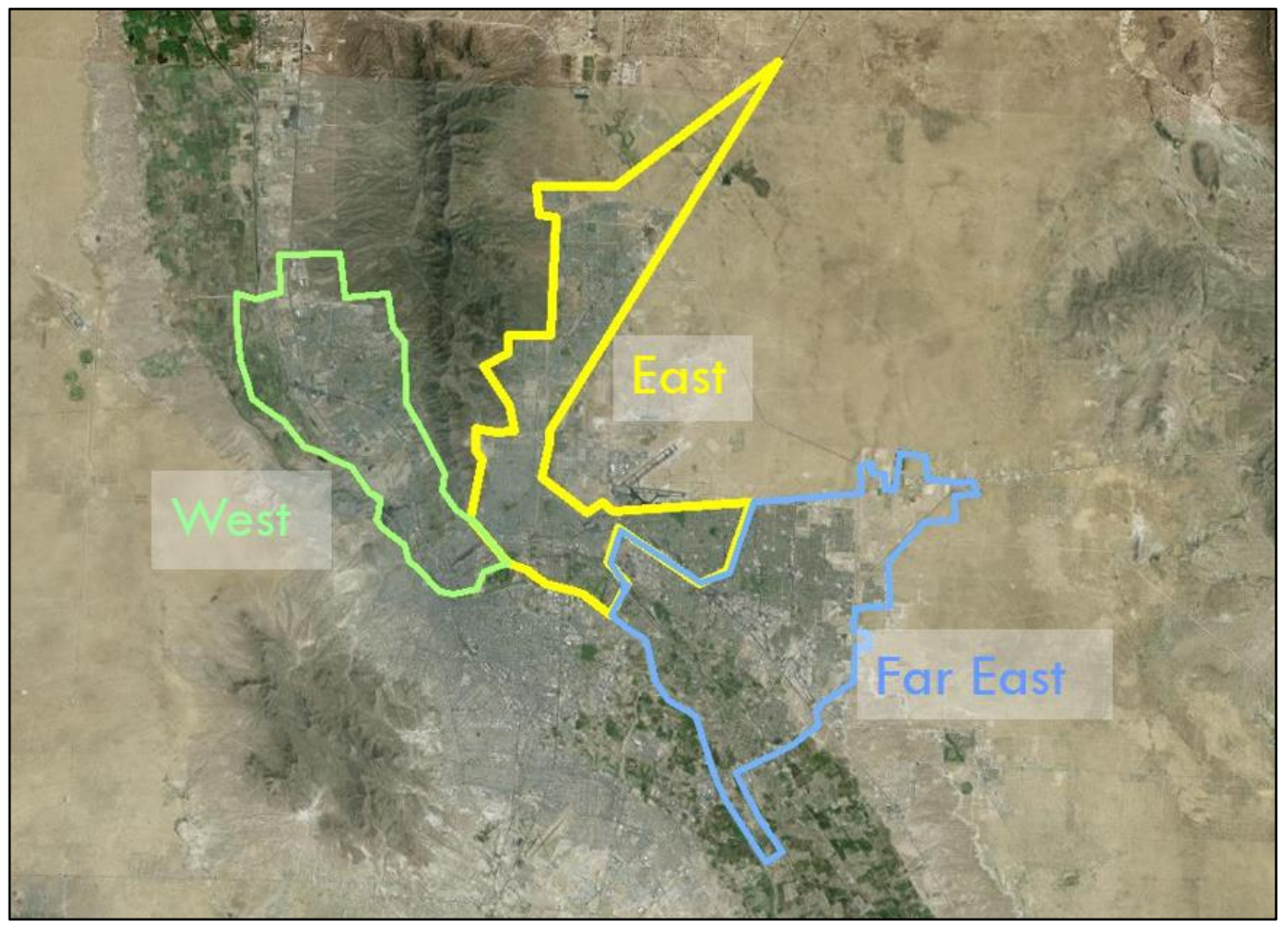

Figure 5.2: Service areas for managing the collection 


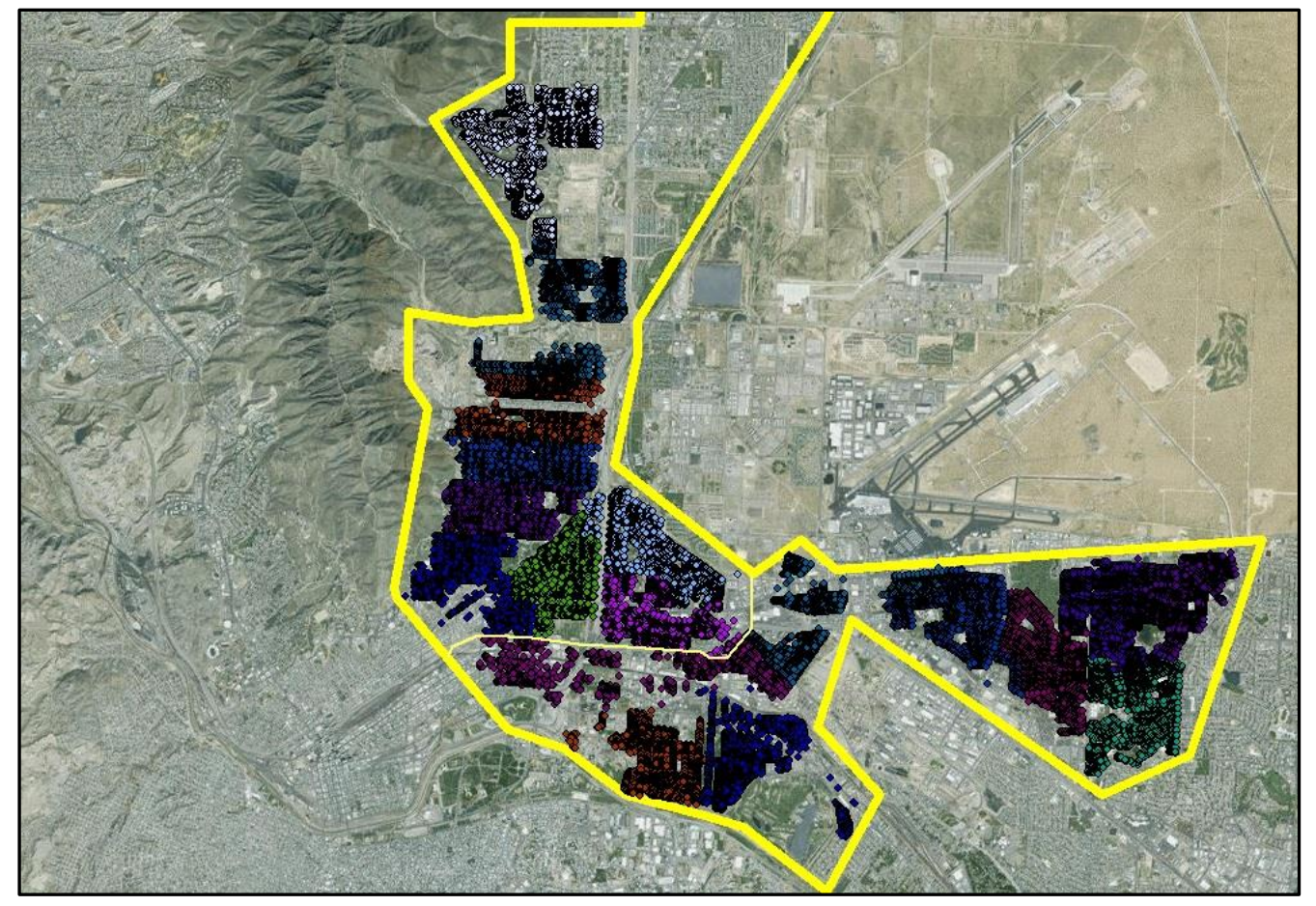

Figure 5.3: All 18 shifts of Tuesday east area

The ESD designed this collection structure by using the Route Smart software (RouteSmart 2015) for macro routing (i.e., the split of the area to the collection days and individual vehicles). The software Route Smart can also be applied to find the optimal route at the micro routing level. However ESD is not satisfied with Route Smart performance in this micro routing task. The ESD is interested in the evaluation of other software (in this research ArcGIS Network Analyst) in dealing with this micro routing task.

\subsection{DRIVERS}

Each driver has a 10-hour long working day (a shift) that consists of two routes. A driver-truck begins its shift in the depot which is next to the headquarters of ESD at 7968 San Paulo Drive. It follows the navigation map provided by the supervisor and collects recyclables in all the blue containers that have been set out in the street for collection. When the driver-truck finishes the first route it proceeds to the processing plant of the Friedman Recycling Company at 5835 Wren Ave. Over there, the recyclables are 
unloaded and then the empty truck goes back to continue with the second route of the shift. After the collection of the second route is completed the driver-truck goes again to the processing plant to unload the second delivery of recyclables. The driver-truck shift ends by heading back to the ESD Headquarter. The processing plant of the Friedman Recycling Company is the only single depot for collecting residential recyclables for all the collection services that ESD provides.

\subsection{TRUCKS}

Trucks that are used by ESD for the recyclables collection are equipped with automated side loading, with a robotic arm on the right hand side. The collection is fully automated so only one employee (driver) is needed per truck. The ESD is using 31-cubic-yard version of Scorpion Automated Side Loader trucks produced by Dadee Manufacturing (Figure 5.4).

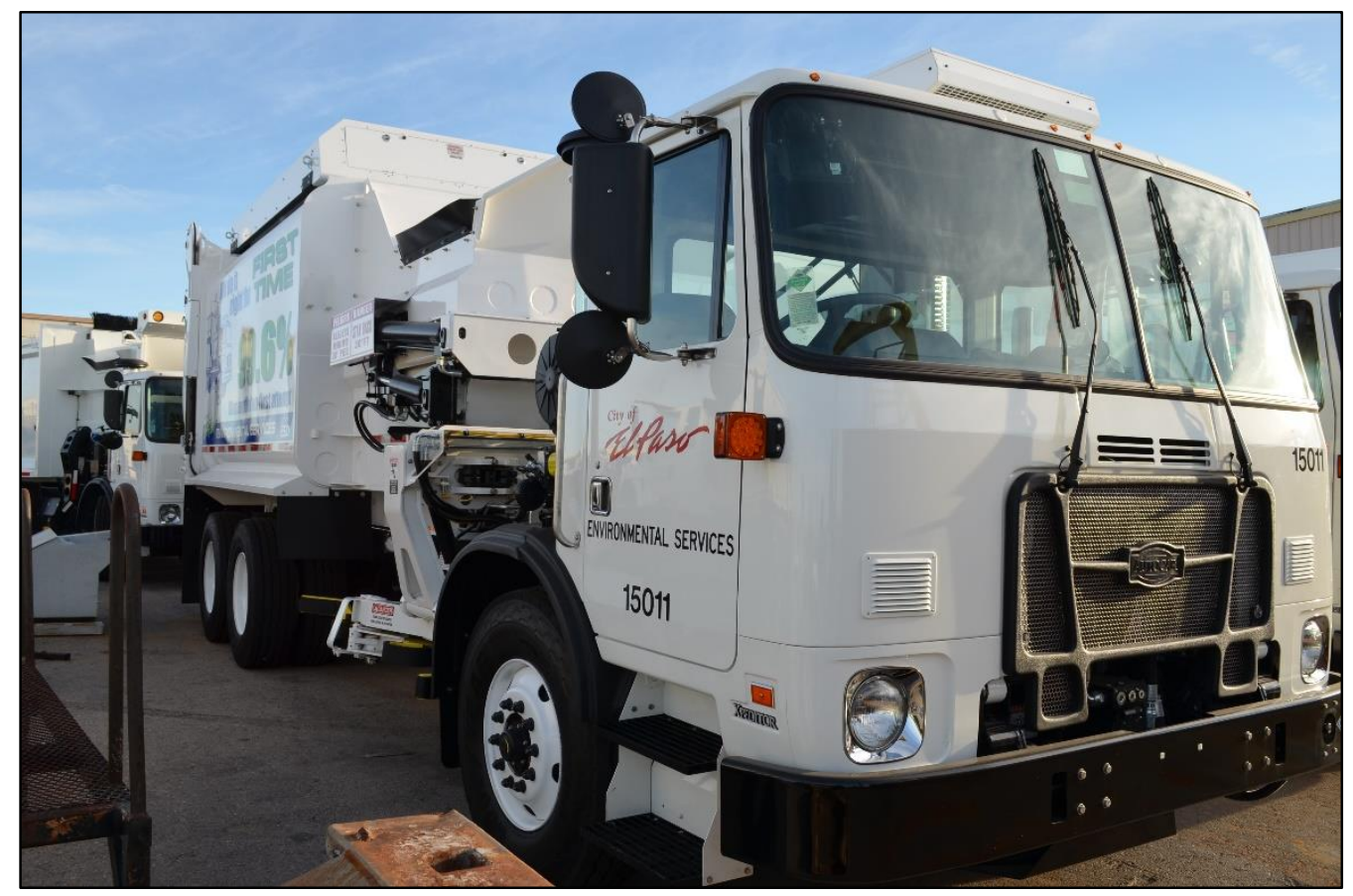

Figure 5.4: City of El Paso ESD collection truck

(Source: ESD 2014) 


\subsubsection{Recyclables Collection Truck Capacity}

The vehicle capacity is important measure for any capacitated routing problem. There is a general condition that MSW and recyclables collection trucks cannot carry more than 10 tons $(9071.85 \mathrm{~kg})$ to be able to legally use public highways in the State of Texas, however in the case of recyclables the truck practically never reach this weight limit, because the volume limit is reached first. This means that recyclables has higher demand in volume and lower in weight compared to MSW.

Single stream recyclables that are collected at the curb from blue bins have very inhomogeneous composition of different materials with different material properties (e.g., volume and weight). Recyclables collection trucks are equipped with a compression mechanism that decrease the volume required for storing the recyclables in the truck, however even with this mechanism truck has a volume limit. This volume limit is hard to determine, because of the inhomogeneity of the collected material.

Because of the high level of uncertainty and insufficient data describing the collected recyclables composition, the estimation of the material collected has to be made based on other information available. This will be explained later in Chapter 6 . 


\section{Chapter 6: Analysis of Recyclables Collection Routes}

In this chapter the work shift of residential recyclable collection that was selected for the analysis is introduced, after that the data that were gathered for the analysis and their sources are described. Then, a model to estimate travel time was proposed and implemented on the routes in the selected shift.

\subsection{SELECTED SHIFT}

For the analysis of ArcGIS capability in solving the recyclables collection routing problem, routes of one shift of Tuesday's collection in east area were chosen. The ESD named this shift as "ER-01" where "E" stands for East area and "R" means that it is for recyclables collection, and "01" means driver-truck number one, or shift number one. Because the shift is divided into two visits to the processing plant, there are two routes named "ER-01A" and "ER-01B" respectively (Figure 6.1). ER-01 was chosen because it contains not only a set of streets that are perpendicular to each other (grid layout) but also areas with streets that are not in grid shaped which is good for testing the performance of the routing algorithm. 


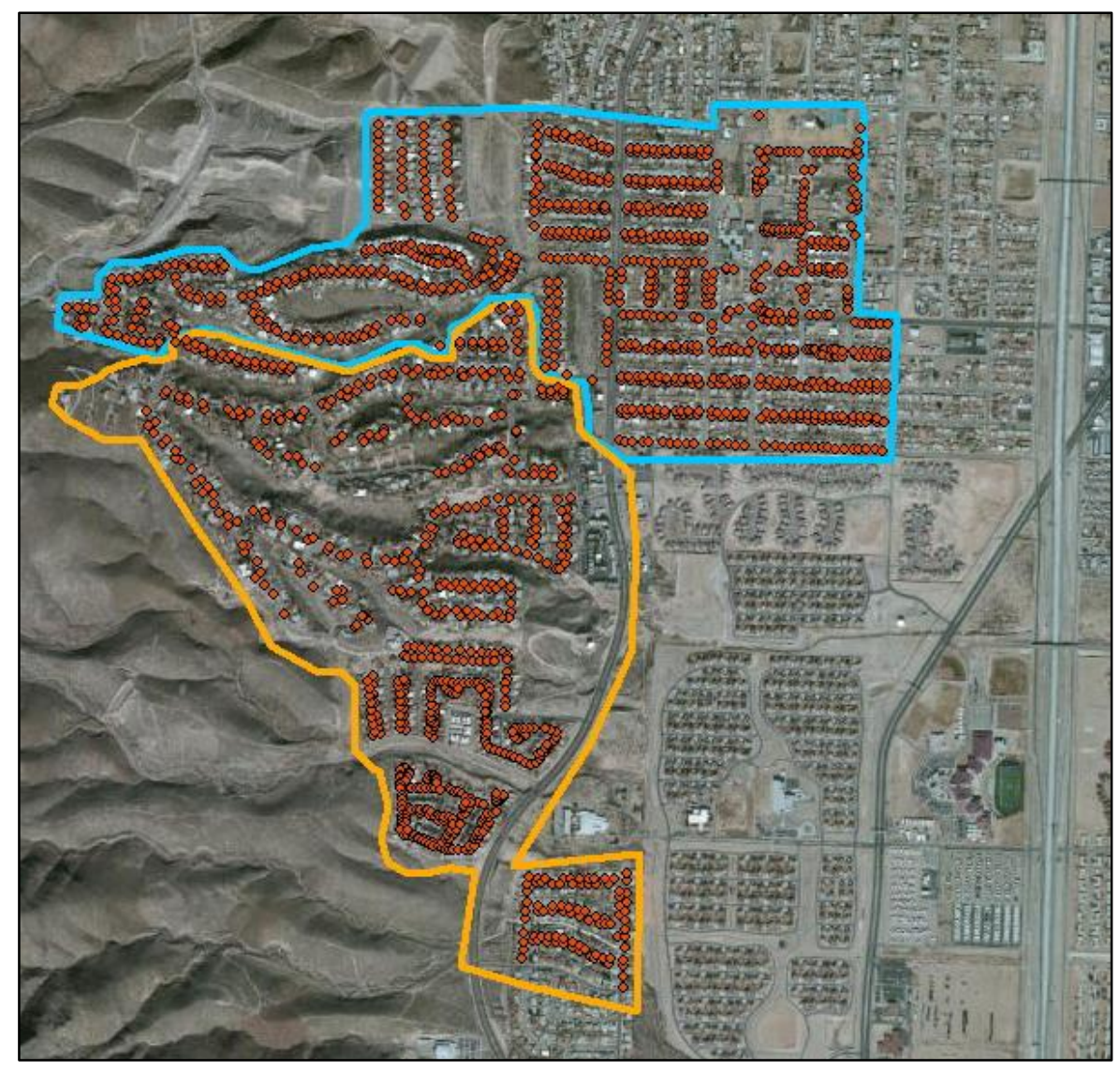

Figure 6.1: Selected shift,

(orange polygon - ER-01A, blue polygon - ER-01B, red points - bins)

A term "set of bins of ER-01A" or "set of bins of the route A" is used to describe all the bins that are served by the route ER-01A. Similarly the terms "set of bins of ER-01B" or "set of bins of the route B" describes the set of all the bins that are assigned to the route B in the present routing solution used by ESD. Route ER-01B is served first since it is closer to the processing plant and that is why it is also called the first route in this thesis, respectively ER-01A is called the second route. 


\subsection{Available Data ANd Their Processing}

Within the selected area, data from various sources were collected. First of all, ESD provided a set of data describing the spatial positions of recyclable bins and the path report of one shift. Statistic about the collected tonnage and bin count was obtained. To create a network in which the truck is moving (in another words to create a network dataset), street centerlines were downloaded from the Paso del Norte Mapa web page (Paso Del Norte Mapa 2015).

\subsubsection{Checking of Container Locations}

The ESD provided an Excel spreadsheet containing the latitude and longitude of each recyclable container, and the corresponding house address. The house address was important, because the GPS positioning of container location can never be $100 \%$ accurate, and therefore the relocations of some bins to the correct positions, where they are most likely be set-out at the time of the collection, were needed. Some of the positioning errors included the bin coordinates located on the other side of the street segment (Figure 6.2), or too close to the crossroad of two streets. To check the correct house number, land parcel layer from the Paso Del Norte Mapa (2015). In some cases, satellite image from the world imagery base map of ArcGIS or Google Street View was applied to decide the correct positions of the bins. 


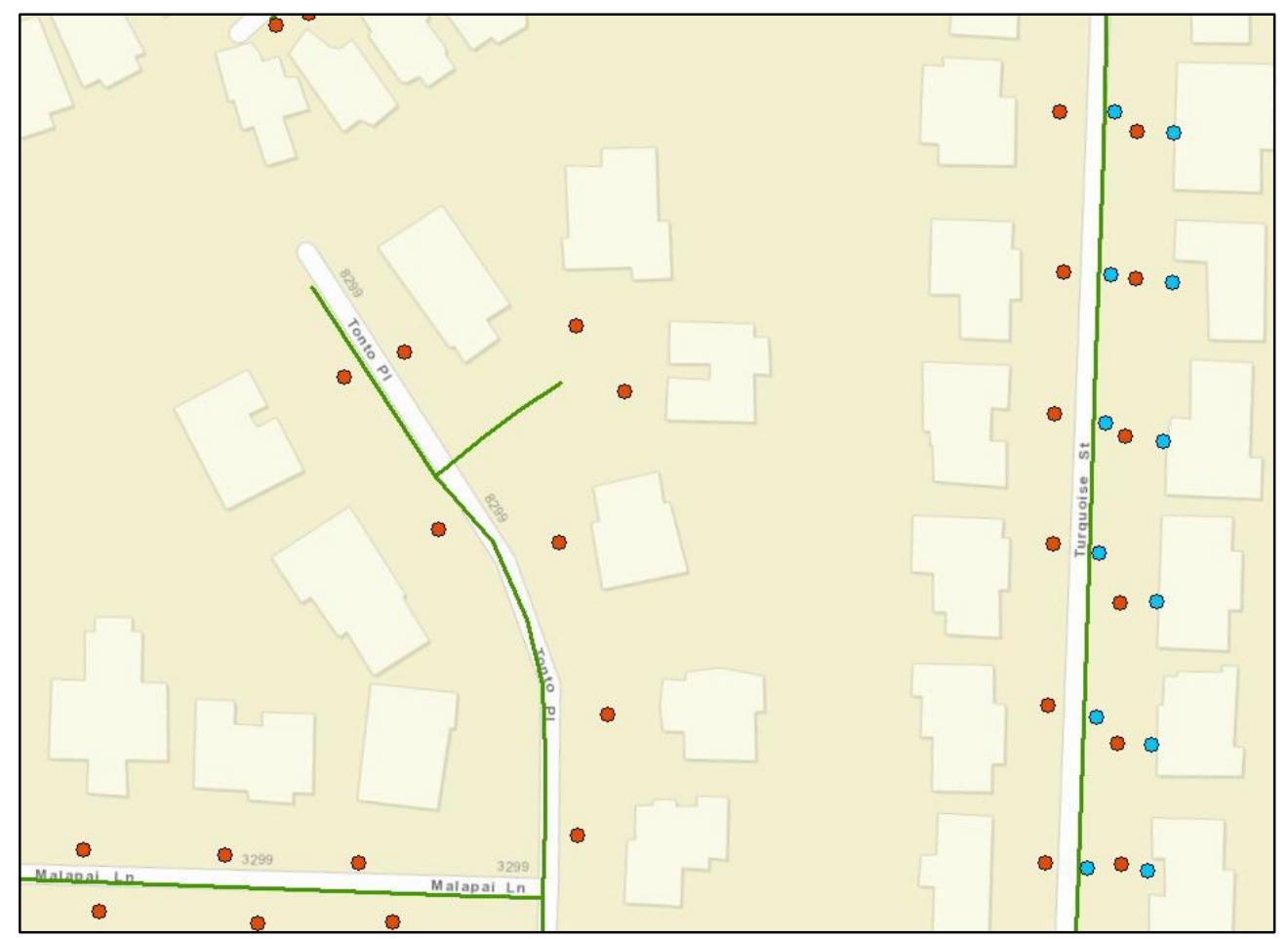

Figure 6.2: Containers located on the other side of street segment,

(Blue points - original container position, red points - correct container position, green line - street centerline.)

\subsubsection{Data Processing of the Path Report}

The second data source is the path report of a single shift that was recorded on October 7, 2014 (Tuesday). This path report data was collected and downloaded from ESD's fleet management system. In the report, information about latitude, longitude, street name, time of the record, truck speed or reason for logging the record was found. There are about 20,000 entries recorded in one shift (Table 6.1). The spatial visualization of this data is shown in Figure 6.3. These records, although contains some errors, gave an idea of the routes the driver took on that day, and the sequence in which the bins were visited. 
Table 6.1: Path report table

\begin{tabular}{|c|c|c|c|c|c|c|c|c|c|c|c|c|}
\hline MyID & Old_FID & Old_Shape * & Asset_ID & Asset_No_Date & Time_MS1Speed_MPH_ & Heading & Log_Reason & Lat & Lon & Zone & Address & Source \\
\hline 1 & 1 & 0 Point & 52 & 2 Collection 7.10 .2014 & 4 04:44:31.0 & 0 North East & Motion Stop & 31,74363 & $-106,343$ & 3 MSC-Mait & it 1035 Lafayette Dr, El Pasc & SCECM \\
\hline 2 & 2 & 1 Point & 52 & Collection 7.10.2014 & $404: 47: 23.0$ & 0 North East & Motion Stop & 31,7437 & $-106,343$ & 3 MSC-Mait & it Hermosillo $\mathrm{Dr}$, El Paso, Tे & T) ECM \\
\hline 3 & 3 & 2 Point & 52 & Collection 7.10 .2014 & $404: 48: 02.0$ & 3,4 North North West & Motion Start & 31,74369 & $-106,343$ & 3 MSC-Mait & it Hermosillo Dr, El Paso, T> & T) ECM \\
\hline 4 & 4 & 3 Point & 52 & Collection 7.10.2014 & $404: 50: 42.0$ & 1,8 North North East & Motion Start & 31,75194 & $-106,346$ & & N Yarbrough Dr, El Paso, & TECM \\
\hline 5 & 5 & 4 Point & 52 & 2 Collection 7.10.2014 & $404: 50: 45.0$ & 0 North North East & Motion Stop & 31,75195 & $-106,346$ & & N Yarbrough Dr, El Paso, & ECM \\
\hline 6 & 6 & 5 Point & 52 & 2 Collection 7.10 .2014 & 4 04:51:01.0 & 12,3 North North East & Motion Start & 31,7521 & $-106,346$ & & N Yarbrough Dr, El Paso, & ECM \\
\hline 7 & 7 & 6 Point & 52 & Collection 7.10.2014 & 4 04:56:55.0 & 0 South West West & Motion Stop & 31,7822 & $-106,405$ & & 6283 Gateway Blvd W, El & I ECM \\
\hline 8 & 8 & 7 Point & 52 & 2 Collection 7.10 .2014 & 4 04:57:13.0 & 3,9 West & Motion Start & 31,78221 & $-106,405$ & & 6277 Gateway Blvd W, El & ECM \\
\hline 9 & 9 & 8 Point & 52 & 2 Collection 7.10 .2014 & $404: 57: 38.0$ & 0 West & Motion Stop & 31,78198 & $-106,407$ & & Gateway Blvd W, El Paso, & o, ECM \\
\hline 10 & 0 & 9 Point & 52 & Collection 7.10 .2014 & 4 04:58:37.0 & 14,5 West & Motion Start & 31,78194 & $-106,407$ & & Gateway Blvd W, El Paso, & o, ECM \\
\hline 12 & & 11 Point & 52 & Collection 7.10 .2014 & 4 05:07:06.0 & 10,7 North West & Motion Start & 31,85512 & $-106,44$ & & Gateway Blvd N, El Paso, & , ECM \\
\hline 13 & & 15 Point & 52 & 2 Collection 7.10 .2014 & 4 05:08:30.0 & 0 West & Motion Stop & 31,855 & $-106,448$ & & 3809 Hercules Ave, El Pas & as ECM \\
\hline 14 & 24 & 24 Point & 52 & Collection 7.10.2014 & $405: 08: 47.0$ & 13 North West & Motion Start & 31,85503 & $-106,448$ & & 8306 Polaris St, El Paso, T & TECM \\
\hline 15 & & 25 Point & 52 & 2 Collection 7.10 .2014 & 4 05:09:26.0 & 0 East & Motion Stop & 31,85618 & $-106,447$ & & 3868 Edgar Park Ave, El P. & PiECM \\
\hline 16 & & 27 Point & 52 & 2 Collection 7.10 .2014 & 4 05:09:28.0 & 0 East & Grabber Close & 31,85618 & $-106,447$ & & 3868 Edgar Park Ave, El P & P:ECM \\
\hline 17 & & 35 Point & 52 & 2 Collection 7.10 .2014 & 4 05:09:41.0 & 12,3 East & Motion Start & 31,85619 & $-106,447$ & & 3876 Edgar Park Ave, El P. & PiECM \\
\hline 18 & & 38 Point & 52 & 2 Collection 7.10 .2014 & 4 05:10:06.0 & 0 South South West & Motion Stop & 31,8553 & $-106,447$ & & 8327 Comet St, El Paso, T. & T.ECM \\
\hline 19 & & 48 Point & 52 & Collection 7.10.2014 & $405: 10: 37.0$ & 13,2 South & Motion Start & 31,8552 & $-106,447$ & & 8319 Comet St, El Paso, T. & T:ECM \\
\hline 20 & & 52 Point & 52 & Collection 7.10.2014 & 4 05:10:43.0 & 0 South South West & Motion Stop & 31,85507 & $-106,447$ & & 8309 Comet St, El Paso, T. & T:ECM \\
\hline 21 & & 53 Point & 52 & Collection 7.10.2014 & 4 05:10:46.0 & 0 South South West & Grabber Close & 31,85507 & $-106,447$ & & 8309 Comet St, El Paso, T. & T.ECM \\
\hline 23 & & 54 Point & 52 & Collection 7.10.2014 & 4 05:11:26.0 & 0 West & Motion Stop & 31,85497 & $-106,449$ & & 3733 Hercules Ave, El Pas & AS ECM \\
\hline 24 & & 71 Point & 52 & 2 Collection 7.10 .2014 & 4 05:11:38.0 & 12,3 West & Motion Start & 31,85497 & $-106,449$ & & 3727 Hercules Ave, El Pas & aSECM \\
\hline 25 & & 75 Point & 52 & Collection 7.10 .2014 & 4 05:11:45.0 & 0 West & Motion Stop & 31,85498 & $-106,45$ & & 3715 Hercules Ave, El Pas & ASECM \\
\hline 26 & & 31 Point & 52 & Collection 7.10.2014 & $405: 11: 55.0$ & 9,7 West & Motion Start & 31,85498 & $-106,45$ & & 3707 Hercules Ave, El Pas & AS ECM \\
\hline 27 & & 22 Point & 52 & Collection 7.10 .2014 & 4 05:12:06.0 & 0 North & Motion Stop & 31,85525 & $-106,45$ & & 8326 Eclipse St, El Paso, T & TECM \\
\hline 28 & & 33 Point & & tion 7 & 15.0 & 1,8 North & Grabber Close & 31,85526 & $-106,45$ & & 8326 Eclipse St, El Pas & TECM \\
\hline 29 & & 37 Point & 52 & Collection 7.10,2014 & $405.12 \cdot 220$ & 0 North & Grabber Close & 31.85527 & -106.45 & & 8328 Fclinse & \\
\hline
\end{tabular}

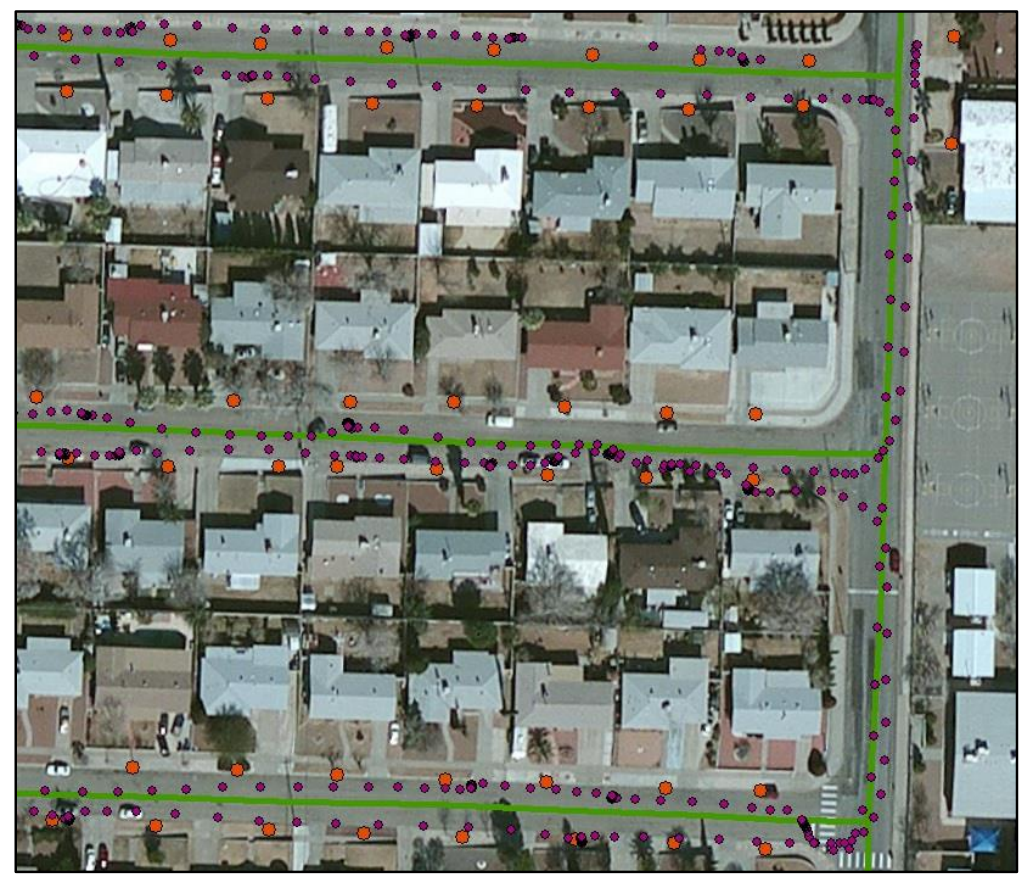

Figure 6.3: Path report visualization in ArcGIS,

(Purple points - path report logs, red points - container position, green line - street centerline.) 
To obtain an idea on the sequence of bins that formed the route, the "join based on the spatial location" function in ArcGIS was used to map the container locations with the entries in the path report. The sequence determined by the ArcGIS function had errors. Two types of errors were the most significant. In the first type of errors, GPS positioning errors of the truck locations in the path report caused the truck to map to a bin on the opposite side of the street. In the second type of errors, the truck path was mapped incorrectly to bins placed in a different street. Figure 6.4 shows the second type of error where bins 381 and 382 were incorrectly assigned to the sequence.

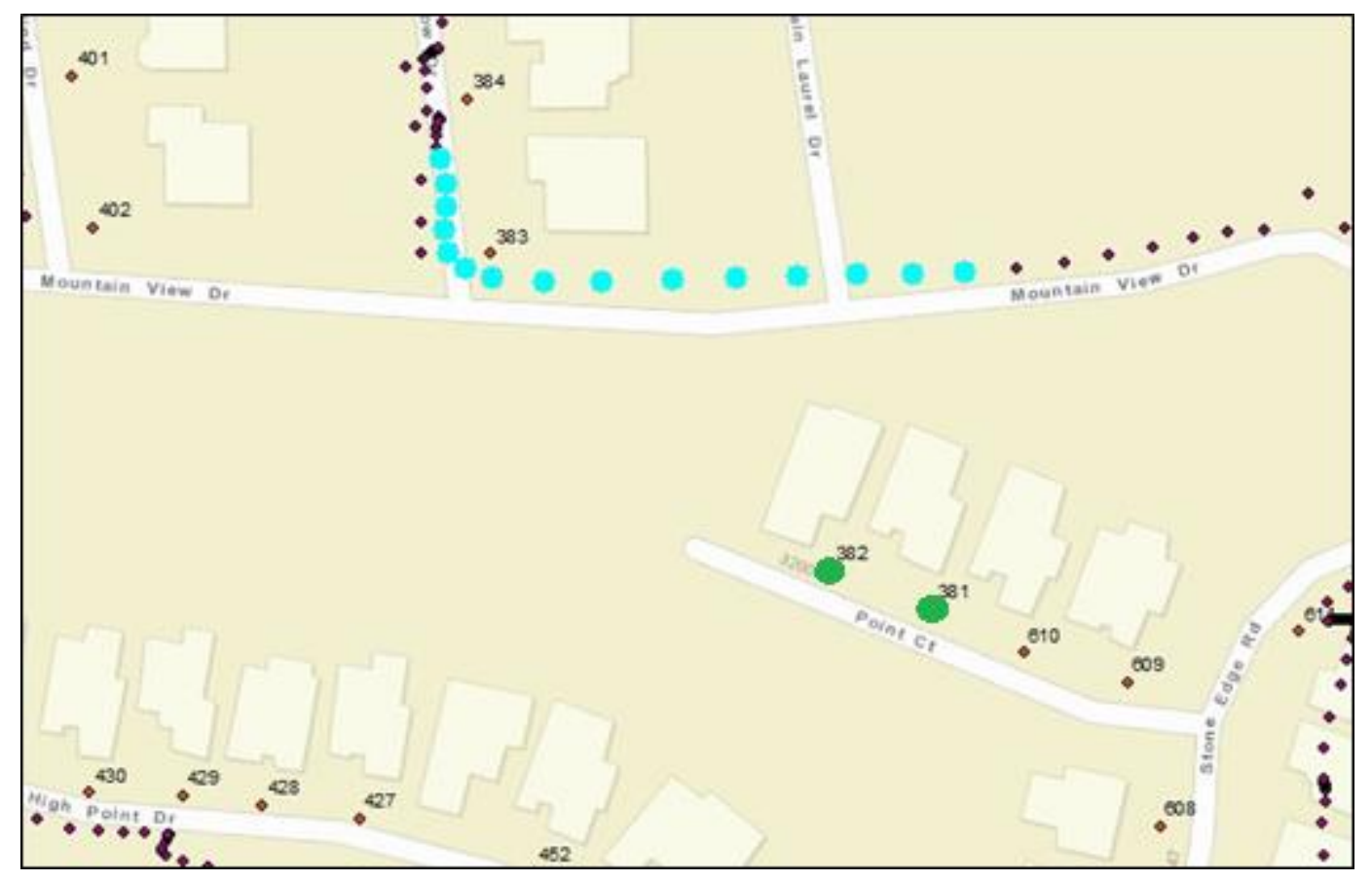

Figure 6.4: Join based on spatial location error,

(Purple points - path report logs, red points - container position, green points - incorrectly assigned bins, blue points - path report logs that caused incorrect assignment.)

All of these errors were manually corrected to obtain the real sequence in which the bins were visited. Multiple Excel advanced filters and SQL procedure were applied to the dataset to filter out the inaccurate readings. Out of the 20,000 entries in the path report 1349 were found to be start and stop 
events. Based on these events, the average speed that truck moved in the collection area was estimated and this speed was used to determinate the travel time on road segments with service. Path report also provided the data to calculate turn penalties.

\subsubsection{Container Count and Tons Collected}

Third data source was the container count and tons collected data. The ESD collected data about how many containers were picked up and the total weight of recyclables that was collected in each route. This weight was measured at the processing plant. Data were obtained for every collection day in the shift for one year and they are used to estimate the average weight of material collected per bin and the capacity of the collection vehicle.

Average weight per bin was determined according to the following steps. First the weight of the collected container for individual collection days $(k)$ was computed by the equation:

$$
B w_{k}=\frac{C_{k}}{W_{k}}
$$

where

$B w_{k}$ is the the weight of the recyclables in a collected container;

$C_{k}$ means the container count ;

$W_{k}$ is the weight collated on the route;

$k$ is the $k$-th collection in the year.

The average values of $B w$ is:

$$
B W_{a v g}=\frac{\sum_{k=1}^{n} B w_{k}}{n}
$$

where

$B W_{\text {avg }}$ is the annual average weight of the recyclables in a collected container; $n$ is the number of collections in the year. 
From this equations the average bin weight for the set of bin of the route ER-01A and ER-01B were determined as $15.5185 \mathrm{lb}(7.0391 \mathrm{~kg})$ and $14.7681 \mathrm{lb}(6.6987 \mathrm{~kg})$ respectively.

In the same way the annual average container count for the route before the first visit of the processing plant (ER-01B) was determined:

$$
C_{\text {avg }}=\frac{\sum_{k=1}^{n} C_{k}}{n}
$$

where:

$\mathrm{C}_{a v g}$ is the annual average container count for the route before the first visit of the processing plant;

Based on $C_{a v g}$ and $\mathrm{B} W_{a v g}$, the truck capacity was estimated. As described in Section 5.3.1 the capacity is based on weight. The following equation was established:

$$
\gamma=C_{a v g} \cdot B W_{a v g}
$$

where:

$\gamma$ is the estimated capacity.

By means of this equation, the capacity limit was estimated to be $6,659 \mathrm{lb}(3.33$ tons, $3,020 \mathrm{~kg})$. With this capacity the maximum order count has to be set in ArcGIS NA. In this routing problem the maximum order count represents the maximum number of bins that can be visited in a one route, which was found to be 898 bins. This is the number of bins that was visited on the first route (ER-01B). By dividing the capacity $\gamma$ with the annual average bin weight $B W_{a v g}$ we get the maximum number of bins collected, which is approximately 451 bins. To obtain the maximum number of bins visited, the maximum number of bins collected has to be divided by the set-out rate which is in this case 0.5021 . More about setout rate is explained further in this chapter. 


\subsubsection{Creating Network Dataset}

Data describing the network that the NA uses for solving the routing problem are derived from the network dataset.

The network dataset models the street network, but to do so it needs input data. The El Paso centerline shape file that is freely available from Paso Del Norte Mapa (2015) was used to deliver these data to the network dataset. This file contains the specific attributes about each road segment: the spatial position of the segment, how the segments are connected, the segment length, road class and for some of the segments the maximum speed.

The most important attributes for creating the network dataset are the segment length and travel time. Segment length was obtained from the centerline, but the travel time attribute were computed.

To compute the road segment travel time, the basic relationship between time, speed and distance is used. The speed that the truck can move on a given road segment is determined by different rules.

\subsubsection{Road Segment Travel Time for Roads without Service}

The attribute "CLASS" in the El Paso centerline layer specifies which class of road applies to the selected road segment (possible values are: "Interstate", "Freeway", "Local”, "Collector", "Minor", "Major" and etc.). After a consultation with ESD, a rule of thumb was set that for segments that were out of the collection area, the speed of collection trucks was set to $25 \mathrm{mph}$, unless the speed limit is lower or the road class is higher than "Local".

The equation used for the creation of the travel time attribute can be described as follows:

$$
T T_{R S n s}=\frac{\text { Segment length }}{\text { Truck speed } \text { no service }}
$$

where:

$T T_{R S n s}$ means travel time on road segment where there is no collection;

Segment length represents the length of the segment;

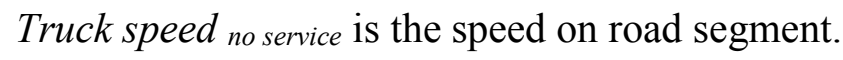




\subsubsection{Road Segment Travel Time for Roads with Service}

Travel times for road segments that have bin collection were calculated differently. From the path report, the average speed between collection stops was estimated to be $12.41 \mathrm{mph}(19.97 / \mathrm{km} / \mathrm{h})$. This speed was than assigned to the whole residential area.

The equation used for the computation of the travel time attribute value is than similar to the one without service:

$$
T T_{R S w s}=\frac{\text { Segment length }}{\text { Truck speed }_{\text {with service }}}
$$

where:

$T T_{R S w s}$ means travel time on road segment where there is collection service;

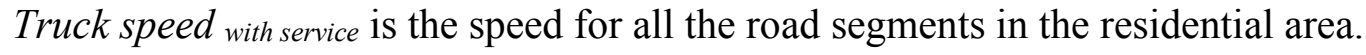

In Figure 6.5, there is the area in which the constant speed of $T T_{R S w s}$ was applied. This area was larger than the actual shift to prevent the algorithm to use the road segments that are on the borders of the shift to make shortcuts to the bins that are close to the border of the shift. The only exception of this rule is the Alabama Street, because it is higher class road with no bins to collect. 


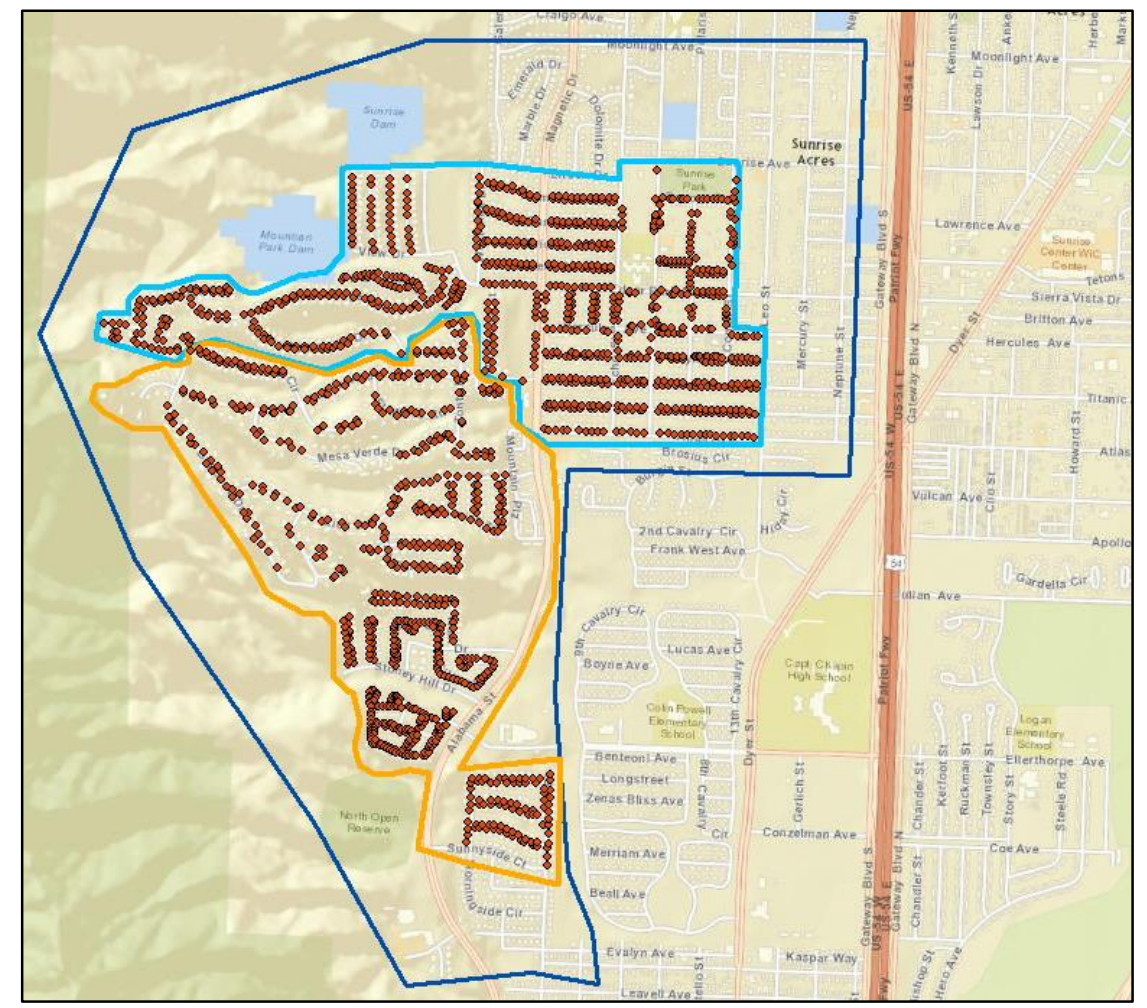

Figure 6.5: Area of constant speed of the truck speed with service

(Dark blue polygon - area of constant speed, orange polygon - ER-01A, light blue polygon - ER-01B, red points - bins)

\subsection{Adjusting Service Time and Bin Weight With Set-out RATe}

In reality, not all the bins are set out on each collection day. However, the truck must visit all the segments in a route where the bins are expected to be set out.

In Everett et al. (1998), the set-out rate is defined as the fraction of residences on a given route along which materials are put out for collection on a given collection day. Set-out rate affects route service time because it directly affects the number of stops, the average distance traveled between stops, and the time spent collecting and loading materials.

The equation for the set-out rate is 


$$
S=\frac{N_{B s t}}{N_{B T}}
$$

where:

$S$ is the set-out rate, in decimal;

$N_{B s t}$ is the number of bins set out in a particular day;

$N_{B T}$ is the total number of bins along the route.

The total service time can be computed as:

$$
T_{c s t}=N_{B s t} \cdot t_{\text {service }}
$$

where:

$T_{c s t}$ is the total service time;

$t_{\text {service }}$ is the time to serve a single bin.

Combining Equations (6.7) and (6.8),

$$
T_{\text {cst }}=S \cdot N_{B T} \cdot t_{\text {service }}
$$

and expanding the right-hand-side,

$$
S \cdot N_{B T} \cdot t_{\text {service }}=\sum_{i=1}^{N_{B T}}\left(S \cdot t_{\text {service }}\right)_{i}
$$

Set-out rate creates a problem for the NA's VRP solver. It is necessary to input all the bins along the route into the orders feature layer in NA, but this complicates the computation of service time. In practice, the service time should be counted only for those bins that are actually set out by the residents. There is no application setting in the NA that could deal with this issue, by using a probability value to model the set-out of each bin in a particular day. Equation (6.10) was used as a solution to overcome this problem. The service time $t_{\text {service }}$ of individual bin is multiplied by the set-out rate and the total collection time is obtained as a sum of these service times (adjusted for the set-out rate) for all the bins along the route.

The similar issue arises with the bin weight and total amount of material collected. The collected weight should be counted only for those bins that were set out for the collection. The following equation for the total weight of material collected was established: 


$$
W_{c o l}=\sum_{i=1}^{N_{B T}}\left(S \cdot B W_{a v g}\right)_{i}
$$

where:

$W_{c o l}$ is the total amount of material collected.

The total amount of material collected $W_{c o l}$ is the parameter compared with the capacity, where constraint $W_{\text {col }} \leq \gamma$ has to be fulfilled. 


\subsection{MODEL DESCRIPTION AND VALIDATION}

\subsubsection{Basic Formulation}

The objectives of this thesis are (1) to analyze the performance of the selected existing routes used by ESD; and (2) to use ArcGIS NA's VRP solver to suggest new routes, and compare the performance of these routes with the existing routes. To evaluate the routing solution, the following model of the total collection time was established:

$$
T T_{m}=\sum_{i=1}^{n}\left(T T_{R S w s_{i}}+T T_{R S n s_{i}}\right)+\sum_{i=1}^{N_{B T}}\left(S \cdot t_{\text {service }}\right)_{i}+\sum_{i=1}^{N_{L t}} t_{\text {Lturns }_{i}}+\sum_{i=1}^{N_{U t}} t_{U^{\prime} u r n s_{i}}+T_{o d}
$$

where:

$T T_{m}$ is the total collection time according the model;

$T T_{R S w s_{i}}$ is the travel time for the $i$-th road segment with service, selected to be in the route;

$T T_{R S n s_{i}}$ is the travel time for the $i$-th road segment with no service, selected to be in the route;

$n$ is the total number of road segments in the route;

$\left(S \cdot t_{\text {service }}\right)_{i}$ is the $i$-th bin service time adjusted for the set-out rate;

$N_{B T}$ is the total number of bins;

$t_{\text {service }}$ is the service time per bin;

$S$ is the set-out rate;

$t_{\text {Lturns }}$ is the average time or penalty per left turn;

$N_{L t}$ is the number of left turns;

$t_{U t u r n s}$ is the average time or penalty per U-turn;

$N_{U t}$ is the number of U-turns;

$T_{o d}$ is the delay caused by various factors such as the traffic congestion in the collection area.

The total collection time $T T_{m}$ is the time it takes to travel from the determined starting point to the determined end point. The penalty delays caused by left turns, U-turns and the other delay are included. On the right-hand-side of the equation, the term $\sum_{i=1}^{n}\left(T T_{R S w s_{i}}+T T_{R S n s_{i}}\right)$ is the sum of the travel times 
along all the road segments and it represents the total travel time. This term is determined by the NA VRP solver. The term $\sum_{i=1}^{N_{B T}}\left(S \cdot t_{\text {service }}\right)_{i}$ represents the total service time considering the set-out rate. The term $\sum_{i=1}^{N_{L t}} t_{\text {Lturns }_{i}}$ represents the total time spent on left turns and $\sum_{i=1}^{N_{U t}} t_{U t u r n s_{i}}$ is the total time spent on U-turns. These two delays are added after the ArcGIS processing. There is no penalty for right turns. The last term $T_{o d}$ deals with travel delays that are not accounted for by this model and it is determined during model validation.

\subsubsection{Determining the Values of Model Parameters}

The sum of all the travel times along the road segments, i.e., $\sum_{i=1}^{n}\left(T T_{R S w s_{i}}+T T_{R S n s_{i}}\right)$ was obtained from the VRP solver by running the solution algorithm on the given network dataset. The total number of bins ( $\left.N_{B T}\right)$ was 1606 for the whole collection area (covered by the ER-01 shift). From the path report, it is known that the number of bins in the first route (ER-01B) was 898 and in the second route (ER-01A) was 708 . The service time per bin $\left(t_{\text {service }}\right)$ was set to 10 seconds. This time was estimated from the data provided in the path report it was assigned as a default attribute in the bin position data, and was verified by field observation of collection truck operation during a site visit. The set-out rate $(S)$ was derived base on the data of the container count. The values for set-out rate differs for individual cases that are solved so these values are explained later.

The average time per left turn and the average time per U-turn were both extracted from the data in the path report. Samples of turns were randomly chosen and based on the spatial positions of a series of consecutive data points. From the identified points, the start and end points of a turn was determined. The difference between the recorded time of these two entries was computed. Example of a U-turn is shown in Figure 6.6, in which the start and end points of the turn are highlighted in blue dots. After the information extraction, the average time to make a turn was computed from the samples, resulting in an average time of 3.1 seconds for a left-turn, and 10.1 seconds for a U-turn. The number of U-turns $N_{L t}$ and the number of left turns $N_{U t}$ are both possible to find in the directions which is one of the NA VRP solver outputs. 


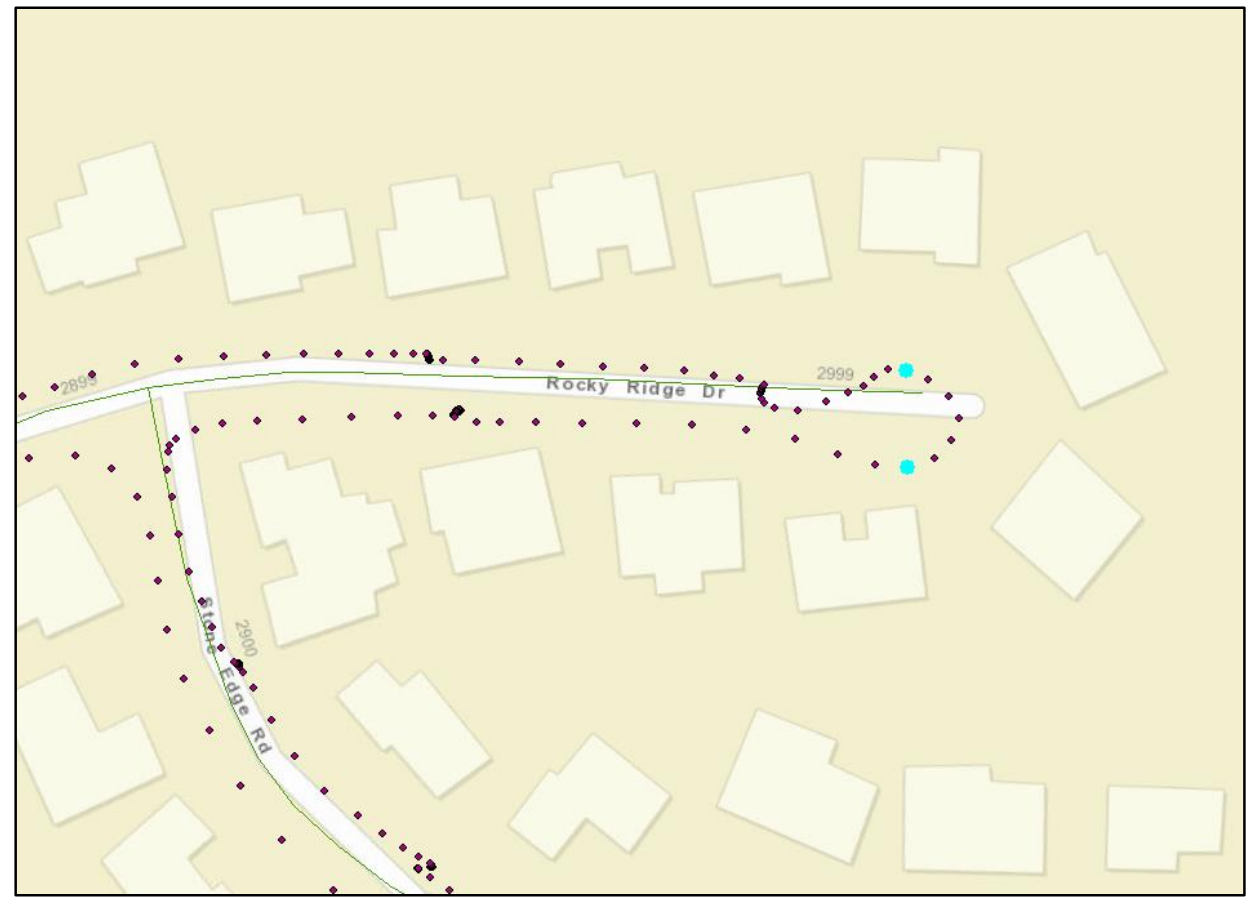

Figure 6.6: Path report U-turn

\subsubsection{Model Validation}

\subsubsection{Model Validation First Route}

The model (Equation (6.12)) was applied to the first existing route (ER-01B) to validate the computed total travel time with the data that were provided in the path report. Based on the path report, the truck entered the area of collection at time $T_{A}=05: 07: 06$ hrs. The last bin was collected at $T_{B}=$ 08:02:00 hrs. The difference between these two times, $\Delta T_{A B}=174.9$ minutes. The following inputs were used to calculate the total travel time in Equation (6.12):

The sum of all the travel times along the road segments $\sum_{i=1}^{n}\left(T T_{R S w s_{i}}+T T_{R S n s_{i}}\right)=$ $106.49 \mathrm{~min}$

Total service time $\sum_{i=1}^{N_{B T}}\left(S \cdot t_{\text {service }}\right)_{i}=63.33 \mathrm{~min}$

Total number of bins $N_{B T}=898$

Service time per bin $\mathrm{t}_{\text {service }}=10 \mathrm{sec}$ 
Set-out rate $S=0.4232$

Average time per left turn $t_{\text {Lturns }}=3.1 \mathrm{sec}$

Number of left turns $N_{L t}=26$

Average time per U-turn $t_{\text {Uturns }}=10.1 \mathrm{sec}$

Number of U-turns $N_{U t}=14$

The set-out rate of $S=0.4232$ for the validation was obtained by matching the path report data with the container count data. On the given day out of the 898 bins, 380 were collected. With all the know values, Equation (6.12) becomes:

$$
T T_{m}=173.53+T_{o d}
$$

Equating $\Delta T_{A B}$ obtained from the path report with $T T_{m}$, it was found that

$$
T_{o d}=1.37 \mathrm{~min}
$$

This value was used in the applications of Equation (6.12) in the same neighborhood as described in Section 6.5 model implementation.

\subsubsection{Model Validation Second Route}

The model (Equation (6.12)) was applied to the second existing route (ER-01A) to validate the computed total travel time in the same way as it was done for the first existing route. Based on the path report, the truck entered the area of collection at time $T_{A}=05: 07: 06 \mathrm{hrs}$. The last bin was collected at $T_{B}$ $=08: 02: 00 \mathrm{hrs}$. Same as for the first route the time difference $\Delta T_{A B}$ was found, $\Delta T_{A B}=166.2$ minutes.

The following inputs were used to calculate the total travel time in Equation (6.12) for the second route:

The sum of all the travel times along the road segments $\sum_{i=1}^{n}\left(T T_{R S w s_{i}}+T T_{R S n s_{i}}\right)=$ $91.03 \mathrm{~min}$

Total service time $\sum_{i=1}^{N_{B T}}\left(S \cdot t_{\text {service }}\right)_{i}=63.33 \mathrm{~min}$

Total number of bins $N_{B T}=708$

Service time per bin $\mathrm{t}_{\text {service }}=10 \mathrm{sec}$

Set-out rate $S=0.5367$ 


$$
\begin{aligned}
& \text { Number of left turns } N_{L t}=21 \\
& \text { Number of U-turns } N_{U t}=19
\end{aligned}
$$

The set-out rate of $S=0.5367$ for the validation was obtained by matching the path report data with the container count data. On the given day out of the 708 bins, 380 were collected. With all the know values, Equation (6.12) becomes:

$$
T T_{m}=158.64+T_{o d}
$$

Equating $\triangle T_{A B}$ obtained from the path report with $T T_{m}$, it was found that

$$
T_{\text {od }}=7.59 \mathrm{~min}
$$

The higher value of other delay for this route was expected, because the model computes with constant speed for both routes and the segment of collection of the second route is more hilly and since the elevation is not considered by the model it results in higher other delay time.

\subsection{MODEL IMPLEMENTATION}

This section compares the existing routes used by ESD with the new routing solutions provided by the VRP solver, where the set of bins for individual routes that are compared are the same. The existing route and VRP solver's solution start from the same starting depot and end at the same end depot. To the existing routes it is referred as to the ER-01A(ESD) and ER-01B(ESD), while the solutions created by the Network Analyst VRP solver are referred as ER-01A(NA) and ER-01B(NA).

The truck path from the truck depot at ESD headquarters to the proximity of the shift and the truck path from the processing plant back to the truck depot were excluded from the analysis for two reasons.

First, it was necessary to decrease the requirements on the network dataset. Second, these parts are not that interesting for optimization. The fastest way from the ESD headquarters to the proximity of the shift is by highway (U.S. 54). The origin destination pair in-between the processing plant and ESD headquarters is clearly defined so it is only shortest path problem. For the starting depot a Virtual start depot was chosen in the proximity to the shift as explained below. 


\subsubsection{First Route}

The first existing route used by ESD to collect recyclables in the residential area, ER-01B(ESD), is shown in Figure 6.7. The starting point was a dummy depot at U.S. 54 Highway exit to Hercules Ave. This was the place, where truck leaves the U.S. 54 Highway when approaching from the actual ESD depot in San Paulo Drive at the beginning of the shift. Bins were visited according the path report sequence. The end depot was the processing plant in the north east corner of Figure 6.7. Artificial barriers were set in the VRP layer to force the truck to use the same streets on its way to the processing plant as it is given in the path report.

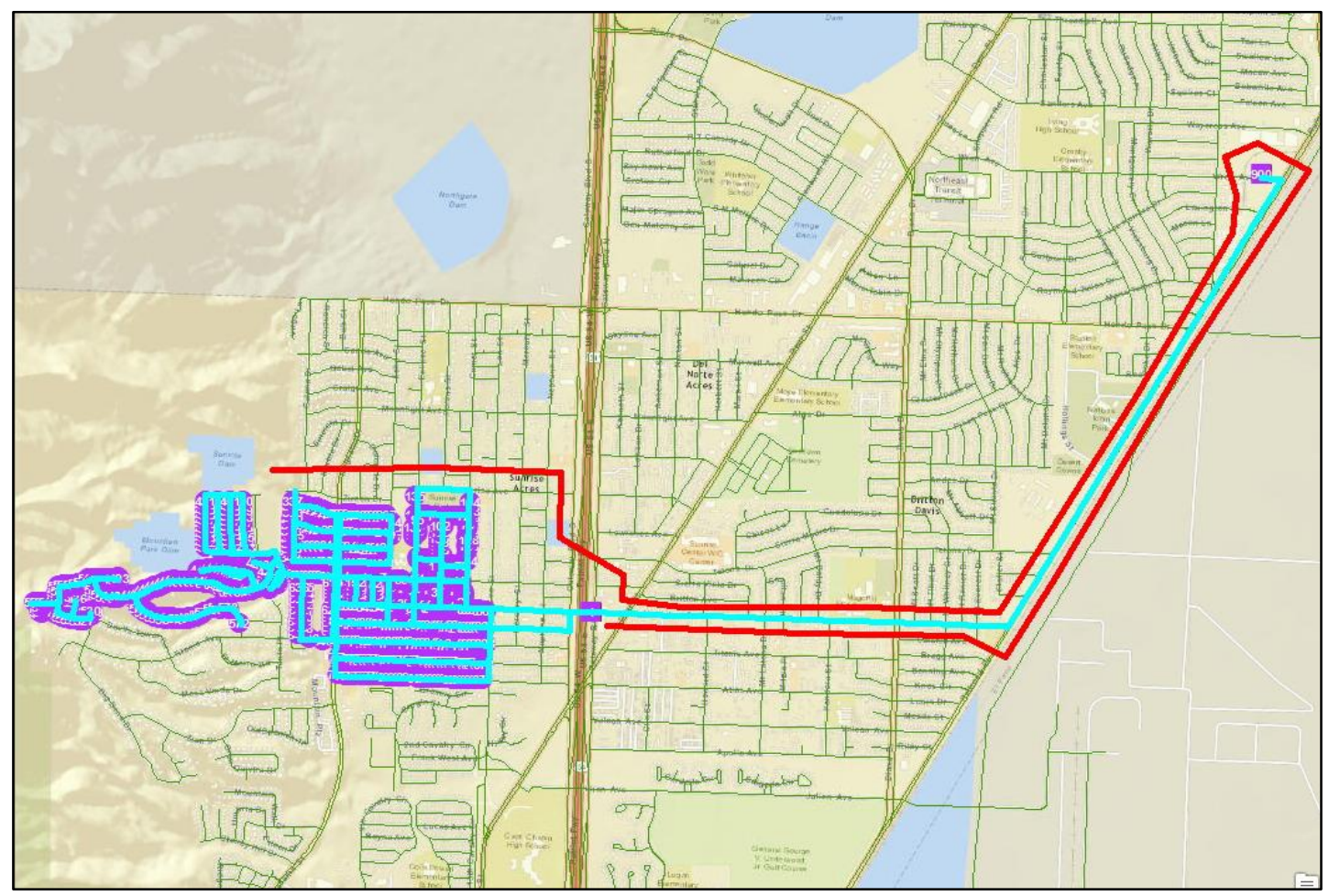

Figure 6.7: First existing route ER-01B(ESD)

(Light blue line - ER-01B(ESD), barriers - red lines)

The input data to compute $T T_{m}$ was the same as described in the model validation for the first route. The only difference was the set-out rate. The set-out rate in this case was computed as the annual 
average container count (for the first route) divided by the number of bins in the first route. This set-out rate has value of $S=0.5021$.

The alternate route ER-01B(NA) was obtained by using the VRP solver. The sequence in which the bins were visited was determined by the VRP solver and corrected according the approach described in Section 4.3. The set-out rate was set to $S=0.5021$. No barrier was set so that the solver found the fastest route from the last bin to the processing plant. The solution provided by the VRP solver is graphically shown in Figure 6.8.

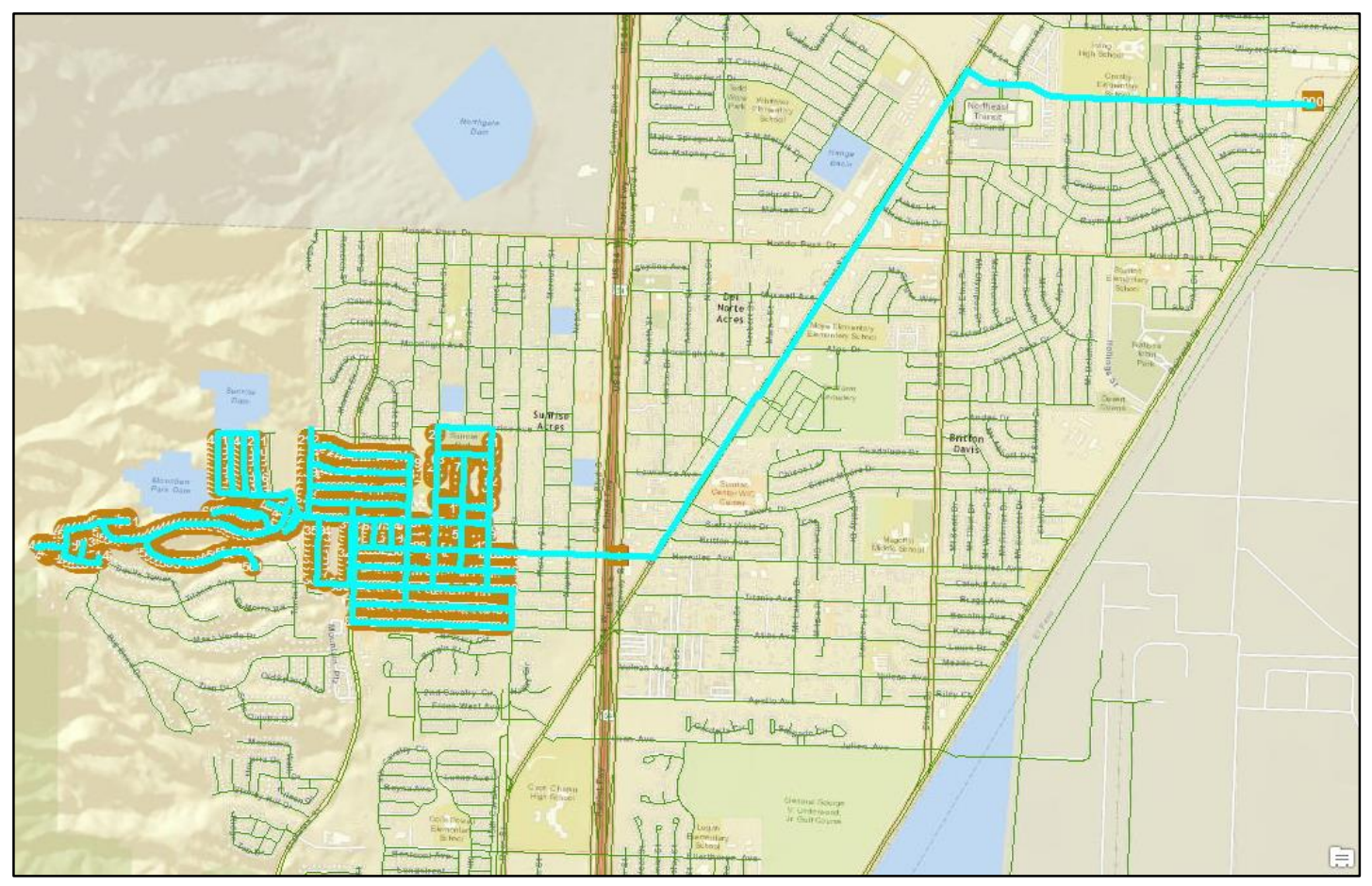

Figure 6.8: VRP solver first route ER-01B(NA)

(Light blue line - ER-01B(NA))

Table 6.2 compares the performance of the existing route and the route created by the VRP solver for the set of bins of ER-01B. Summary table is divided in two sections. In the first section the values obtained directly from NA are presented, in the second section turn impedances are added. 
Table 6.2: Summary of the results for the first route

\begin{tabular}{|c|c|c|c|}
\hline & \begin{tabular}{|c|} 
Existing route \\
ER-01B(ESD) \\
\end{tabular} & $\begin{array}{c}\text { NA route } \\
\text { ER-01B(NA) } \\
\end{array}$ & Improvement \\
\hline Start time: & $5: 07: 06$ & 5:07:06 & \\
\hline First bin arrival time: & 5:09:04 & 5:09:04 & \\
\hline Last bin departure time: & 8:08:36 & $8: 11: 36$ & \\
\hline End time at depot: & $8: 17: 48$ & 8:18:02 & \\
\hline Total travel time (min): & 115.55 & 115.79 & -0.24 \\
\hline Total service time (min): & 75.15 & 75.15 & 0.00 \\
\hline $\begin{array}{l}\text { Travel time from V. start depot to the } 1^{\text {st }} \\
\qquad \operatorname{bin}(\min ) \text { : }\end{array}$ & 1.96 & 1.96 & 0 \\
\hline $\begin{array}{l}\text { Travel time from the last bin to processing plant } \\
\qquad(\min ) \text { : }\end{array}$ & 9.20 & 6.43 & 2.77 \\
\hline Time collecting (min): & 179.53 & 182.53 & -3.00 \\
\hline Total Distance (mi): & 26.11 & 26.08 & 0.04 \\
\hline Number of left turns: & 29 & 67 & -38 \\
\hline Left turn time (min): & 1.50 & 3.46 & -1.96 \\
\hline Number of U-turns: & 14 & 10 & 4 \\
\hline U-turn time (min): & 2.36 & 1.68 & 0.67 \\
\hline$T T_{m}$ Total collection time (without $T_{o d}$ ) (min): & 194.55 & 196.08 & -1.53 \\
\hline$T T_{m}$ Total collection time (with $\left.T_{o d}\right)(\mathrm{min})$ : & 195.92 & 197.45 & -1.53 \\
\hline
\end{tabular}

The difference between the total travel time $\left(\sum_{i=1}^{n}\left(T T_{R S w s_{i}}+T T_{R S n s_{i}}\right)\right)$ of both solutions is 0.24 minutes which is approximately 14 seconds. The VRP solver's solution takes longer time. The travel time to the processing plant was computed as the difference between the End time and departure time from the last bin and it is 2 minutes and $45 \mathrm{sec}(2.77 \mathrm{~min})$ shorter for the VRP solver's solution. The time that the VRP solver gains on the way to the processing plant is unfortunately lost in the collection area as it is 
shown by negative 3 minutes difference for the time collecting. Time collecting is the productive time in the neighborhood before the consideration of turn impedances, it was computed as a sum of total travel time and total service time subtracted of the travel time from Virtual start depot to the $1^{\text {st }}$ bin and the travel time from the last bin to processing plant. The total number of left turns in the solver's solution is 67 which is 38

more than in the present solution. However the solver's solution has only 10 U-turns, so 1.96 minutes is lost on left turns but 0.67 minutes is gained on U-turns. This difference together with the initial 0.24 minutes lost on travel time contributes makes the existing route the better solution, where difference in total collection time $T T_{m}$ is 1.53 minutes.

\subsubsection{Second Route}

The second existing route used by ESD to collect recyclables in the residential area, ER-01A(ESD), started at the processing plant depot right after the recyclables from the first route were unloaded. Truck visited the bins of the second existing route according the sequence in the path report and returned to the processing plant. There is only one depot in this route, the processing plant, as shown in Figure 6.9. Artificial barriers were set in the VRP layer to ensure that truck will follow the same path from and back to the processing plant as it does according to the path report. 


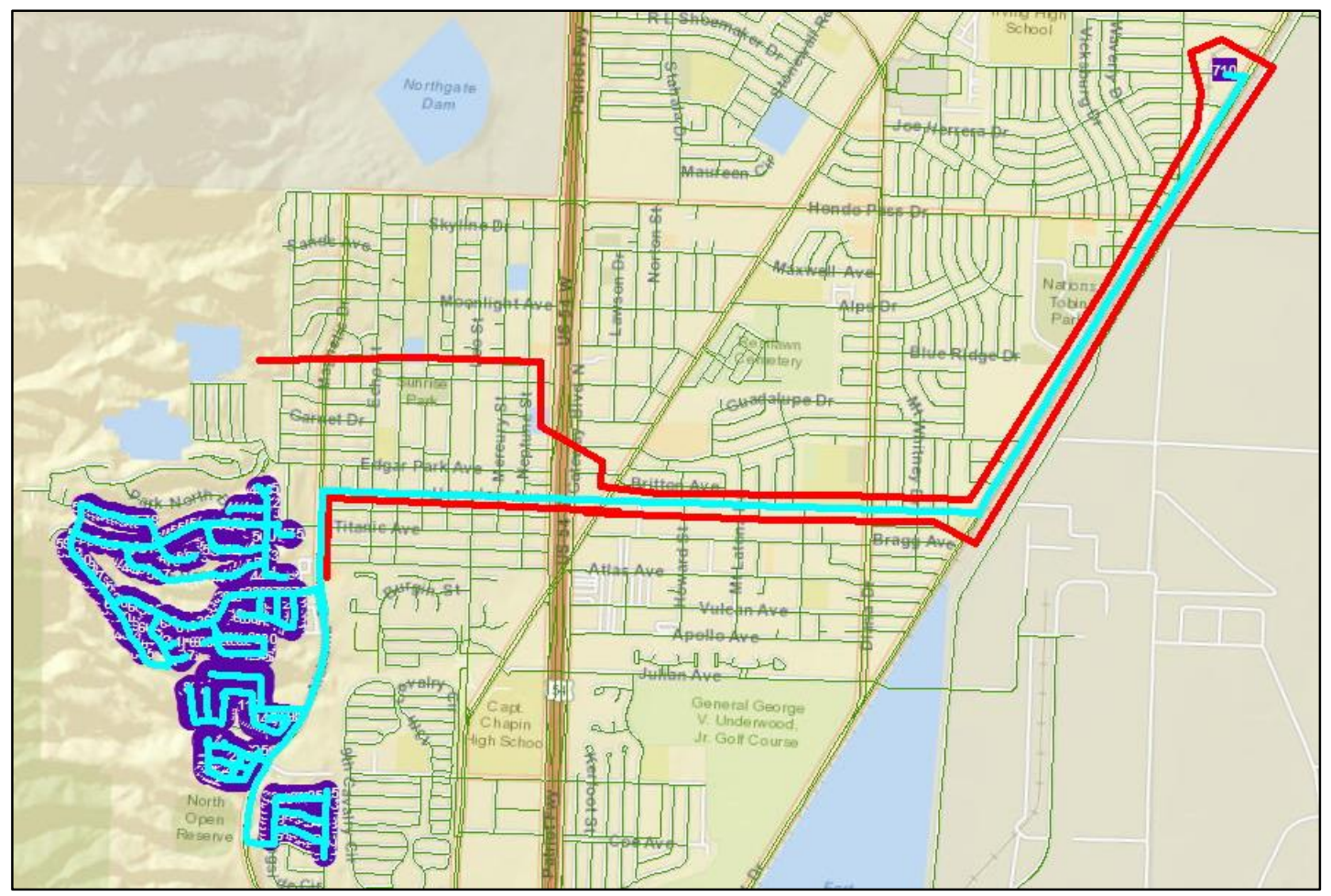

Figure 6.9: Second existing route ER-01A(ESD)

(Light blue line - ER-01A(ESD), barriers - red lines)

The input data to compute $T T_{m}$ was the same as described in the model validation for the second route. Input setting was changed only for the set-out rate. The set-out rate in this case was computed as the annual average container count (for the second route) divided by the number of bins in the second route. This setout rate was $S=0.3776$.

Also for this second route the VRP solver was used to obtain the alternative solution ER-01A(NA). A barrier was set in this case to the westernmost end of the Titanic Ave. because the collection truck does not enter this street segment (ESD leaves it for manual collection). The VRP solver's solution is depicted in Figure 6.10, the following figure (Figure 6.11) shows the detail of the barrier at the Titanic Ave. 


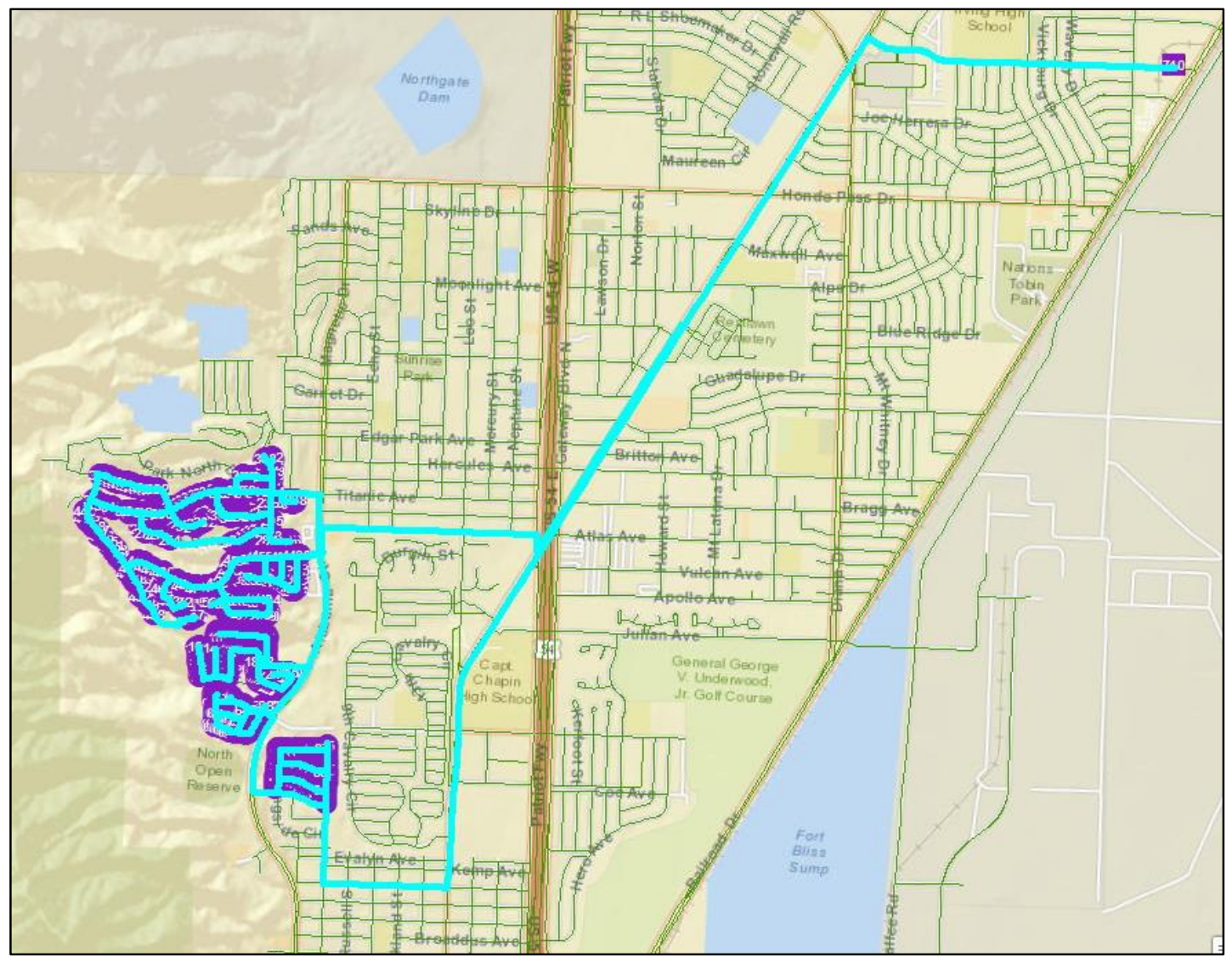

Figure 6.10: VRP solver second route ER-01A(NA)

(Light blue line - ER-01A(NA)) 


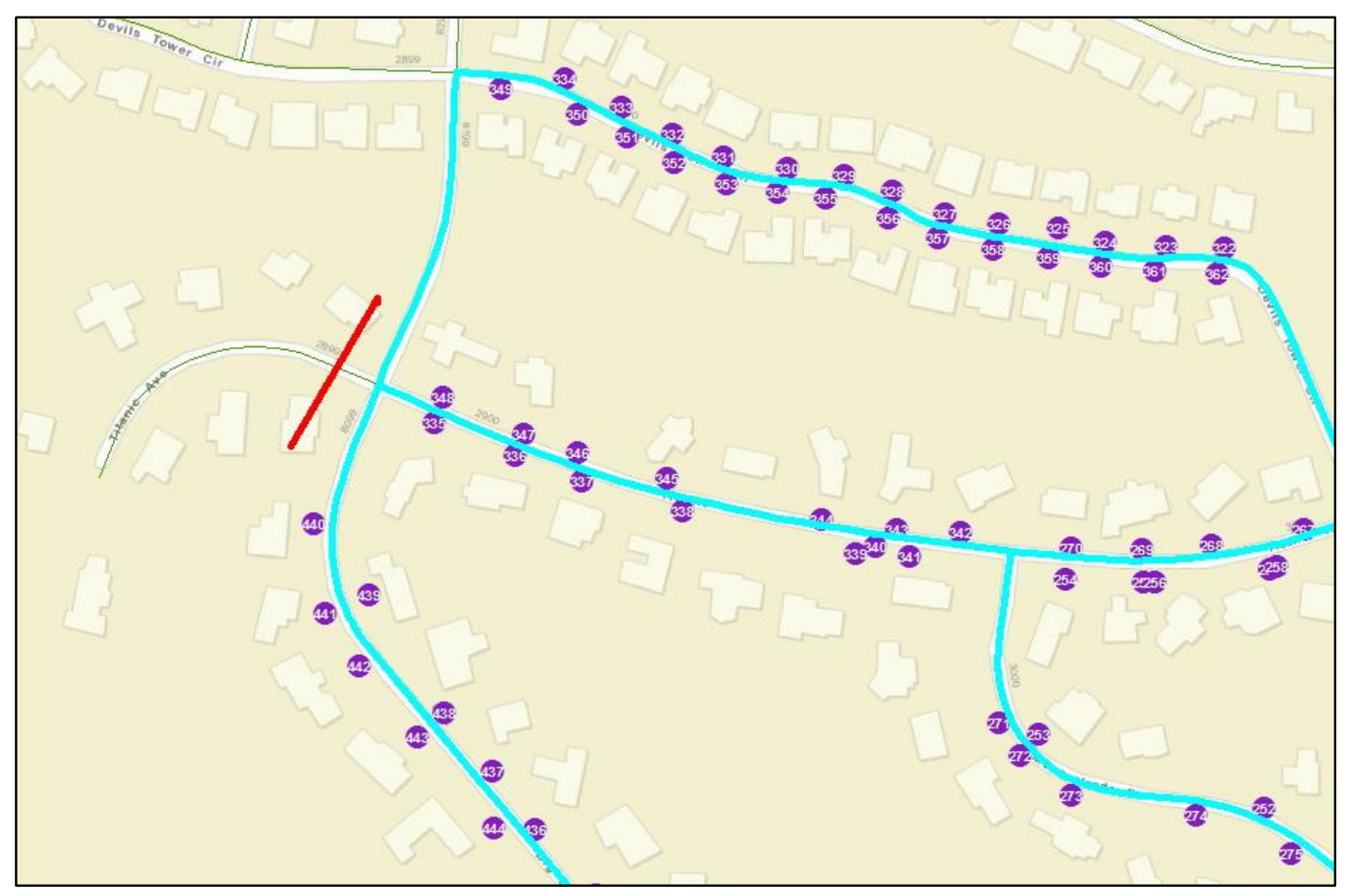

Figure 6.11: Barrier detail

Table 6.3 compares the performance of the existing route and the route created by the VRP solver for the set of bins of ER-01A.

For the second route the VRP solver produced a solution that takes 3 minutes and 29 seconds (3.48 minutes) longer in total travel time than the existing solution. The VRP solver has improved the so called non-productive times. The travel time from the processing plant to the first bin is 1 minute and 42 seconds (1.7 $\mathrm{min}$ ) shorter. Similarly, the travel time from the last bin back to the processing plant is better, saving 1 minute and 11 seconds $(1.18 \mathrm{~min})$. However these improvements can only slightly reduce the time that the VRP solver lost in the process of collection. For the productive time (the time collecting) there is a delay of 6.37 minutes in the NA route in compare to the existing route. There is a longer total distance for ER-01A(NA), 17 more left turns and three more U-turns, which adds another 0.88 minutes to be lost on left turns and 0.51 on U-turns. In total the existing route is capable to complete the collection in a time that is 4.87 minutes shorter (the difference for total collection time $T T_{m}$ ). 
Table 6.3: Summary of the results for the second route

\begin{tabular}{|c|c|c|c|}
\hline & $\begin{array}{c}\text { Existing route } \\
\text { ER-01A(ESD) }\end{array}$ & $\begin{array}{c}\text { NA route } \\
\text { ER-01A(NA) } \\
\end{array}$ & Improvement \\
\hline Start time: & $8: 20: 41$ & $8: 20: 41$ & \\
\hline First bin arrival time: & $8: 32: 25$ & $8: 30: 43$ & \\
\hline Last bin departure time: & $10: 41: 23$ & 10:46:03 & \\
\hline End time at depot: & $10: 52: 14$ & $10: 55: 43$ & \\
\hline Total travel time (min): & 106.99 & 110.48 & -3.48 \\
\hline Total service time $(\min )$ : & 44.56 & 44.56 & 0.00 \\
\hline $\begin{array}{l}\text { Travel time from processing plant to the } 1^{\text {st }} \\
\qquad \operatorname{bin}(\min ) \text { : }\end{array}$ & 11.73 & 10.03 & 1.70 \\
\hline $\begin{array}{l}\text { Travel time from the last bin to processing plant } \\
\qquad \text { (min): }\end{array}$ & 10.85 & 9.67 & 1.18 \\
\hline Time collecting ( $\mathrm{min})$ : & 128.97 & 135.33 & -6.37 \\
\hline Total Distance (mi): & 27.85 & 30.70 & -2.85 \\
\hline Number of left turns: & 24 & 41 & -17 \\
\hline Left turn time (min): & 1.24 & 2.12 & -0.88 \\
\hline Number of U-turns: & 19 & 22 & -3 \\
\hline U-turn time (min): & 3.20 & 3.70 & -0.51 \\
\hline$T T_{m}$ Total collection time (without $T_{o d}$ ) (min): & 155.99 & 160.86 & -4.87 \\
\hline$T T_{m}$ Total collection time (with $\left.T_{o d}\right)(\mathrm{min})$ : & 163.58 & 168.44 & -4.87 \\
\hline
\end{tabular}




\section{Chapter 7: Evaluation of Results}

\subsection{CARP SOlVEd BY NA FOR THE RESidential RECYClables COLleCtion.}

In the previous chapter the possibilities for improvement in the individual routes were investigated, while the sets of bins assigned to each route did not change. In this section, The VRP solver is allowed to divide the whole set of bins of the shift into two routes, which the VRP solver identifies as the optimal.

In the individual routes solution presented in Section 6.5 (in this chapter called modified routing solution) the capacity and maximum number of bins in one route were also set, but the division of the shift in two routes was the same as in the existing routes.

Figures 7.1 and 7.2 shows the routes proposed by the VRP solver. The set of bins is split on the east and west parts. Routes were named east route and west route and this routing solution is referred as redesigned routing solution. East route contains 869 bins to visit, while in the west route there are 737 bins to be visited by the collection vehicle. The starting and end depot were the same as in Chapter 6 . The east route is the one that is performed first, and after that the west route is served. 


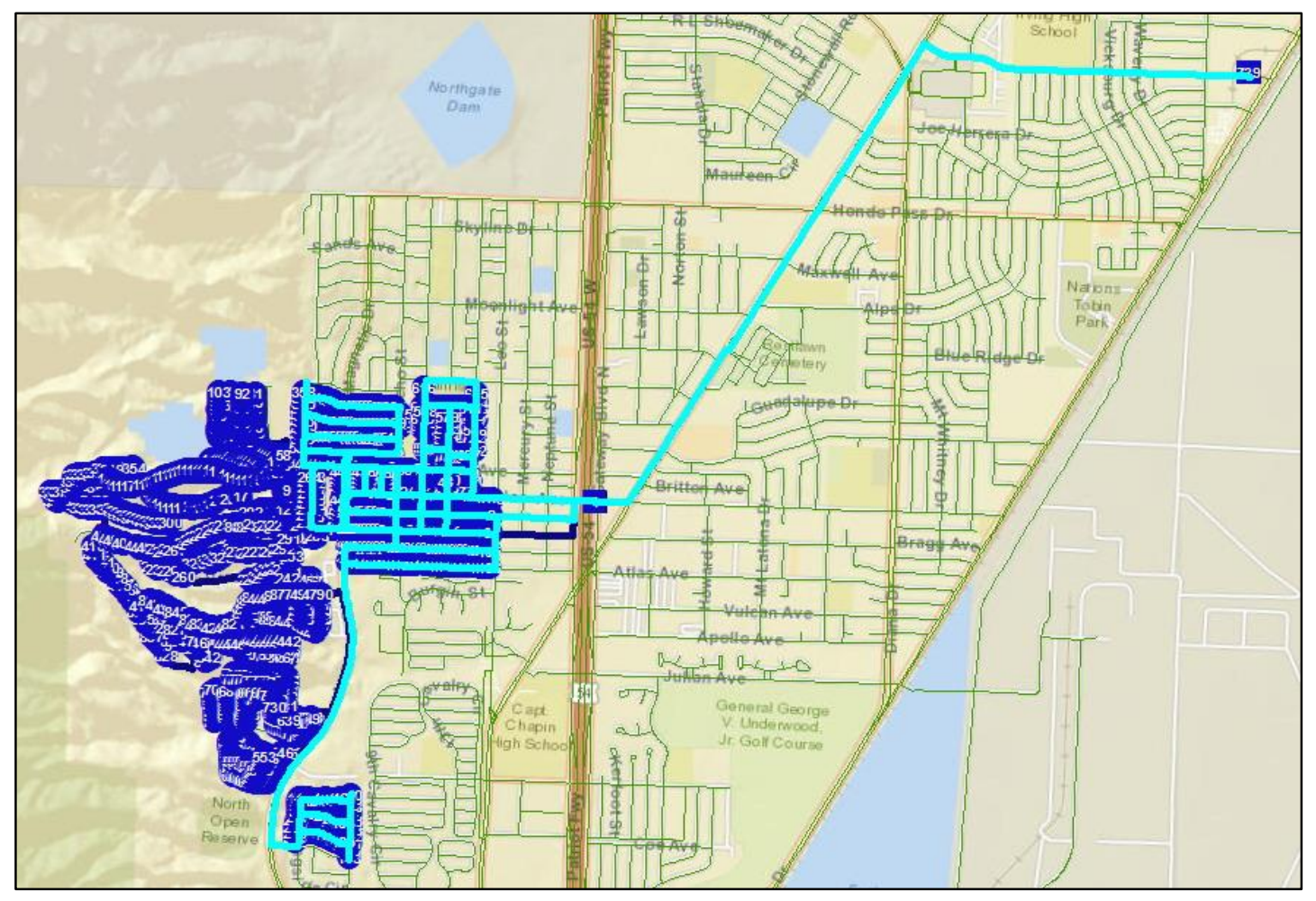

Figure 7.1: East route 


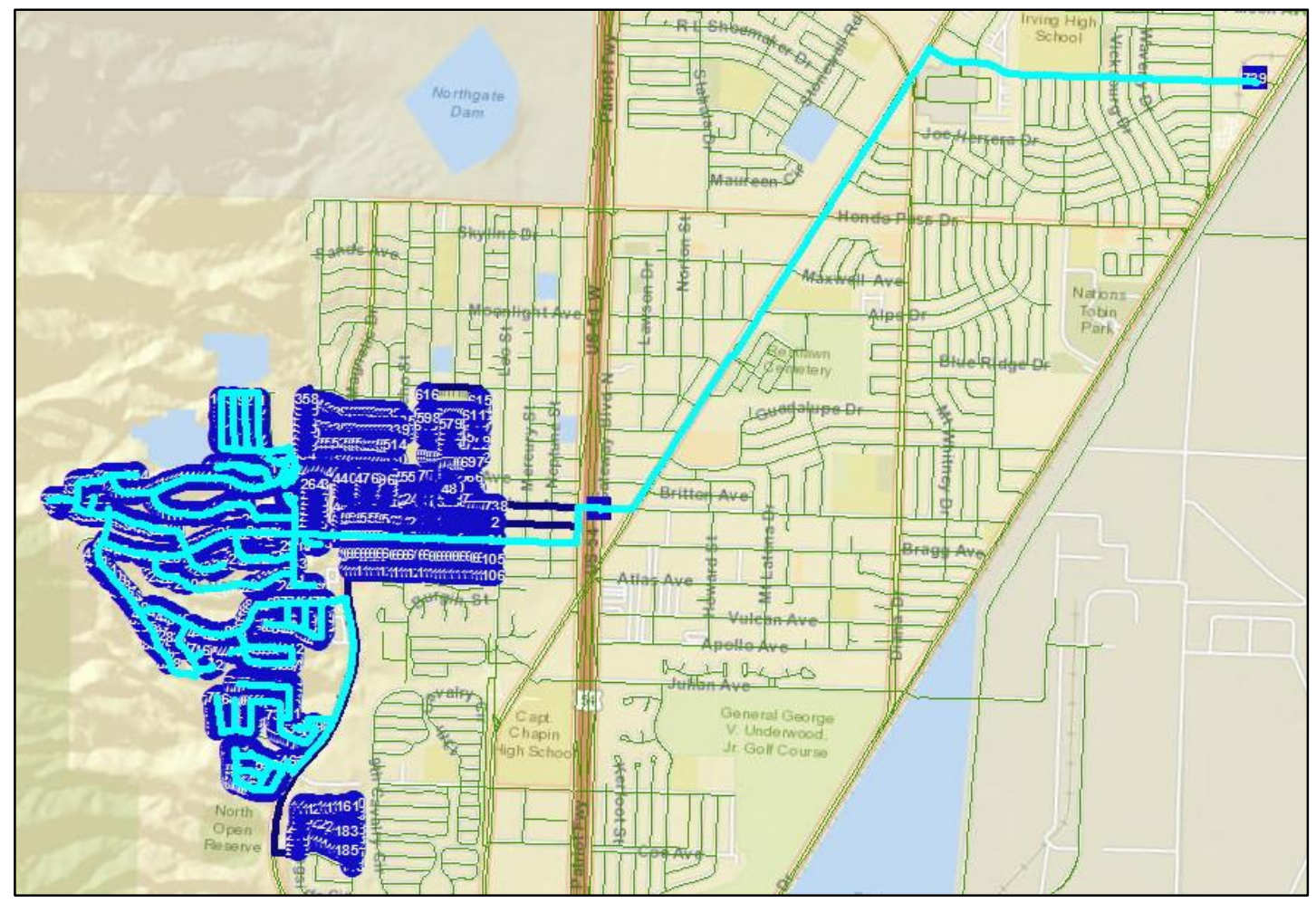

Figure 7.2: West route

In Figure 7.1 the east route contains a smaller neighborhood that is separated from the rest of the route in the southern end. This separated neighborhood is connected with the rest of the area by Alabama St. In the network dataset, a higher speed is assigned to the corresponding network segments of Alabama St. so in terms of the travel time this separated neighborhood is closer to the rest of the bins and that is why this neighborhood is a part of the east route. 
The summary of the results for the east and west route is in the table 7.1.

Table 7.1: Summary of the results for the east and west route

\begin{tabular}{|c|r|r|}
\hline & East route & West route \\
\hline Start time: & $5: 07: 06$ & $8: 20: 41$ \\
\hline First bin arrival time: & $5: 08: 40$ & $8: 30: 30$ \\
\hline Last bin departure time: & $7: 33: 15$ & $11: 24: 55$ \\
\hline End time at depot: & $7: 39: 41$ & $11: 35: 02$ \\
\hline Total travel time (min): & 97.66 & 129.58 \\
\hline Total service time (min): & 54.93 & 64.77 \\
\hline Travel time to the 1 ${ }^{\text {st }}$ bin(min): & 1.57 & 9.82 \\
\hline (the last bin to processing plant (min): & 6.43 & 10.12 \\
\hline Time collecting (min): & 144.59 & 174.41 \\
\hline Total Distance (mi): & 23.85 & 32.07 \\
\hline Number of left turns: & 63 & 53 \\
\hline Left turn time (min): & 3.26 & 2.74 \\
\hline Number of U-turns: & 6 & 26 \\
\hline U-turn time (min): & 1.01 & 4.38 \\
\hline$T_{m}$ Total collection time (without $\left.T_{\text {od }}\right)(\min ):$ & 156.85 & 201.46 \\
\hline \hline
\end{tabular}

\subsection{Results Evaluation}

Some of the performance parameters of the existing routing solution used by ESD, the modified routing solution, and the redesigned routing solution can be compared. This comparison is presented in table7.2. 
Table 7.2: Comparison of the routing solutions

\begin{tabular}{|c|r|r|r|}
\hline & \multicolumn{1}{c|}{$\begin{array}{c}\text { Existing } \\
\text { routing }\end{array}$} & \multicolumn{1}{c|}{$\begin{array}{c}\text { Modified } \\
\text { routing }\end{array}$} & \multicolumn{1}{c|}{$\begin{array}{c}\text { Redesigned } \\
\text { routing }\end{array}$} \\
\hline Total travel time (min): & 222.54 & 226.26 & 227.23 \\
\hline Travel time to the $1^{\text {st }}$ bin(min): & 13.70 & 12.00 & 11.38 \\
\hline Travel time to processing plant (min): & 20.05 & 16.10 & 16.55 \\
\hline Time collecting (min): & 308.50 & 317.87 & 319.00 \\
\hline Total Distance (mi): & 53.96 & 56.78 & 55.92 \\
\hline Number of left turns: & 53 & & 116 \\
\hline Left turn time (min): & 2.74 & 5.58 & 5.99 \\
\hline Number of U-turns: & 33 & & 32 \\
\hline U-turn time (min): & 5.56 & 5.39 & 5.39 \\
\hline (without $\left.T_{o d}\right)(\mathrm{min}):$ & 350.54 & 356.94 & 358.32 \\
\hline
\end{tabular}

If we compare the three routing alternatives, the existing routing has the best performance. It has the lowest values for the total travel time, total distance, number of left turns and time collecting, which denotes the productive time spent in the neighborhood collecting bins. Because of the lowest values at all this parameters it performs the best also in the key parameter - Total collection time.

The service time is not included in the table because it is the same for all three cases and has a value of 119.7 minutes. In the total travel time the redesigned routing takes 4 minutes and 41 seconds (4.69 minutes) longer time than the present solution used by ESD (existing routing). Same as in the investigation of the route improvement on individual routes also here an improvement can be found for the non-productive travel time. The travel time to the first collected bin for the redesigned routing solution is 2 minutes and 19 seconds shorter than the existing routing and for the travel time from the last bin to the processing plant the difference is even 3 minutes and 30 seconds. Modified routing has longer total distance than redesigned routing, although the total travel time is shorter for modified routing. This is caused by more extensive use of Alabama St. in the modified routing. On the Alabama St the truck can 
go faster, because of higher speed set, so it gains traveled distance but does not gain that much time. There are 63 more left turns in the VRP solver solution than in the present route, which contributes to an additional delay of 3 minutes and 16 seconds. There is one less U-turn in the redesigned solution however it means an improvement of 10.1 seconds only.

Total collection time (here the $T T_{m}$ without $T_{o d}$ ) sums up the differences for the travel time and turns. It is obvious that the modified routing has higher total collection time than existing routing, since it is the sum of two routes that already were presented as routing solutions with not as good performance as the existing routing. The redesigned routing scores even lower in total collection time. The modified routing takes 6.40 minutes longer time than the existing routing and the redesigned routing takes 7.78 minutes longer time than existing routing in terms of total collection time.

The fact that no better solution than the existing routing solution was found by the NA does not mean that there is no better solution for this routing problem, but it means that the NA is not able to find any better solution with a current settings made and information given.

It has been proven that it is possible to use the ArcGIS NA VRP solver to solve routing problems in MSW or recyclables collection, where more than 1600 bins are served in two routes, however a special approach and further processing of the first VRP solver output has to be made and final routing solution might not be the best possible routing in the given set of bins.

\subsection{Recommendations to the City of El Paso Environmental Services Department (ESD)}

In this section the possible time saving by removing some of the bins out of the shift considering that these bins were added to the other collection shift instead is evaluated. The time increase caused by adding these bins to the shift that was not investigated cannot be determined, however ESD was interested in the estimation of time savings of this kind in the studied shift.

The borders of the shift were searched for bins that are potential candidates for relocation to the neighboring shift. Four bins in two different street segments were identified as having a potential for improvement if relocated. One bin in the set of bins of ER-01B on the north end of West Line Dr. (Figure 7.3) is the only bin in this segment of road. Detail of the location of this bin is in Figure 7.4. The other 
three bins are in the road segment in the set of bins of ER-01A on the south end of Byron St. Detail of the location is in Figure 7.5

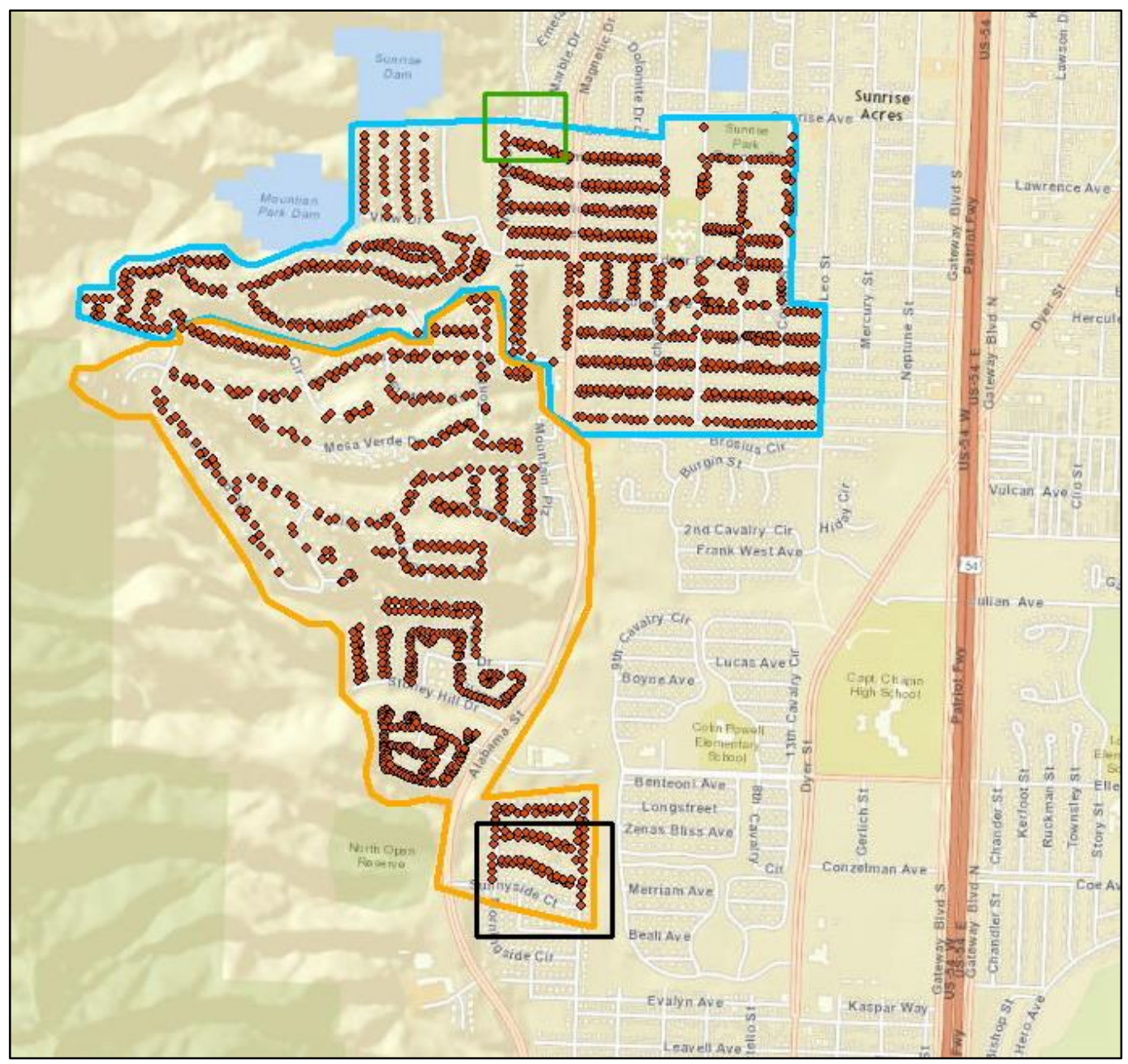

Figure 7.3: Selected shift with marked borders of routes and picture details

(orange polygon - ER-01 A, blue polygon - ER-01B, red points - bins, green square - detail in figure 7.4, black square - detail in figure 7.5) 


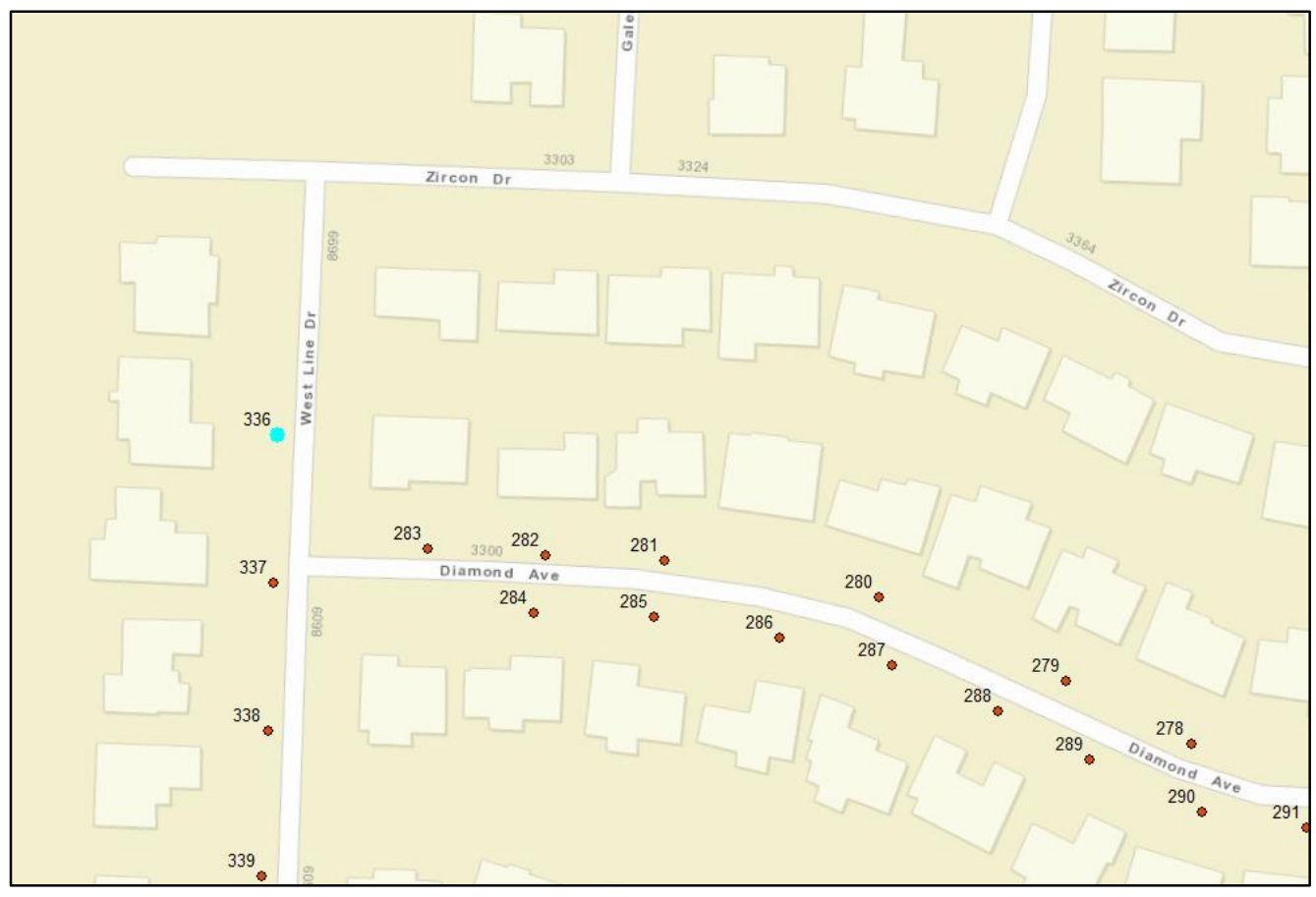

Figure 7.4: Detail for north end of West Line Dr.

(Light blue point - bin candidate for relocation)

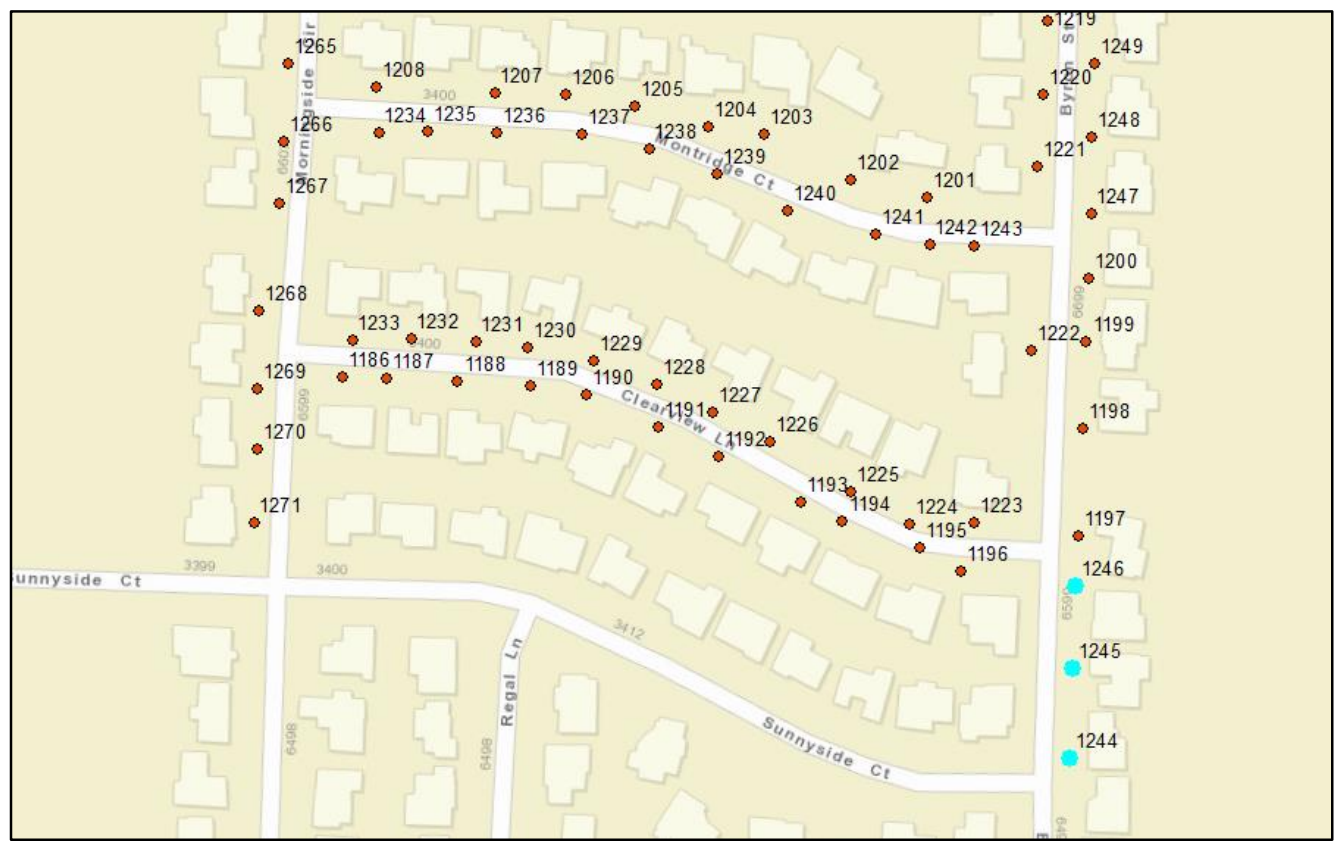

Figure 7.5: Detail for south end of Byron St.

(Light blue points - bin candidates for relocation) 
In the set of bins of ER-01B the reduction of one bin in the north end of West Line Dr. decrease the total collection time $T T_{m}$ of 0.55 minutes which is 33 seconds, this does not mean a significant time reduction especially when it is consider that adding the bin to the other shift would probably mean to approach the bin from Zircon Dr. and thus there will be added one left turn $(3.1 \mathrm{sec})$ and one U-turn $(10.1$ sec ) as a part of the time increase in the other shift.

For the set of bins of ER-01A the time saving is 1.5 minutes in the total collection time $T T_{m}$. Thanks to the relocation of bins to the southern shift there is one less U-turn in the route ER-01A(ESD) however one left turn was added. Interesting is that of this one and half minute the travel time part consist of 1.19 minutes which is significantly more than the travel time distance on the given arc $(0.5 \mathrm{~min}$ from one end to the other and back). This means that there is a high chance for time saving if the arc will be relocated.

\subsection{RECOMMENDATIONS FOR FUTURE USE OF ARC GIS}

Every analysis by the ArcGIS NA extension is as good as the network dataset that was created. In the presented solutions all the turns are evaluated after solving the routing problem, which means that the time delay caused by the turns is considered in the model for evaluation but the program does not take the turns into a count while creating the routes. The reason for this procedure is the malfunction of GTDE. Except for the GTDE, ArcGIS NA allows also one other way of implementing turn impedances for the VRP solver and it is the creation of turns feature class. In the turns feature class possible turns together with the turn time impedances for every junction point in the network dataset are defined. In this routing problem the network dataset was newly designed. No data describing the turns in the centerline or any other data source were found. If there are no input data, then implementing the turns feature class requires manually creating allowable turns at every junction point. Since the implementing the turn feature class was found too time demanding, it was not utilized.

With the implemented turns feature class the first step to eliminate the anomalous sequencing as described in Section 4.3 can be changed. The options for U-turns can be set to "Allow U-turns at 
intersections and dead ends" because the turns feature class can define the prohibited U-turns via impedances. Potentially better routing solution can be obtained by these changes.

An alternative option how to use the VRP solver to solve ARP routing problems in ArcGIS Network Analyst is mentioned in the GIS community forum (Geonet 2013) and also in O'conor (2013). It is suggested to transform the ARP to the suitable input for the NA VRP solver by assigning a single point for each road segment and sum the demand from the orders (bins) on the road segment to this single point. Because of the side dependency, two points would be needed, one for each side of the street. In this arrangement, to ensure that the solver will not crate routes where the truck will make U-turns at each stop and visit the other side, the U-turns at junctions has to be set to "Allowed Only at Dead Ends" (Sandhu 2015). There are around 200 segments in the shift that require collection service, which means 400 order points. According to the experiment described in Section 4.3 the anomalous sequencing will appear in a set of this size as well. Thus it is unlikely that a better routing solution can be found by this demand point transformation, and so it was not implemented.

For solving the residential recycling collection routing problems it will be very helpful to have an ARP solver in the ArcGIS. The RouteSmart Technologies, Inc. offers an extension of the ArcGIS with the capability to solve ARP. This extension is called Route Smart for ArcGIS and it is designed to be applied to residential and commercial service vehicle routing (RouteSmart 2015). Route Smart for ArcGIS is available only in a package of service that includes full implementation into the organizational structure of the client that is using this extension. There is a potential for this or similar extension to be sold also separately without additional implementation service. 


\section{Chapter 8: Conclusion}

\subsection{SUMMARY OF RESEARCH}

The potential of GIS for solving residential recyclables collection routing problems was tested on the ArcGIS 10.1 software and its extension Network Analyst (NA). Recyclables collection was identified as a capacitated arc routing problem (CARP) with specific constraints. There is no solver for arc routing problems in NA, thus a VRP solver was used. The VRP solver was not designed with an intention for being used for solving high density routing tasks as residential recyclable collection, thus this tool produces anomalous sequence of bins in its solutions. A five step method to overcome this problem and obtain an acceptable routing solution by the NA VRP solver was developed.

A mathematical model describing the time requirements for residential recyclables collection was created. This model is described by equation 6.12 and it determines the total collection time as a sum of travel time, service time with a consideration of set-out rate and time required for left turns and U-turns. For evaluation of turns, it was found that the Global Turn Delay Evaluator (GTDE) in ArcGIS is not compatible with the VRP solver, thus GTDE was not used for evaluation of the effect of turns, but the turn penalties were evaluated in post processing of the solutions that were obtained from NA. This means that the program did not consider turns as an element to optimize, but the turn effect on the obtained solutions were considered.

To evaluate the capability of this approach to deliver routing solutions, a recyclables collection shift in the city of El Paso, TX, consisting of two routes was investigated for potential routing improvements. There are 1606 bins to visit in the shift, divided into first and second routes of 898 and 708 bins respectively. To analyze this, shift data describing bin position, street centerline, container count, tons collected and truck path report were gathered. The data processing stage involved two significant cases of utilizing the power of GIS spatial relation of data handling. First, the join function based on spatial location was used to link the GPS positions of the truck with the positions of the bins to determine the 
sequence in which the bins are visited in the existing routing solution. Second, the spatial positions of truck path report was used to estimate the time requirements for left turns and U-turns.

Existing routes were individually compared with routing solutions created by NA for the same set of bins. For the first route, the existing route was found to be 1.53 minutes faster in total collection time than the one designed by NA. For the second route, the difference was 4.87 minutes, where the existing route was the one with the shorter total collection time. This means that the modified routing solutions by NA takes 6.40 minutes longer time than the existing routes. In the redesigned routing obtained by NA the shift is divided into east and west routes of 869 and 737 bins respectively. The redesigned routes take 7.78 minutes longer time than the existing routes in terms of total collection time. The fact that turns were evaluated separately resulted in having more left turns for the modified routes (108 left turns) and the redesigned routes (116 left turns). Whereas for the existing routes there is only 53 left turns. The difference in time caused by this higher number of left turns is 2.84 minutes for the modified routes and 3.25 minutes for the redesigned routes. However the main source of longer total collection time in NA routing are not the turn impedances, but the time collecting bins in the neighborhood. On the other hand, NA improved the non-productive times by finding shorter path from the last collected bin to the processing plant.

ArcGIS NA was identified as not ideal software for solving residential recyclables collection routing problems. NA is capable of solving routing problems in recyclables collection, where 1606 bins are served in two routes, but special approach has to be made and the solution might not be the one with the minimal total collection time. The main disadvantage of this extension for a regular GIS user is the absence of the ARP solver. However ArcGIS itself was found to be a powerful tool for analyzing recyclables collection data. Based on digitalizing the existing routing, potential global time saving by relocation of some of the border bins to a neighboring shift was identified in the second route. 


\subsection{CONTRIBUtion}

The main contributions of this thesis are:

- Method to overcome anomalous sequencing in high density routing problems solved by NA.

- Model and general approach to evaluate recyclables collection routing, with the available data.

- Evaluation of ArcGIS NA capability in solving real life recyclables collection routing problems.

- Comparison of different ArcGIS NA outputs and existing routing solutions.

\subsection{FUTURE RESEARCH}

In future research in the ArcGIS NA utilization the following directions are suggested. First, improving network dataset with turns feature class to define all the turns at every crossroad, and add impedances to all turns so that the turn delay will be considered by the VRP solver. Second, the GIS model can be extended to include the elevation and its effect on fuel consumption and GHG emission .Third, adding delays caused by the lights at crossroads as turn penalties. Fourth, dynamic routing with the historical time-dependent traffic data describing congestions considered can be implemented.

In the future research of the recyclables collection itself, the possible directions are: First, perform the same analysis of routing for the shifts in the neighborhood to analyzed shift to evaluate the effect of possible relocation of the bordering bins. Second, decrease the uncertainty caused by the container set-out rate, by studying multiple path reports to determine the set-out rate for each individual bin, and through that obtain more accurate estimates of service time and weight collected. Third, implement a volume measure to the collection truck to have a better input describing truck capacity. 


\section{References}

Adams, R. (2011). "Residential Recycling Study." report presented to the Faculty of the Graduate School of The University of Texas at El Paso in partial fulfillment of the requirements for the degree of Master of Science

American City and County. (2012). "Small town implements curbside recycling program". American City and County <http://americancityandcounty.com/site-

files/americancityandcounty.com/files/imagecache/medium_img/uploads/2012/11/cartersvil le-georgia-curbside-recycling-201210.jpg> (Jan. 25, 2015).

American Society of Civil Engineers (ASCE) (2013) Report Card for America's infrastructure.

Bat'ha, M. (2010). “File:Praha, Malostranské náměstí - svoz odpadu 651.jpg - Wikimedia Commons." Commons.wikimedia.org, $<$ http://commons.wikimedia.org/wiki/File:Praha,_Malostransk\%C3\%A9_n\%C3\%A1m\%C4 \%9Bst\%C3\%AD_-_svoz_odpadu_651.jpg> (Jan. 25, 2015).

Brownlee, J. (2014). “Tabu Search - Clever Algorithms: Nature-Inspired Programming Recipes.” Cleveralgorithms.com, <http://www.cleveralgorithms.com/natureinspired/stochastic/tabu_search.html> (Mar. 13, 2015).

Department of Information Technology Services (DoITS). (2014). "Trash/ Recyclables Collection Schedule." City of El Paso Department of Information Technology Services <http://gis.elpasotexas.gov/collections/index.html> (Oct. 20, 2014).

Environmental Services Department (ESD). (2014). Personal communication, City of El Paso Environmental Services Department.

ESRI (2010). "Algorithms used by Network Analyst." $<$ http://webhelp.esri.com/arcgisdesktop/9.3/body.cfm?tocVisable=1\&ID=4365\&TopicName $=$ Algorithms $\% 20$ used $\% 20$ by $\% 20$ Network\%20Analyst $>$ (Mar. 14, 2015). 
ESRI. (2012). “Introducing ArcGIS 10.1.” ArcNews

<http://www.esri.com/news/arcnews/spring12articles/introducing-arcgis-101.html> (Mar. 14, 2015).

ESRI. (2015). "ArcGIS Network Analyst Overview."

$<$ http://www.esri.com/software/arcgis/extensions/networkanalyst> (Mar. 14, 2015).

European Environment Agency (EEA). (2010). The European environment - state and outlook 2010. Copenhagen, 69 - 90.

Eurostat. (2014) (1). "Municipal waste generated by country in selected years - Statistics Explained." $<$ http://ec.europa.eu/eurostat/statisticsexplained/images/archive/3/30/20150319204229!Municipal_waste_generated_by_country_i n_selected_years.png $>($ Mar. 25, 2015).

Eurostat. (2014) (2). "Municipal waste landfilled incinerated recycled and composted in the EU27 1995 to 2012 - Statistics Explained.” <http://ec.europa.eu/eurostat/statisticsexplained/images/archive/5/5e/20150320094714!Municipal_waste_landfilled_incinerated_r ecycled_and_composted_in_the_EU27_1995_to_2012new1.PNG> (Mar. 25, 2015).

Everett, J., Maratha, S., Dorairaj, R., and Riley, P. (1998). "Curbside collection of recyclables I: route time estimation model.” Resources, Conservation and Recycling, 22(3-4), 177-192.

Flapper, S., Van Nunen, J., and Van Wassenhove, L. (2005). Managing closed-loop supply chains. Springer, Berlin.

Geonet. (2010). "Vehicle Routing Problem (trash collection and vector control routes)." $<$ https://geonet.esri.com/thread/6102> (Mar. 14, 2015)

Geonet. (2012). "VRP - MaxOrderCount Limt of 1,000?.” <https://geonet.esri.com/thread/60205> (Mar. 14, 2015).

Geonet. (2013). "GIS high density vehicle routing solution.” <https://geonet.esri.com/thread/76075> (Mar. 14, 2015). 
Geonet. (2014). "Does global turn delay evaluator really work in Network Analyst?" $<$ https://geonet.esri.com/thread/116750> (Apr. 12, 2015).

Golden, B., and Wong, R. (1981). “Capacitated arc routing problems.” Networks, 11(3), 305-315.

González-Torre, P., Adenso-Díaz, B., and Ruiz-Torres, A. (2003). "Some comparative factors regarding recycling collection systems in regions of the USA and Europe.” Journal of Environmental Management, 69(2), 129-138.

Hawks, K. (2006). "Reverse Logistics Magazine - What is Reverse Logistics?” RL Magazine Reverse Logistics Association. <http://www.rlmagazine.com/edition01p12.php> (Oct. 20, 2014).

Jaktridit. (n.d.). "Výsip plasty." $<$ http://www.jaktridit.cz/uploads/images/Gallery/fotogalerie/plast/svoz/svoz-plasty2.jpg> (Jan. 25, 2015).

Laporte, G. and Osman, I. (1995). "Routing problems: A bibliography.” Annals of Operations Research, 227 - 262.

McDougall, F., White, P., and Franke, M. (2007). Integrated Solid Waste Management. John Wiley \& Sons, Chichester.

O'Connor, D. L. (2013). Solid Waste Collection Vehicle Route Optimization for the City of Redlands, California. major individual project submitted to the University of Redlands in partial satisfaction of the requirements for the degree of Master of Science in Geographic Information Systems.

$<$ http://inspire.redlands.edu/cgi/viewcontent.cgi?article=1203\&context=gis_gradproj $>$ (Mar. $15,2015)$

Paso Del Norte Mapa. (2015). "Datasets - El Paso City/County.” $<$ http://www.pdnmapa.org/HTML/datasets.html> (Mar. 15, 2015). 
Resources ArcGIS. (2014). “ArcGIS Help 10.1.”

$<$ http://resources.arcgis.com/en/help/main/10.1/index.html\#//004700000001000000> (Mar. $14,2015)$.

Rogoff, M. (2014). Solid waste recycling and processing. William Andrew, Waltham, MA.

RouteSmart. (2015). "Residential \& Commercial Collection - Route Optimization Software." $<\mathrm{http}$ //www.routesmart.com/industry-solutions/public-works-vehicle-routing-softwaresystems-vehicles-management-solutions/areas-of-expertise/trash-collection-truck-routingsoftware-route-optimization/> (Mar. 14, 2015).

Sandhu, J. (2015) "Network Analyst transform ARP to VRP How to create a mid-point for each segment?" < https://geonet.esri.com/thread/121513 > (Feb. 9, 2015)

Santos, L., Coutinho-Rodrigues, J., and Antunes, C. (2011). "A web spatial decision support system for vehicle routing using Google Maps.” Decision Support Systems, 51(1), 1-9.

Support ESRI. (n.d.). "GIS - GIS Dictionary." $<\mathrm{http} / /$ support.esri.com/en/knowledgebase/GISDictionary/term/GIS > (Mar. 14, 2015).

Toth, P., and Vigo, D. (2002). The vehicle routing problem. Society for Industrial and Applied Mathematics, Philadelphia.

United States Environmental Protection Agency (U.S. EPA). (1999). "Getting More for Less: Improving Collection Efficiency."

United States Environmental Protection Agency (U.S. EPA). (2002). Beyond RCRA: waste and materials management in the year 2010. Washington D.C.

United States Environmental Protection Agency (U.S. EPA). (2012). "Municipal Solid Waste Generation, Recycling and Disposal in the United States: Facts and Figures for 2012."

United States Government Accountability Office (U. S. GAO). (2012). GEOSPATIAL INFORMATION OMB and Agencies Need to Make Coordination a Priority to Reduce Duplication. 4. 
Wilson, B., and Baetz, B. (2001). "Modeling Municipal Solid Waste Collection Systems Using Derived Probability Distributions. I: Model Development.” Journal of Environmental Engineering, 127(11), 1031-1038.

Worrell, W., and Vesilind, P. (2012). Solid waste engineering. Cengage Learning, Australia. 


\section{Vita}

Karel Kůs was born in Prague, Czech Republic on February 16, 1990. In 2013, he finished his bachelor studies in the bachelor study program Transportation Engineering in Technology in Transportation and Telecommunications - Management and Economics of Transportation and Telecommunications by defending his bachelor thesis "Application of the mathematical modelling in supply chain" and graduated with honor from the Czech Technical University in Prague (CTU). For the Master studies he entered the Transatlantic Dual Master Degree Program In Transportation and Logistics Systems run by the Department of Civil Engineering at the University of Texas at El Paso in cooperation with the Czech Technical University in Prague.

Permanent address: Voskovcova 1130/26

Prague, Czech Republic, 15200

This thesis was typed by Karel Kůs. 